Pontifícia Universidade $C_{\text {atólica }}$

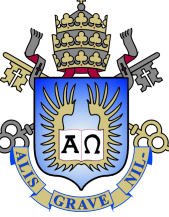

Anderson Gonçalves Uchôa

On Gamifying an Existing Software System:

Method, Conceptual Model and Lessons

Learned

Dissertação de Mestrado

Dissertation presented to the Programa de Pós-graduação em Informática da PUC-Rio in partial fulfillment of the requirements for the degree of Mestre em Informática.

Advisor: Prof. Alessandro Fabricio Garcia

Rio de Janeiro

April 2019 


\section{On Gamifying an Existing Software System: Method, Conceptual Model and Lessons \\ Learned}

Dissertation presented to the Programa de Pós-graduação em Informática da PUC-Rio in partial fulfillment of the requirements for the degree of Mestre em Informática. Approved by the undersigned Examination Committee.

Prof. Alessandro Fabricio Garcia

Advisor

Departamento de Informática - PUC-Rio

Prof. Marcos Kalinowski

Departamento de Informática - PUC-Rio

Prof. ${ }^{a}$ Débora Christina Muchaluat Saade Instituto de Computação - UFF

Rio de Janeiro, April 26th, 2019 
All rights reserved.

\section{Anderson Gonçalves Uchôa}

Anderson holds a Bachelor's in software engineering from Federal University of Ceará, Brazil, in cooperation with Sapienza University of Rome, Italy (2016). He has joined Pontifical Catholic University of Rio de Janeiro (PUC-Rio) in 2017 as a Master's student in informatics. He has worked for research projects in software engineering and information systems for healthcare, in collaboration with institutions from Brazil and the United Kingdom (UK). Relevant venues and journals have accepted his work for publication, such as International Conference on Software Reuse (ICSR), International Conference on Software Engineering (ICSE), and Information Systems (IS). Anderson collaborates with various researchers in Brazil (more recently, UFAL, UFPE, and PUCRS) and UK (Newcastle University). He has received the best paper award from 3rd Latin-American School on Software Engineering (ELAES 2016). He is a research scholar in software engineering for OPUS Research Group at PUC-Rio. His main research interests are software gamification, code review, software reuse, software evolution, software maintenance, and human aspects.

Bibliographic data

Uchôa, Anderson Gonçalves

On Gamifying an Existing Software System: Method, Conceptual Model and Lessons Learned / Anderson Gonçalves Uchôa; advisor: Alessandro Fabricio Garcia. - 2019.

$121 \mathrm{f}$ : il. color. ; $30 \mathrm{~cm}$

Dissertação (mestrado)-Pontifícia Universidade Católica do Rio de Janeiro, Departamento de Informática, 2019.

Inclui bibliografia

1. Informática - Teses. 2. Gamificação de Sistemas;. 3. Sistema de Assistência à Saúde;. 4. Método de Gamificação;. 5. Modelo de Gamificação Conceitual;. 6. Relato de Experiência.. I. Garcia, Alessandro. II. Pontifícia Universidade Católica do Rio de Janeiro. Departamento de Informática. III. Título. 


\section{Acknowledgments}

First and foremost I want to thank God for being by my side at all times. My courage to move on came from my faith in Him.

I would like to express my gratitude to my family, who have supported me since the beginning of this journey. Thanks to my father, Antonilo Uchôa Pereira, who taught me to always be the best version of myself and for always accompanying me in my decisions. Thanks to my mother, Evalene Maria Gonçalves Uchôa, for her unconditional love and for saying "hello" at most every 5 hours, even whether I am almost 26 years old. Thanks to my brothers, Pâmela Gonçalves Uchôa and Alesson Gonçalves Uchôa, for being always available when I needed it. Last, but - absolutely - not the least I would like to thank the people who cannot celebrate this success with me, but that I am sure would have been proud of me: my grandparent and all the people who left me too early. I will never forget their lessons and love.

My sincerest gratitude to my advisor Alessandro Garcia. I have no words to describe my admiration and gratitude. Alessandro has contributed significantly to my professional growth by providing the means for me to exceed my limits. I am grateful for your patience and for believing in me. I know how many problems I gave him, but he never lost his faith in me. So I am eternally grateful. Thank you very much.

During these two years, I also had the pleasure and honor to work with some emerging researchers in Brazil. Their contributions to my professional growth, as well as the research presented in this dissertation, cannot be described in words. For this reason, I must thank Baldoino Fonseca and Leopoldo Teixeira. I also want to thank the member of my dissertation defense team: Marcos Kalinowski, Débora Saade, and Simone Barbosa. I also thank all the professor form PUC-Rio for their invaluable contribution to my education.

My deepest gratitude to Eduardo Fernandes. He practically held my hand when I started my master course, and he taught me how to be a good young researcher. I academically grew up following the lessons learned by observing and talking to the aforementioned peoples. Thanks for all the effort spent and the suggestions you gave me. I hope I have not disappointed expectations.

I had the non-trivial opportunity to work together with colleagues and friends, achieving several results during my master's course. Thanks to the members of the VazaZika project, especially Anderson Oliveira, Caio Barbosa, Diogo Carvalho, Diego Cedrim, Eduardo Fernandes, Gabriel Nunes, Gabriel Ibson, Jairo Rafael, Luis Barroca, Leonardo Sousa, and Rafael de Mello for the direct and indirect contributions to the success of my Master's research. 
During my journey as a master's student, I lived in a distant and different city. I always felt at home. One of the main reasons for this statement is the presence of an "additional family" who has always shared good and bad times. Thanks, Ana Carla, who has always been engaged in spreading the cuisine of Alagoas, she no doubt became a Masterchef. Thanks, Eduardo Fernandes, for the strength to carry on although the problems, and the conversations about life and the future. Thanks, Hugo Guarín, for the philosophical conversations, and also for the amazing time of relaxation and surprising ideas that came after having drunk too many drinks.

I would like to thank all of the new and old colleagues from the OPUS Research Group and from the Software Engineering Laboratory: Amadeu Neto, Anderson Oliveira, Anderson Santos, Ana Carla Bibiano, Alan Andrade, Alexander Lopez, Anne Benedicte Agbachi, Caio Barbosa, Chrystinne Fernandes, Daniel Tenorio, Eduardo Fernandes, Francisco Cunha, Hugo Guarín, Isabella Vieira, Leonardo Sousa, Luiz Carvalho, Marx Viana, Nathalia Nascimento, Rafael de Mello, Rodrigo Laigner, Tassio Sirqueira, and Willian Oizumi. Finally, my sincere thanks to the administrative staff of the Department of Informatics at PUC-Rio, especially Alex Alves, Cosme Leal, and Regina Zanon.

This study was financed in part by the Coordenação de Aperfeiçoamento de Pessoal de Nível Superior - Brasil (CAPES) - Finance Code 001. 


\section{Abstract}

Uchôa, Anderson Gonçalves; Garcia, Alessandro (Advisor). On Gamifying an Existing Software System: Method, Conceptual Model and Lessons Learned. Rio de Janeiro, 2019. 121p. Dissertação de mestrado - Departamento de Informática, Pontifícia Universidade Católica do Rio de Janeiro.

Software gamification aims to leverage the user engagement with key features of software systems. Engagement is promoted by a conceptual gamification model that associates game elements (e.g., points) and rules (e.g., ranking policy) with features. It is quite common to gamify existing systems that were not originally designed with gamification in mind. Unfortunately, the development activities required to gamify a system are barely supported in practice. Gamifying an existing system requires: (i) the definition of a gamification model for guiding the incorporation of game elements and rules into an existing system; and (ii) the knowledge about key development activities to gamify this existing system. However, there are only a few models aimed to support the gamification of existing systems, and none is specific to software domains such as the prevention of mosquito-borne diseases. More critically, there is no systematic method aimed to guide the activities of gamifying existing systems. This Master's dissertation addressed the aforementioned limitations based on our experience with gamifying the VazaZika system. VazaZika is a system that encourages the prevention of mosquitoborne diseases such as Zika, Dengue, and Chikungunya. We introduce a gamification method that supports key activities during the gamification of existing systems, plus a gamification model composed of 12 game elements and 16 rules. Second, we evaluate our model with 20 users by means of ease of use, user interface, user fun, user motivation, and the potential for both constant system use and system dissemination. Our results are promising: (i) after some experience-based refinements, our method was successfully applied in the VazaZika gamification; (ii) we have identified 22 development activities that became challenging for developers to perform along the VazaZika gamification; these activities helped us to shape our method; and (iii) our gamification model has resulted in an easy-to-use system that is able to improve user engagement with critical healthcare-related features, such as the report of mosquito breeding sites. In summary, this dissertation contributed with additional guidance for supporting gamification of existing systems while shedding light on opportunities for future work.

\section{Keywords}

Software Gamification; Healthcare System; Gamification Method; Conceptual Gamification Model; Experience Report. 


\section{Resumo}

Uchôa, Anderson Gonçalves; Garcia, Alessandro. Gamificação de um Sistema de Software Existente: Método, Modelo Conceitual e Lições Aprendidas. Rio de Janeiro, 2019. 121p. Dissertação de Mestrado - Departamento de Informática, Pontifícia Universidade Católica do Rio de Janeiro.

A gamificação de sistemas visa engajar usuários com as principais funcionalidades de sistemas. Tal engajamento é alcançado via um modelo conceitual de gamificação que associa elementos do jogo (pontos, etc.) e regras (políticas de classificação, etc.) às funcionalidades. Vários sistemas existentes, isto é, que não foram originalmente projetados com gamificação em mente, precisam ser gamificados. Porém, o apoio prático às atividades de desenvolvimento necessárias para gamificar sistemas existentes é precário. Gamificar um sistema existente requer: (i) a definição do modelo de gamificação que guia a incorporação de elementos de jogos e regras ao sistema; e (ii) um conhecimento das atividades necessárias à gamificação desse sistema. Infelizmente, há poucos modelos de gamificação bem definidos, menos ainda focados no apoio à saúde pública, especialmente na prevenção de doenças transmitidas por mosquitos. Também não há método sistemático que guie as atividades específicas da gamificação de sistemas existentes. Esta dissertação de mestrado endereça as limitações mencionadas acima com base na experiência prática de se gamificar o sistema VazaZika. VazaZika é um sistema que encoraja a prevenção a doenças transmitidas por mosquito como Zika e Dengue. Primeiro, nós refinamos um método da literatura para lidar com a gamificação de sistemas existentes. Segundo, nós introduzimos um modelo de gamificação com 12 elementos e 16 regras de jogos para gamificar sistemas de prevenção das doenças acima. O nosso modelo foi avaliado com 20 usuários em termos de facilidade de uso, interface, diversão, motivação, potencial de uso constante e potencial de disseminação do sistema. Nossos resultados são promissores: (i) após refinamentos baseados em experiência, o método foi aplicado com sucesso na gamificação do VazaZika; (ii) identificamos 22 atividades de desenvolvimento que se tornaram desafiadoras para os desenvolvedores durante a gamificação; e (iii) nosso modelo de gamificação apoiou a construção de um sistema fácil de usar e capaz de engajar usuários em funcionalidades essenciais à saúde, como o relato de criadouros de mosquito. Esta dissertação provê guias adicionais à gamificação de sistemas existentes e realça oportunidades para trabalhos futuros.

\section{Palavras-chave}

Gamificação de Sistemas; Sistema de Assistência à Saúde; Método de Gamificação; Modelo de Gamificação Conceitual; Relato de Experiência. 


\section{Table of contents}

1 Introduction $\quad 13$

$\begin{array}{lll}1.1 & \text { Problem Statement } & 15\end{array}$

1.2 A Refined Method for Gamifying Existing Software Systems $\quad 17$

1.3 Systematic Exploration of Challenging Development Activities 18

1.4 A Conceptual Gamification Model to Prevent Mosquito-borne Diseases 19

$\begin{array}{ll}1.5 \text { Research Publications } & 20\end{array}$

$\begin{array}{ll}1.6 & \text { Dissertation Outline } \\ \end{array}$

2 Background and Related Work $\quad 22$

2.1 Basics of Software Gamification 23

2.2 Existing Methods for Supporting Software Gamification 25

2.3 Software Gamification in the Healthcare Domain 26

2.4 Limited Support to the Gamification of Existing Systems 28

2.4.1 Lack of a Systematic Method for Gamifying Existing Systems 28

2.4.2 Challenging Development Activities along Software Gamification 29

2.4.3 Lack of a Gamification Model to Prevent Mosquito-borne Diseases 30

2.5 Summary 30

3 A Refined Method for Gamifying Existing Software Systems 32

3.1 The Need for Gamifying a Healthcare System 33

$\begin{array}{lll}3.2 & \text { Research Methodology } & 35\end{array}$

3.2.1 Goal and Research Questions 36

3.3 Study 1: A Self-Observation of the Refined Method 37

3.3.1 Study Steps 37

$\begin{array}{lll}\text { 3.3.2 Results and Discussions } & 39\end{array}$

3.3.3 Threats to Validity and Concluding Remarks 45

3.4 Study 2: An Interview-based Experiment Report 46

3.4.1 Study Steps and Artifacts 47

3.4.2 Results and Discussions $\quad 49$

3.4.3 Threats to Validity $\quad 55$

3.5 A Method for Guiding the Gamification of Existing Software Systems 56

3.6 Limitations of the Proposed Method 61

$\begin{array}{lll}3.7 & \text { Summary } & 63\end{array}$

4 A Gamification Model to Prevent Mosquito-borne Diseases 64

4.1 Design of the Conceptual Gamification Model 65

4.2 Goal and Research Questions $\quad 71$

4.3 Study Steps and Artifacts 73

4.4 Citizen Characterization and Environment Settings 74

4.5 Results and Discussions $\quad 75$

4.6 Towards a Holistic Assessment of Our Conceptual Gamification Model 86

$\begin{array}{lll}4.7 & \text { Threats to Validity } & 87\end{array}$

$\begin{array}{lll}4.8 \text { Summary } & 88\end{array}$ 
$5 \quad$ Conclusion and Future Work $\quad 89$

5.1 Contributions to Software Engineering Community 90

5.2 Contribution to the Brazilian Public Healthcare Policies 91

5.3 Future Work 92

$\begin{array}{lr}\text { Bibliography } & 94\end{array}$

$\begin{array}{ll}\text { APPENDIX } & 101\end{array}$

A Appendix A: Participant Characterization Form 102

B Appendix B: Interview Script 106

C Appendix C: Elicited Gamified Systems 108

D Appendix D: Consent Form 110

E Appendix E: Participant Characterization Form 113

$\begin{array}{ll}\text { F Appendix F: List of Experiment Activities } & 115\end{array}$

G Appendix G: Activity Experiment Form 118

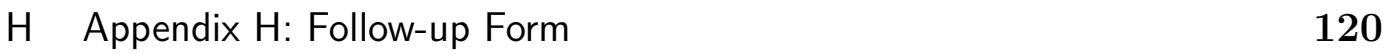




\section{List of figures}

Figure 2.1 Gamification Model Notation used in this Master's Dissertation

Figure 3.1 Overview of the Participatory Action Research 35

Figure 3.2 Study Steps of the Self-Observation Study 37

Figure 3.3 Overview of the Evolution History of the Gamification Method

Figure 3.4 Refinements Applied in System Preparation Phase 40

Figure 3.5 Refinements Applied in User Analysis Phase 41

Figure 3.6 Refinements Applied in Context Analysis Phase 42

Figure 3.7 Refinements Applied in Requirements Elicitation Phase 43

Figure 3.8 Refinements Applied in Gamification Design Phase 44

Figure 3.9 Refinements Applied in Software Design Phase 45

Figure 3.10 Study Steps and Artifacts of the Interview-based Study 47

Figure 3.11 Self-assessed Developer Skills 49

Figure 3.12 A Method for Gamifying Existing Systems 57

Figure 4.1 The Designed Conceptual Gamification Model 71

Figure 4.2 Study Phases and Artifacts 73

Figure 4.3 Sample of the Evolution of the Mobile Application's Interface 


\section{List of tables}

Table 1.1 List of Research Publications 21

Table 2.1 Some Popular Game Elements 23

Table 3.1 Research Questions of the Action Research 36

Table 3.2 Groups of Challenging Activities Elicited from the Interviews 51

Table 4.1 Gamification Goals $\quad 66$

Table 4.2 List of VazaZika FR, GR, and NR 67

Table 4.3 Elicited Gamified Systems (URLs per System in Appendix C) 68

Table 4.4 Game Elements in Existing Systems (and Selected Game Elements) 69

Table 4.5 Game Elements Incorporated into our Gamification Model 69

Table 4.6 Game Rules and Goals They Help in Addressing Gamification 70

Table 4.7 Research Questions of the Empirical Study 72

Table 4.8 Summary of the Citizen Background 74

Table 4.9 Crossover Study Design 75

Table 4.10 Quality Attributes Mentioned by Citizens About the User Interface $\quad 77$

Table 4.11 Citizens Perception About Ease to Use 78

Table 4.12 Citizens Perception About User Fun 80

Table 4.13 Citizens Perception About User Motivation 81

Table 4.14 Spearman's Rank Correlation Results 82

Table 4.15 Constant Use and and System Dissemination 84 


\title{
List of Abreviations
}

\author{
ADP Adapted \\ ADD Added \\ BPMN Business Process Model and Notation \\ CAPES Coordination for the Improvement of Higher Education Personnel \\ DIS Discarded \\ EE Element-Element \\ FR Functional Requirements \\ GT Grounded Theory \\ GR Gamification-specific Requirements \\ NFR Non-Functional Requirements \\ REU Reused \\ RQ Research Question \\ SU System-User \\ UK The United Kingdom \\ UI User Interface \\ UX User Experience
}




\section{1 \\ Introduction}

Gamification means applying game elements and game rules into nongame contexts in order to engage people with software features (68). Game elements are basic mechanisms adopted to reward and challenge people, thereby promoting people engagement (12). An example of a game element is the point, i.e., the unit of reward that a person earns. Many other game elements exist, such as badges, i.e., more complex rewards, and ranking policy, i.e., how to rank system user by performance $(12,63,68)$. Game rules define the interactions of people and game elements, e.g., a person earns points after completing a given task (63). Tasks are specific actions that people perform in a given context. In the Brazilian public healthcare context, citizens usually report issues to the health secretariats. Thus, public health agents are allocated to address the reported issues (3).

Different domains have taken advantage of gamification for engaging people with tasks from varied natures. Previous studies report that gamification has been successfully used in marketing $(67,68)$, welfare $(26,46)$, and innovation (65). In the development of software systems, gamification has been used by developers for keeping the users constantly engaged with software features (45). By incorporating game elements and rules into a system, gamification plays an important role in making the system enjoyable to the users (68). Let us suppose that we have a system aimed to support the public healthcare. Gamification could be used for promoting a constant report of issues in order to enable public health agents to address these issues and prevent diseases, for instance. Thus, the system could assign points to citizens, which are the system users, whenever citizens report issues, thereby promoting constant reports.

The combination of different game elements aims at making the system users frequently and effectively engaged with the system features $(4,33)$. An example of a successful gamified software system that combines multiple game elements is Stack Overflow ${ }^{1}$. This is a popular system that enables developers to share knowledge through questions and answers. In Stack Overflow, the system users earn points and badges by performing a variety of tasks, such as asking and answering questions, commenting on answers and questions

\footnotetext{
${ }^{1}$ https://stackoverflow.com/
} 
provided by other users, and up or down voting existing questions and answers. By accumulating points, the user increases his ranking in the system. As a result, the incorporation of various game elements into Stack Overflow has positively impacted the user engagement $(4,33)$.

Stack Overflow was designed to accommodate game elements and rules from its early development phases, i.e., from the scratch (28). Gamification from scratch means planning the system gamification from the initial specification of requirements and design. In contrast, there is an emerging need for introducing game elements and rules into existing systems $(55,58)$. Such introduction is quite hard because it requires revisiting certain existing software artifacts, such as requirements and design documentation. Especially, gamifying existing systems also requires a deep understanding of to what extent the system gamification would impact certain key artifacts, such as source code and databases. Usually, the incorporation of game elements and rules into an existing system follows the definition of a conceptual gamification model (68). This model specifies the interactions of users and game elements into the system through game rules $(18,61)$.

In order to reduce initial gamification effort and long-term software maintenance costs, development teams have used gamification libraries such as Bunchball $^{2}$, GetBadges ${ }^{3}$, and Open Badges ${ }^{4}$. These libraries provide features for enabling the integration of both game elements and rules into an existing software system. Thus, depending on which software project will be gamified, one might consider that using these libraries as the only solution to eventual challenging activities might suffice. However, gamifying an existing system is much harder than simply using a gamification library. In fact, incorporating game elements and rules into an existing system often requires many changes in system requirements, design, implementation, and test suites $(18,61)$. Most of these changes are required even when incorporating the simplest game elements, such as points and badges. Consequently, the developers might fail to accommodate game elements into an existing software system. Such failure may occur especially if there is no clear comprehension of the most challenging activities along the gamification, and the developers do not know what solutions could properly help coping with each challenging activity.

\footnotetext{
${ }^{2}$ https://www.bunchball.com/

${ }^{3}$ https://getbadges.io/

${ }^{4}$ https://openbadges.org/
} 


\section{1 \\ Problem Statement}

There are two approaches to gamifying software systems. The first approach is the so-called gamification from scratch, which is widely supported by previous studies $(29,34,40,50)$. These studies provide practical support to the gamification process (40), architectural design (29,34), and other activities (50). The second approach involves the gamification of an existing system. It consists of redesigning the existing artifacts of an existing system, such as the requirements specification, architecture design, and the source code, in order to incorporate game elements and rules into the system. Although there is an increasing demand for gamifying existing systems $(55,58)$, the current support to development teams is quite scarce. There is no systematic guidance for revisiting and refining existing software artifacts. There is even limited knowledge on which development activities often become challenging along software gamification. Finally, the current conceptual gamification models for software domains in which user engagement is crucial, e.g., healthcare systems for preventing diseases, are limited if not nonexistent. The scarce support may lead developers to struggle with gamifying existing systems.

General Problem. Developers lack guidance to support the gamification of their existing software systems. They lack both: (i) a method that guides software development activities, and (ii) conceptual gamification models.

In this Master's dissertation, we have addressed our general problem in the context of an international research collaboration between Brazilian and British institutions that aimed to gamifying an existing healthcare system called VazaDengue (58) for improving prevention and control of Zika. VazaDengue consisted of a mobile and a web application, and these applications intercommunicate via web services. The major system goal is supporting Brazilian health secretariats in preventing diseases transmitted by the Aedes aegypti such as Dengue (58). By monitoring the reports of mosquito breeding sites in real time, public health agents can track disease outbreak and eliminate mosquito breeding sites. After years of system deployment, we observed a lack of user engagement that affected the number of reports $(18,61)$. Thus, public health agents found hard to guide their work through these reports. Aimed to leverage the user engagement, we gamified VazaDengue for making it enjoyable and challenging to potential users. The resulting gamified system is called VazaZika (18). We expect that VazaZika, with its game elements and rules, will increase the number of reports. 
From our general problem, we derived three specific problems to be addressed in this Master's dissertation. We introduce each problem as follows.

Methods for Gamifying Existing Software Systems. While gamifying the VazaDengue healthcare system (58), we felt the lack of systematic guidance to the key software development activities of gamifying existing systems. In fact, there was not method aimed to systematically guide development teams along the incorporation of game elements and rules into an existing system. Previous studies propose a few methods aimed to guide the requirements elicitation, user profiling, design, and implementation of gamified systems from scratch $(29,34,40,50)$. Unfortunately, they provide little insights about the key activities required to gamify existing systems. Examples of key activities are: (i) the refinement of functional and non-functional requirements previously elicited for the existing system, and (ii) the identification of technological and architectural constraints that hinder the incorporation of certain game elements and rules $(18,61)$. We could not find any method that has been successfully employed to gamify one or more existing systems and, therefore, have been shown applicable in practice.

Problem 1. Development teams lack guidance in performing key software development activities to the gamification of existing systems.

\section{Software Development Activities that Become Challenging along the} Gamification of Existing Systems. Previous studies $(29,34,40)$ discuss that certain software development activities become particularly challenging along the gamification from scratch. Unfortunately, little is known about the development activities that become challenging when developers are gamifying existing systems. This limited knowledge affected VazaDengue gamification (61). We considerably struggled with designing and restructuring our system. Similarly, other development teams may still struggle with performing certain activities that are key to the gamification of existing systems. Thus, an understanding of which development activities are considerably challenging along the gamification of existing systems may be valuable to other developers. This understanding could also guide researchers in proposing new techniques to better support these activities. Finally, the knowledge about challenging development activities faced by developers could support the refinement of methods intended to guide the gamification of existing systems. 
Problem 2. There is a lack of empirical evidence about development activities that become challenging along the gamification of existing systems.

\section{Conceptual Gamification Models for Guiding the Gamification of Health-}

care Systems. Some healthcare systems failed in engaging users with critical system features (5). These systems presented a decrease in numbers of accesses and users, which is critical in the healthcare domain $(5,54)$. We have experienced such decrease in the VazaDengue case (58). We observed a significant lack of user engagement and system dissemination (18). Thus, public health agents found hard to address health issues due to low rates of issue reports provided by system users (18). Aimed to leverage the user engagement, conceptual gamification models play an essential role (63). A conceptual gamification model defines how users and game elements interact. Unfortunately, while gamifying VazaDengue, we only identified models for specific healthcare domains, such as chronic disease management (6) and physical activity (69). These models are not intended to support the constant report and validation of health issues, as well as the cooperation of citizens and public health agents, which is essential to prevent mosquito-borne diseases such as Zika, Dengue, and Chikungunya (27). Thus, a well-defined and validated conceptual gamification model for the domain of mosquito-borne disease prevention is desired. Otherwise, it becomes hard to properly gamify certain existing systems in this domain, such as VazaDengue (61).

Problem 3. Developers lack conceptual gamification models for gamifying healthcare systems of critical domains such as the prevention of mosquitoborne diseases.

\section{2}

\section{A Refined Method for Gamifying Existing Software Systems}

Our first attempt to gamify VazaDengue was guided by an existing method aimed at gamifying software systems from scratch (40). Such method encompasses certain development phases that range from domain documentation and requirements elicitation to software implementation and testing. However, as expected due to the purpose of the existing method, we lacked proper support to certain development activities that are essential to the gamification of existing systems. In particular, we had no support to: (i) revisit the existing system artifacts; (ii) reason about the limitations of our current implementation; and (ii) understand the impact of incorporating game elements 
and rules into the existing system. Aimed to better support the gamification of existing systems, we decided to incrementally extend the existing method (40).

For this purpose, we relied on our particular experience with gamifying the VazaDengue healthcare system. Whenever we observed the need for performing one or another development activities towards the system gamification, we refined the existing method to address those needs. Thus, our practical experience has strongly impacted the method design (i.e., the activities and execution flow that constitute the method). The resulting method refined 25 activities from the existing method to particularities of gamifying existing systems; 10 activities were adapted; four were fully reused; nine new activities were introduced in order to guide developers in revisiting existing requirements and system features; and two activities were discarded. Our method enables us to successfully gamify VazaDengue.

Contribution. We have built a gamification method based on successive experience-based refinements. We have developed the VazaZika gamified healthcare system aimed to support the prevention of mosquito-borne diseases. The process of gamifying this system was explicitly supported by our gamification method. We expect our method to be applicable to the gamification of similar healthcare systems.

\section{3}

Systematic Exploration of Challenging Development Activities

Both practitioners and researchers rarely share their experience acquired with the gamification of existing systems. As a consequence, newcomers on gamifying existing systems are not able to learn from others' experience. They do not become aware, for instance, of what software development activities may require special attention. In order to fill this gap, we report our practical experience with gamification of VazaDengue.

Many software development activities were challenging along the VazaDengue gamification. The lack of experience with software gamification, summed up with past decisions on design and technology for VazaDengue, led developers to struggle with certain activities. For instance, adding both game elements and rules into the existing systems required high effort to: (i) understand the overall impact of implementing certain game elements and rules on the system requirements, especially the non-functional ones such as interoperability and availability; (ii) make decisions regarding a technological modernization (e.g., API replacement) in order to facilitate the software gamification; 
and (iii) evolve the systems' architecture to gamify the system. Certain game elements and rules were postponed and discarded due to the challenging nature of some activities. From requirements elicitation to software testing, developers struggled with certain key activities to the system gamification.

Aimed to identify the challenging activities during the gamification of the existing system, we interviewed 15 developers who collaborated with the systems' design, implementation, and testing. We asked them about the activities perceived as challenging along the VazaDengue gamification. By applying qualitative analysis procedures $(8,15)$, we elicited 22 challenging activities from which 18 are closely related to gamification. Thus we were able to share our experience with practitioners and researchers.

Contribution. We reported our practical experience with gamifying VazaDengue. We empirically derived a conceptual mapping of development activities that became challenging along the system gamification.

\section{4}

\section{A Conceptual Gamification Model to Prevent Mosquito-borne Diseases}

A conceptual gamification model or simply gamification model defines how system users and game elements interact through well-defined game rules (63). Due to our lack of experience with the gamification of software systems before gamifying VazaDengue, we first looked for gamification models proposed by previous studies. Unfortunately, the majority of existing gamification models proposed so far, e.g. $(1,6)$, are only informally documented and vaguely described. More critically, these models do not address the gamification goals that help to prevent mosquito-borne diseases: (i) to promote the constant report of health issue such as the mosquito breeding sites, and (ii) to promote the effective validation of issue reports provided by citizens, so that public health agents can guide their work.

Aimed to guide the gamification of healthcare systems in the domain of mosquito-borne diseases prevention, we have followed our gamification method (Section 1.3) and built a gamification model composed of 12 game elements and 16 game rules. We have incorporated this model into an existing healthcare system (VazaZika, in our case). We evaluated our gamification model through an experiment with 20 citizens focused on the VazaZika mobile application. Our major goal was assessing our gamification model through ease of use, fun, motivation, potential for the constant use of key system features, and potential for disseminating the system use among citizens. 
As a result, we observed that about $55 \%$ of citizens found easy to use the mobile application; a half of citizens associated either game elements or rules with the ease of use. When asked about the user interface, citizens mentioned 13 aspects from which $69 \%$ were positively rather than negatively perceived (special highlight to the interface simplicity). We identified some opportunities to improve the information presentation (e.g., due to unclear information into the mobile application). Most citizens found fun to use the application (65\%), they felt motivated to use the system again (95\%), and they would recommend the system to friends in order to disseminate the system use (85\%).

Contribution. We built a conceptual gamification model that guided the definition of game elements and rules into VazaDengue. Through an empirical study with 20 citizens, we confirmed that the gamification model that underlies our mobile application has the potential to improve user engagement and the system dissemination.

\section{5}

\section{Research Publications}

The empirical studies of this Master's dissertation were reported in papers already published or under review. Table 1.1 lists all papers derived from this dissertation in Rows 1 to 4 . Two out of the four papers are not yet published. The table also lists, in the remained lines, the other papers produced along with my Master's in cooperation with other colleagues.

\section{6}

\section{Dissertation Outline}

The remainder of this Master's dissertation is organized as follows. Chapter 2 introduces basic concepts and related work aimed to support the understanding of this dissertation. Chapter 3 introduces our gamification method aimed to support the gamification of existing systems. This chapter also discusses the software challenging development activities along the gamification of our existing system. Chapter 4 introduces our gamification model that aims to support the gamification of healthcare systems in the domain of mosquito-borne diseases prevention. This chapter also discusses opportunities for improvement of our gamification model. Finally, Chapter 5 concludes this Master's dissertation and suggests future research. 
Table 1.1: List of Research Publications

\begin{tabular}{|c|c|c|c|}
\hline Type & Paper & Reference & Chapter \\
\hline \multirow{3}{*}{$\begin{array}{l}\text { Master's } \\
\text { Research }\end{array}$} & $\begin{array}{l}\text { Fernandes, E., Uchôa, A. et al. (2019). VazaZika: A Software } \\
\text { Platform for Surveillance and Control of Mosquito-Borne } \\
\text { Diseases. In: 16th International Conference on Information } \\
\text { Technology: New Generations (ITNG), pp. 1-4 }\end{array}$ & (18) & 4 \\
\hline & $\begin{array}{l}\text { Uchôa, A. et al. (2019). On Gamifying an Existing Health- } \\
\text { care System: Method, Conceptual Model and Evaluation. } \\
\text { In: 1st International Workshop on Software Engineering for } \\
\text { Healthcare (SEH) co-located with 41st International Confer- } \\
\text { ence on Software Engineering (ICSE), pp. } 1-8 \text {. }\end{array}$ & (61) & 3,4 \\
\hline & $\begin{array}{l}\text { Uchôa, A. et al. (2019). On Gamifying Service-Oriented } \\
\text { Systems: Experience Report and Challenges Ahead. Software: } \\
\text { Practice and Experience (S:P\&E). (To submit) }\end{array}$ & $\mathrm{N} / \mathrm{A}$ & 3 \\
\hline \multirow{7}{*}{$\begin{array}{c}\text { Other } \\
\text { Contributions }\end{array}$} & $\begin{array}{l}\text { Uchôa, A. et al. (2017). Do Coupling Metrics Help Char- } \\
\text { acterize Critical Components in Component-based SPL? An } \\
\text { Empirical Study. In: 5th Workshop on Software Visualiza- } \\
\text { tion, Evolution and Maintenance (VEM) co-located with VIII } \\
\text { Brazilian Conference on Software: Theory and Practice (CB- } \\
\text { Soft), pp. } 46-53\end{array}$ & $(62)$ & $\mathrm{N} / \mathrm{A}$ \\
\hline & $\begin{array}{l}\text { Sousa, L., de Mello, R., Cedrim, D., Garcia, A., Missier, P., } \\
\text { Uchôa, A. et al. (2018). VazaDengue: An Information Sys- } \\
\text { tem for Preventing and Combating Mosquito-Borne Diseases } \\
\text { with Social Networks. Information System (IS), } 75,26-42\end{array}$ & $(58)$ & $\mathrm{N} / \mathrm{A}$ \\
\hline & $\begin{array}{l}\text { Ferreira, I., Fernandes, E., Cedrim, D, Uchôa, A. et al. } \\
\text { (2018). The Buggy Side of Code Refactoring: Understanding } \\
\text { the Relationship between Refactorings and Bugs. In: 40th } \\
\text { International Conference on Software Engineering (ICSE): } \\
\text { Poster Track, pp. } 406-407\end{array}$ & $(20)$ & $\mathrm{N} / \mathrm{A}$ \\
\hline & $\begin{array}{l}\text { de Mello, R., Uchôa, A., et al. (2019). Investigating the Social } \\
\text { Representations of Code Smell Identification: A Preliminary } \\
\text { Study. In: 12th International Workshop on Cooperative and } \\
\text { Human Aspects of Software Engineering (CHASE) co-located } \\
\text { with 41st International Conference on Software Engineering } \\
\text { (ICSE), pp. 1-8 }\end{array}$ & (10) & $\mathrm{N} / \mathrm{A}$ \\
\hline & $\begin{array}{l}\text { Fernandes, E., Uchôa, A. et al. (2019). On the Alternatives } \\
\text { for Composing Batch Refactoring. In: 3rd International Work- } \\
\text { shop on Software Refactoring (IWoR) co-located with 41st In- } \\
\text { ternational Conference on Software Engineering (ICSE), pp. } \\
\text { 1-4 }\end{array}$ & (19) & $\mathrm{N} / \mathrm{A}$ \\
\hline & $\begin{array}{l}\text { Martins, J., Bezerra, C., Uchôa, A. (2019). Analyzing the } \\
\text { Impact of Inter-smell Relations on Software Maintainability: } \\
\text { An Empirical Study with Software Product Lines In: 15th } \\
\text { Brazilian Symposium on Information Systems (SBSI) }\end{array}$ & $(37)$ & $\mathrm{N} / \mathrm{A}$ \\
\hline & $\begin{array}{l}\text { Uchôa, A., et al. (2019). The Scent of Critical Components: } \\
\text { A Study with Component-based Software Product Lines In: } \\
\text { Software Quality Journal (SQJ) (To submit) }\end{array}$ & $\mathrm{N} / \mathrm{A}$ & $\mathrm{N} / \mathrm{A}$ \\
\hline
\end{tabular}




\section{2 \\ Background and Related Work}

Gamification has been largely adopted for engaging people with tasks through the incorporation of game elements and rules into non-game contexts $(12,68)$. In the software development context, gamification plays an important role by leveraging the user engagement with a system through its features (63). For enabling the user engagement, gamifying a software may require a well-defined gamification method. This method systematically guides the development activities required to gamify a system, including the requirements elicitation and the definition of system features and design. Thus, developers can incorporate game elements (e.g., points) and rules (e.g., ranking policy) into the gamified system (40). Enabling user engagement also may require the definition of a conceptual gamification model, which represents how system users and game elements should interact through the game rules $(63,68)$.

As discussed in Section 1.1, there are two software gamification approaches: (i) the gamification from scratch that consists of planning the incorporation of game elements and rules into a software system from the early development phases, and (ii) the gamification of an existing software system that consists of evolving a non-gamified system by either adding or refining existing system features to accommodate game elements and rules. The first approach has been explored and supported by previous studies $(25,40)$. However, the second approach remains poorly explored by the literature, though it is very common in practice $(55,58)$. Consequently, development teams may struggle to gamify their existing systems in practice (61).

This Master's dissertation introduces a series of empirical studies that enhance the current knowledge about the gamification of existing systems. This chapter provides background information aimed at supporting the comprehension of this Master's dissertation. Section 2.1 presents the basic concepts of software gamification. Section 2.2 discusses the existing software gamification methods and some development activities that may become considerably challenging along the software gamification. Section 2.3 discusses about gamification applied to healthcare systems. Section 2.4 discusses limitations of previous work regarding the support to the gamification of existing systems. Finally, Section 2.5 concludes this chapter. 


\section{1}

\section{Basics of Software Gamification}

Gamification consists of using game elements and well-defined rules into non-game contexts with the purpose of engaging people with a variety of tasks $(12,68)$. Gamification has been largely adopted by software companies and developers in different domains. For instance, gamification has been successfully used for boosting people consumption in market segments (67), engaging students with learning tasks (41), and promoting the people wellbeing and health (46). Gamification has been also applied with the purpose of supporting the software development tasks (45), by promoting the completion of eventually repetitive and time-consuming tasks such as writing software test cases (51). In this Master's dissertation, we are concerned about the gamification applied to software systems aimed at engaging users with the system features, which call software gamification (63).We discuss the basic constituent elements of any gamified software system as follows.

Game elements. They represent the basic components of any gamified system. Table 2.1 list some game elements discussed by previous work $(12,68)$. The choice for game elements that help to address the gamification goals will define the possibilities of user interactions with the gamified system (12). For instance, assigning points to users will not just reward the user interaction, thereby promoting constant interactions in the future, besides creating competition among users given the points count associated with the user.

Table 2.1: Some Popular Game Elements

\begin{tabular}{|c|c|}
\hline Game Elements & Characteristics \\
\hline $\begin{array}{l}\text { Avatar: A visual representation of } \\
\text { the system user }(12,68)\end{array}$ & $\begin{array}{l}\text { It makes the system user more more immerse into the } \\
\text { system. }\end{array}$ \\
\hline $\begin{array}{l}\text { Badge: Special reward earned by } \\
\text { users }(12,68)\end{array}$ & $\begin{array}{l}\text { It aims at recognizing the user skills as the user interacts } \\
\text { with the system. }\end{array}$ \\
\hline $\begin{array}{l}\text { Challenge: Set of tasks with a com- } \\
\text { mon purpose }(12,68)\end{array}$ & $\begin{array}{l}\text { It represents a set of actions that the system user should } \\
\text { perform to earn more rewards than those provided by a } \\
\text { single task. }\end{array}$ \\
\hline $\begin{array}{l}\text { Level: A control of the user } \\
\text { progress }(12,68)\end{array}$ & $\begin{array}{l}\text { Usually counted in terms of earned points and badges. } \\
\text { Levels can control how certain system feature are un- } \\
\text { locked for the users to interact with. }\end{array}$ \\
\hline $\begin{array}{l}\text { Ranking: A sorted list of users (12, } \\
68)\end{array}$ & $\begin{array}{l}\text { It provides a general view of the system users' progresses. } \\
\text { Usually computed by the users' levels and points. It aims } \\
\text { at promoting the user competition. }\end{array}$ \\
\hline $\begin{array}{l}\text { Point: A unit of reward earned by } \\
\text { users }(12,68)\end{array}$ & $\begin{array}{l}\text { It usually reflects the use } \\
\text { are commonly assigned } t\end{array}$ \\
\hline Task: An atomic user action $(12,68)$ & $\begin{array}{l}\text { It represents a specific type of user action. Each task } \\
\text { should have a clear and reward the system users when- } \\
\text { ever completed successfully. }\end{array}$ \\
\hline $\begin{array}{l}\text { Team: Group of users } \\
\text { purpose }(12,68)\end{array}$ & $\begin{array}{l}\text { It aims at promoting a user group engagement with } \\
\text { the system. Teams usually promote competition and } \\
\text { cooperation among users. }\end{array}$ \\
\hline
\end{tabular}

Game rules. The game rules define the interactions of people and game elements towards people engagement. Basically, there are two types of game 
rules as follows. The first type of rules defines the relations between the system and its users. Let us exemplify these rule types via points and rankings. In our gamified software system, named VazaZika (Chapter 4), each report of a mosquito breeding site rewards the user $(18,61)$. These report awards aim at keeping the user engaged with the system. Thus, the system has to acknowledge the user with points that are accumulated in a points count. The second type of rule defines the relations between game elements. Based on the previous example, the points assigned to a user that has reported a mosquito breeding site are aggregated for determining the user ranking. In this case, there is a relation between points and ranking.

Conceptual gamification model. The gamification model defines the game elements (e.g., points) and rules (e.g., ranking policy), and associates them with the system's features (63). The model can also be visually represented. In this Master's dissertation, we have defined a graphical representation of gamification models as follows. The system user is represented by a blue-colored box. The game elements that should be incorporated by the gamified system are represented by green boxes with rounded corners. The game rules are represented by arrows. Continuous arrows represent actions performed by the system user on the system (user-system actions). Dashed arrows represent actions performed by one game element on another (interelements actions). Dotted arrows represent dependencies between two game elements (inter-elements dependencies). Figure 2.1 illustrates an example of gamification model. We describe this gamification model as follows.

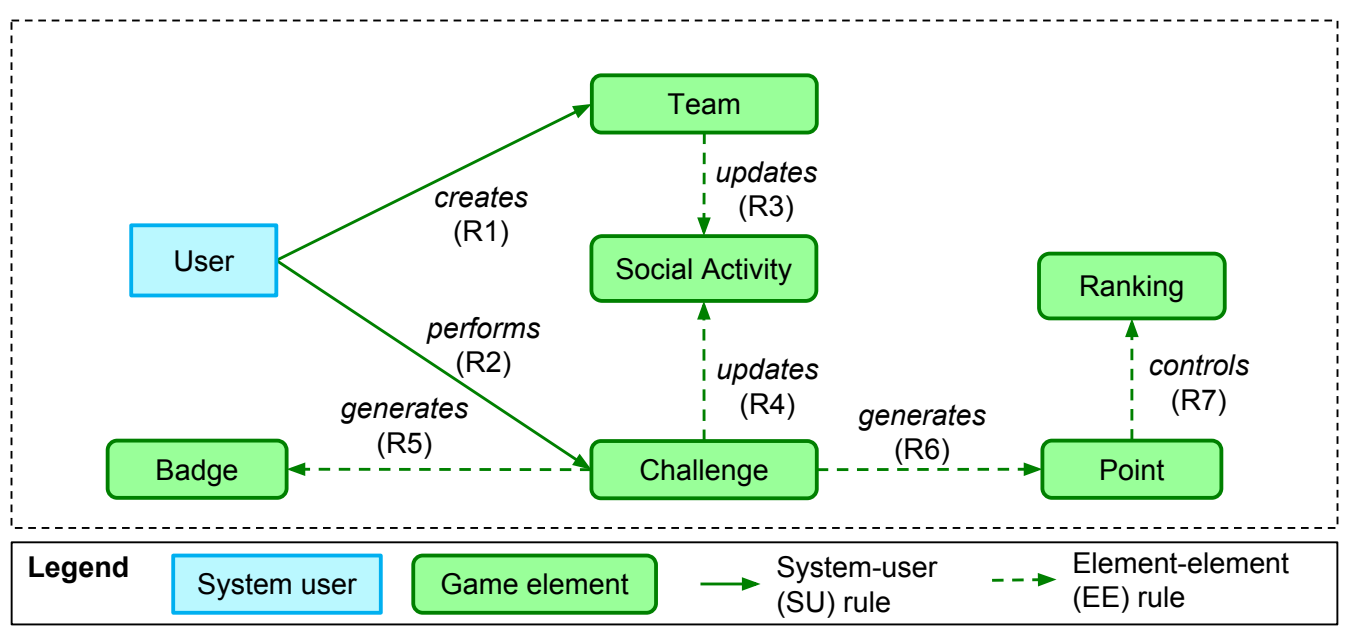

Figure 2.1: Gamification Model Notation used in this Master's Dissertation

This gamification model is defined by six game elements, namely badge, team, social activity, challenge, point, and ranking, besides seven game rules (R1 to R7). The system user can create a new team for performing activities 
together with other system users (R1). The system user can also perform a particular type of task called challenge, which consists of two or more tasks aggregated within a unit task (R2). To create a new team triggers the social activity of the software systems, which means that the team creation will be informed to all system users (R3). Similarly, to engage a challenge updates the social activity (R4). Whenever a system user completes a challenge, he is rewarded with a badge (R5). The challenge completion also gives points to the system user (R6). Finally, the points count of a user is used to control the user ranking $(\mathrm{R} 7)$.

\section{2}

\section{Existing Methods for Supporting Software Gamification}

We have found some studies $(29,34,40,50)$ that introduce methods for guiding software gamification, i.e., the incorporation of game elements and rules into a software system. Unfortunately, none of these methods aimed to target the particularities of gamifying existing systems. Thus, all the existing methods guide development activities that concern the software gamification from scratch rather than the gamification of systems that were previously implemented without gamification in mind. Particularly, the existing gamification methods are quite limited in scope: most methods targeted the business context and they were conceived as user-centered designs, i.e., the user and their goals are the central focus of the design and development (39). In addition, the existing methods are highly abstract and provide little implementation support to developers. We discuss each study as follows.

One study (50) introduced a gamification method composed of five phases: (i) business objectives definition; (ii) game model and characteristics definition; (iii) methodology and tools of software development; (iv) game design and software development; and (v) gamification quality control and feedback. In a general view, this method sounds quite comprehensive because it encompasses activities from requirements elicitation to implementation and quality control. However, this method does not support some key activities required to gamify existing systems. An example of a key activity is revisiting the existing software artifacts, such as requirements documentation, in order to reason about the impact of incorporating game elements and rules into the system. In addition, the proposed method was shaped to address major needs of designing web systems from the e-business domain.

Other two studies $(29,34)$ did not actually introduce gamification methods but they provide insights to developers in charge of defining the system architecture and implementing the gamified software systems. Both 
studies focused on sharing guidelines that can be useful to design the internal component organization of gamified systems, besides the component intercommunications. For instance, they describe an architecture for systematically gamifying a software system with service-oriented and event-driven principles. Nevertheless, these studies did not intend to systematically define a method with development activities and their execution flow.

Finally, a recent study (40) introduced a method, named here as Morschheuser's method, for guiding the software gamification from scratch. The method is structured in seven phases: 1) Project Preparation aims to define the system gamification goals. The Project Preparation phase encapsulates five activities, i.e., identify and list objectives, rank objectives, justify objectives, assess gamification applicability and identify requirements; 2) Context Analysis aims to elicit and discuss the development organizational context, including business processes, organization culture, and technology available to implement the gamified system. The Context Analysis phases encapsulate three activities, i.e., identify context, understand the context, and define success metrics; 3) User Analysis aims to define and characterize the target users. The User Analysis phase encapsulates four activities, i.e., define target users, identify the user needs, identify the user motivations, and create personas.

The fourth phase Idealization guides gamification design thinking and documentation. This phase encapsulates two activities, i.e., brainstorm ideas and consolidate ideas; 5) Design aims to build the system prototypes that realize the gamification design. This phase encapsulates four activities, i.e., create user journey, design prototype, create the prototype, and evaluate prototype; 6) Implementation guides the system implementation, testing, and incremental refinement. This phase encapsulates six activities, i.e., decide implementation, prepare development, advise and manage implementation, implement the design, playtesting, and pilot. 7) Evaluation aims to assess if the gamification goals have been successfully addressed, and 8) Monitoring aims to monitor the system use in order to track opportunities for improvement. We further discuss the limitations of this method (and those others also discussed here) in Section 2.4 .

\section{3}

\section{Software Gamification in the Healthcare Domain}

We mined the literature on the application of software gamification to healthcare systems, especially in the context of mosquito-borne disease prevention, such as Dengue, Zika, and Chikungunya. As a result, we have found only a few studies on this topic, thereby confirming previous literature observa- 
tions (54). Most of the studies found by us introduce non-gamified healthcare systems, i.e., systems that do not incorporate game elements and rules. We discuss below some of the previous studies that are more closely related to ours.

Non-gamified healthcare systems. InfoDengue (7) is an information system that analyzes social media data collected from Twitter to track Dengue. This system relies on data about climate changes posted by social network users. Citizens are not allowed to report data manually in order to complement the data mined from social media. "Observatorio do Aedes aegypti" is another information system aimed to track Aedes aegypti-borne diseases. The system supports citizens in reporting mosquito breeding sites and suspected cases of Dengue, Zika, and other related diseases. Through geo-located data, public health agents can plan and execute strategies for preventing diseases. Contrarily to InfoDengue, this system does not explore social media data. Finally, VazaDengue $(21,58)$ is an information system that combines social media data with manual reports of mosquito breeding sites provided by citizens. The major system goal is supporting public health agents in tracking Dengue.

Serious games for healthcare. We did not find studies that introduce gamified software systems for healthcare in the domain of prevention of mosquito-borne diseases. The closest we found to gamified systems are the so-called serious games. Basically, a serious game is a video game that holds a serious (e.g., education or instruction) purpose (54). Aedes Game (11) is a serious game aimed at raising the awareness of citizens in combating the spread of Dengue and other related diseases. Players answer a variety of questions, e.g., In which locations Aedes aegypti mosquitos more likely to spread?, For each correctly answered question, a virtual mosquito is hit by an electric racket, points are given to the player, and a new game level is unlocked. X-Dengue (35) is a serious game with a quite similar purpose. Players are guided through phases in which mosquito breeding sites have to be eliminated. Finally, Zika Gamification (22) implements points, badges, and rankings aimed at training public health agents in tasks of disease prevention and control. However, this application does not focus on engaging citizens in critical healthcare-related features, such as the report of mosquito breeding sites.

This Master's dissertation exploits the gamification of an existing system called VazaDengue (58). The gamification resulted in the VazaZika gamified version (18). Our gamified system is innovative because it promotes healthcarerelated activities that directly support disease prevention including the constant report and validation of mosquito breeding sites. In addition, our system

\footnotetext{
${ }^{1}$ http://observatoriodadengue.telessaude.ufrn.br/
} 
differs from the aforementioned systems by incorporating game elements and rules aimed to leverage user engagement with key healthcare-related features. We explain in detail how our gamified system has aimed at improving user engagement by incorporating game elements and rules in Chapter 4 .

\section{4}

\section{Limited Support to the Gamification of Existing Systems}

We have found many limitations of previous studies concerned with the gamification of existing software systems. These limitations were mostly observed along the gamification of an existing healthcare system called VazaDengue, as mentioned in the previous section. We discuss the major limitations and how there were addressed by this Master's dissertation as follows.

\subsection{1}

\section{Lack of a Systematic Method for Gamifying Existing Systems}

This section summarizes the limitations of the existing methods for gamifying existing systems, which were previously described in Section 2.2. Before gamifying the VazaDengue system, we have searched in the literature for methods and frameworks that could assist the developers in gamifying our existing system. Unfortunately, we have found only a few methods (29, 34, $40,50)$ that only aimed at supporting gamification from scratch. A previous work (50) introduces a method composed by five steps that range from defining the system goals to defining and validating the system gamification design. There are two major limitations of this method: (i) no guidance to revisiting the existing software artifacts targeting their adaptation and the identification of constraints to the system gamification, and (ii) too much focus on the ebanking domain, which makes it hard to apply the method to other domains.

Studies such as (29) and (34) provide guidelines to drive system gamification in certain phases. Herzig et. al (29) focus on requirements elicitation and architectural design. As far as requirements elicitation is concerned, the authors discuss non-functional requirements that should be considered when designing an architecture for gamified systems (simplicity, reusability, and decoupling of functionality). The authors also discuss certain requirements that are specific of the gamification domain, e.g., a gamified system should provide immediate feedback and promote challenges among users. Regarding architectural design, the authors propose a service-oriented architecture to support the gamification of systems. Kardan and Arani (34) overview certain related activities with software gamification, and different situations in which game elements might be used in practice. However, both aforementioned studies 
do not provide methods that guide the gamification of existing systems from requirements to testing. Instead, these studies focus on general guidance to architecture design and system implementation.

Fortunately, we have found a previous work (40) whose gamification method that encompasses various phases though aimed to support the system gamification from scratch. Such method encompasses certain development phases that range from domain documentation and requirements elicitation to software implementation and testing. Contrary to previous work $(29,34,50)$, this particular study introduces a well-documented method, whose phases are scrutinized by means of well-defined development activities. Given guidelines about how to conduct each phase to gamify a software system. As we discuss in Chapter 3, we chose the method proposed by Morschheuser et. al. (40) for refinement along with the VazaDengue system gamification.

\subsection{2}

\section{Challenging Development Activities along Software Gamification}

We did not find studies that systematically discuss the challenging development activities along the gamification of existing systems. Nevertheless, we found a study (40) that discusses some challenging activities related to the design of gamified software systems in general. The authors claim that gamifying a software system is complex and requires multidisciplinary knowledge, which ranges from psychology to design and coding. Besides, the authors discuss the role of gamification in influencing human behavior rather than just entertaining people. This study discusses that the understanding of technological constraints is often mentioned as a key requirement to successfully design gamified systems. In fact, in Chapter 3 we discuss how the lack of such knowledge affected the gamification of our system.

Another study (29) has discussed six challenges that affect developers in designing and implementing service-oriented gamified systems. An example of a challenge is called Front-end Integration. This challenge regards the problems that emerge from the integration of the back-end of a gamified system (which includes the implementation and data persistence of game elements and rules) with the front-end that provides a visual representation to the system users. As we discuss in Chapter 3, the developers of the VazaDengue system have faced challenges from this nature in real settings. Similarly, other study (34) elicited four hypothetical challenges faced by developers along the architecture design of web systems, mostly related to organizational and human aspects that hinder the gamification process. An example of a challenge elicited by the authors is Engineering Infrastructure. This challenge regards the massive data 
processing due to the incorporation of game elements and rules into the system that requires an appropriate infrastructure. We also discussed in Chapter 3 the challenges faced from this nature in real settings.

Part of this Master's dissertation is dedicated to systematically explore the development activities that became challenging along the gamification of the VazaDengue system. VazaDengue is a healthcare system aimed to support public health agents in tracking outbreaks of diseases transmitted by the Aedes aegypti mosquito, such as Dengue, Zika, and Chikungunya. This system is composed of a web and a mobile application, so that some challenging activities pointed out by previous work have been empirically confirmed and others were revealed for the first time. More details can be found in Chapter 3.

\subsection{3}

\section{Lack of a Gamification Model to Prevent Mosquito-borne Diseases}

A recent systematic review (54) summarized 46 studies that propose some form of using games or game elements in healthcare systems. More than half, i.e. 26 out of the 46, of the studies involve gamified systems. The other 20 studies explore serious games, i.e., systems with a serious purpose (12). Only 15 out of the 26 gamified systems support some sort of disease prevention, but none targeted at mosquito-borne disease. They aim to combat non-borne diseases such as diabetes (6) and rheumatoid arthritis (1), for which prevention and control are significantly different from mosquito-borne diseases such as Dengue, Zika, and Chikungunya (27).

Even worse, most of the conceptual gamification models in such studies are not explicitly defined. They present an overview of the system's features and interface, but the game elements and rules (as well as their relationships) are not systematically defined. In any case, they are not focused on assisting the prevention of mosquito-borne diseases such as Zika by promoting the citizen's engagement to constantly report of mosquito breeding sites. As well as performing collaborative prevention tasks, helping the public health agents tracking disease outbreaks and eliminating the reported sites. Besides, these models encompass a few game elements (e.g., points and ranking policy).

\section{5}

\section{Summary}

This chapter provided background information aimed to support the understanding of this Master's dissertation. We presented and discussed the basics of software gamification, gamification methods, and gamification applied to healthcare. We expect to provide readers with key concepts, so that they 
can properly read this dissertation and understand its major contributions. As much as possible, we discussed the limitations of previous studies in order to emphasize the novelty and importance of our work with respect to the current knowledge on software gamification. Especially, we discuss how previous studies guided our study on the gamification of existing software systems rather than gamification from scratch.

In the next chapter, we introduce the first study of this Master's dissertation. We present action research aimed to refine an existing gamification method aimed to support the specific needs of gamifying existing software systems. We present the various refinements applied to the existing method and how our practical experience with the gamification of a real-world system shaped the new proposed method. 


\section{3}

\section{A Refined Method for Gamifying Existing Software Systems}

The support to gamification from scratch has been extensively exploited by previous studies, as we discussed previously in Section 2.2. In fact, we have found a relevant number of gamification methods aimed to guide developments teams in gamifying systems from the early phases, including requirements and elicitation and domain analysis. However, there is an increasing demand in industry for gamifying existing systems that were not originally designed with gamification in mind $(55,58)$. Unfortunately, the current support to the gamification of existing systems is scarce if not nonexistent. Thus, developers can incorporate game elements and rules into these systems with the support of a gamification method, thereby making the system enjoyable and challenging.

A desired gamification method should guide the reasoning about existing software artifacts and how they should be refined in order to accommodate gamification (61). Current methods tend to support requirements elicitation and design of gamified systems from scratch $(29,34,40,50)$, i.e., those systems originally developed with gamification in mind. However, these methods are not tailored to situations where gamification needs to be integrated into an existing system. Consequently, development teams may significantly struggle with gamifying their existing systems (61).

This chapter introduces a method aimed to support the gamification of existing systems. Our method refines a previously gamification method proposed by Morschheuser et. al. (40) (Section 2.2). We relied on a particular experience with gamifying the VazaZika healthcare system from the domain of mosquito-borne disease prevention. We have employed a participatory action research (16) for adapting, discarding, adding, and reusing development activities from the Morschheuser's method.

The action research was composed of two complementary studies: a selfobservational study (17) whereby two researchers engaged in meetings to reason about refinements to apply on the existing gamification method, and an interview-based study (66) aimed to capture the feedback of developers on the development activities that constitute the method and identify opportunities for additional refinements. By performing the interview-based study in about half of the self-observation process, we were able to enhance our gamification 
method based on developers' perceptions about challenging development activities and how to cope with these activities in practice.

Our method has six development phases (e.g., User Analysis and Requirements Elicitation) composed of: 25 activities adapted from the Morschheuser's method to the needs of gamifying an existing system; four activity fully reused from that method; and nine new activities introduced for guiding developers in revisiting existing system artifacts. The study reported in this chapter is covered by our papers published in the 16th International Conference on Information Technology: New Generations (ITNG) (18) and the 1st International Workshop on Software Engineering for Healthcare (SEH) (61), co-located with 41st International Conference on Software Engineering (ICSE).

The remainder of this chapter is organized as follows. Section 3.1 overviews the need for proposing the gamified version of an existing healthcare system called VazaDengue. Section 3.2.1 describes our participatory action research aimed to refine a previously gamification method (40). Section 3.3 presents our self-observational study aimed to incrementally refine the method. Section 3.4 presents the interview-based study from which we identified challenging development activities along the VazaDengue gamification. We used the developer feedback for refining our method whenever possible. Section 3.5 introduces the final version of our gamification method. Section 3.6 discusses the limitations of our gamification method. Finally, Section 3.7 summarizes the contributions of this chapter and introduces the next chapter.

\section{1}

\section{The Need for Gamifying a Healthcare System}

In this Master's dissertation, we used an existing healthcare system called VazaDengue (58), as an object of analysis of the two studies presented in this chapter. We discussed the need for gamifying a healthcare system as follows.

The success of many healthcare systems largely depends on the engagement of their users, such as health professionals and citizens $(5,18,42,61)$. Thus, the incorporation of game elements and rules in existing healthcare systems has been recently explored in a wide range of domains (54). Examples of game elements include points and badges. Rules define the interaction of system users and game elements, and examples include policies for ranking users and assigning points to them while exploring a certain system's feature.

Only a few healthcare systems assist the prevention of diseases such as Zika, Dengue, and Chikungunya (58), which are transmitted by the Aedes aegypti mosquito. This mosquito is a global threat that has rapidly spread in economically emerging countries due to poor basic sanitation plus warm 
and humid weather (27). Traditional prevention solutions have been shown insufficient to engaging citizens $(18,27)$. Engaging citizens with healthcarerelated tasks is challenging in practice (54). In this context, a system called VazaDengue $(21,58)$ was proposed: a healthcare system that collects reports of disease cases and mosquito breeding sites. The system also automatically mines post in social networks, i.e., Twitter and Instagram, to collect reports from citizens. The main system goal is to provide real-time monitoring of such reports for public health agents and citizens so that prompt action could be taken to eliminate mosquito breeding sites.

Unfortunately, over three years that VazaDengue system had been deployed, was observed the decay in the number of new system users, views, and installations (18). Such decay suggested a lack of continuous user engagement with the system. Thus, public health agents had an insufficient number of reports to cope with disease outbreaks. As a response to the lack of user engagement, we have decided to gamify this existing system (12) for making VazaDengue enjoyable and motivating, while not making the system more difficult to use. This decision was driven by our major long-term goal of promoting a constant report of mosquito breeding sites. The gamification of VazaDengue resulted in the VazaZika gamified version (18).

The VazaZika system resulted of an international research project entitled Leveraging Gamification and Social Networks for Improving Prevention and Control of Zika. This project was performed by researchers in Software Engineering and Data Analytics from Brazil and the United Kingdom (UK). A total of 25 members participated in the project: one project manager; four development team leaders, one per team; 15 software developers, including the team leaders, distributed in two Brazilian cities, each with at least one developer per team, and; seven senior researchers, five from Brazil and two from UK. The project counted on the active contribution of a dozen Brazilian public health agents, which assisted many development activities.

The project members were allocated to at least one out of the four following teams. Design Team: responsible for eliciting the system requirements, conceiving the gamification design, and prototyping both user interface (UI) and user experience with the system (UX). Implementation Team: responsible for programming the back-end and front-end layers of the web and mobile applications that constitute the VazaZika system. This team was also responsible for implementing the specific layer that supports the system gamification. Testing Team: responsible for programming and running unit test cases, besides conducting interface testing. Research Team: responsible to conduct academic research on gamification and data analytics applied to healthcare. 
This Master's dissertation systematically exploits our experience with gamifying the VazaDengue healthcare system from its start. Our major goal was, from a practical perspective, some key needs of a particular development team in gamifying an existing system that was not originally designed with gamification in mind. We have used the VazaDengue gamification as a study case to investigate our research questions, as further described in the next section. In other words, we analyzed the VazaDengue gamification for (i) shaping a gamification method that guides the gamification of existing systems and (ii) proposing a gamification model aimed to incorporate game elements and rules into healthcare systems for preventing mosquito-borne diseases.

\section{2}

\section{Research Methodology}

When we started the VazaDengue gamification, we did not find methods for guiding us in gamifying our existing system. However, we needed to gamify VazaDengue aimed to leverage both the constant report and the validation of mosquito breeding sites in Brazil. Thus, we decided to rely on an existing method proposed in a previous work (40) as first guidance. We discussed in detail the existing method in the Section 2.2. We opted by conducting a participatory action research (47) in order to incrementally refine the Morschheuser's method. For this purpose, we have conducted two complementary empirical studies. Figure 3.1 provides a general view of how both studies complement one another with respect to their inputs and outputs. The figure also indicates the number of developers involved in each study.

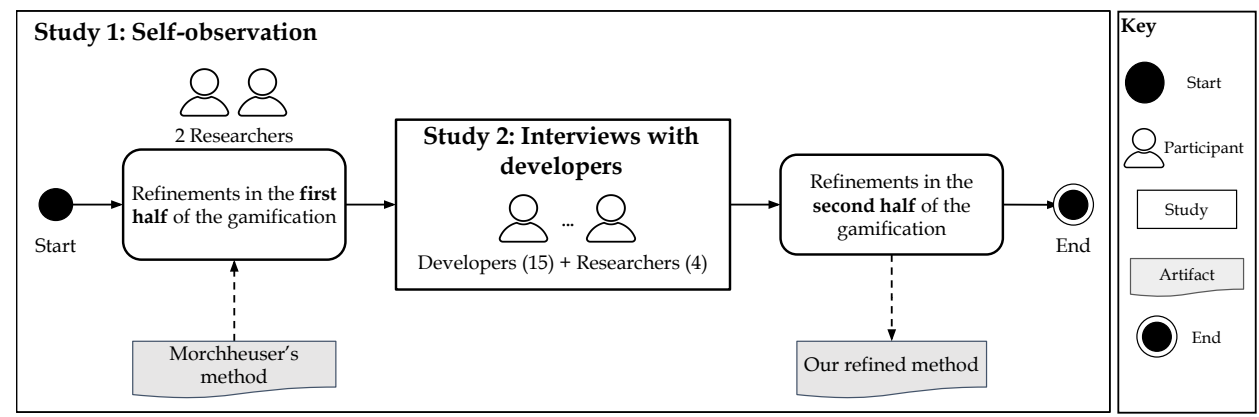

Figure 3.1: Overview of the Participatory Action Research

The first study consists of a self-observational study (17), whose goal is to observe how the VazaDengue development team behaved along the system gamification, which needs have emerged and how Morschheuser's method should be refined to overcome the developers' needs. In this case, two researchers engaged in meetings to reason about refinements to apply on the existing method based on a weekly observation of the gamification process. 
The second study was an interview-based study (66), which consisted of interviewing the 15 VazaDengue developers about the employed gamification method. Four researchers conducted the interviews, from which three are included in the set of 15 developers that were interviewed. Our major goal was capturing those development activities that became more challenging along the system gamification. Thus, we could identify opportunities for refining the gamification method towards a more comprehensive and lightweight one. At the end, we expected to derive a method specifically tailored to support the introduction of gamification in existing systems. To achieve the expectation, we needed to analyze to what extent the Morschheuser's method was appropriate.

\subsection{1}

\section{Goal and Research Questions}

We describe our study goal as follows (66): analyze an existing method for gamifying systems from scratch (40); for the purpose of refining this method, named Morschheuser's method, in order to guide developers in gamifying existing systems; with respect to the key development phases and activities for the gamification of an existing system; our analysis is performed from the viewpoint of software engineering researchers and developers; in the context of the VazaDengue healthcare system gamification performed by developers along software gamification. Table 3.1 lists our research questions (RQs).

Table 3.1: Research Questions of the Action Research

\begin{tabular}{cl}
\hline RQ & Description \\
\hline $\mathrm{RQ}_{1}$ & $\begin{array}{l}\text { What needs to be refined in the Morscheuser's method to support the } \\
\text { gamification of existing systems? }\end{array}$ \\
$\mathrm{RQ}_{1 \cdot 1}$ & $\begin{array}{l}\text { Which activities need to be refined to support the gamification of existing } \\
\text { systems? }\end{array}$ \\
$\mathrm{RQ}_{1 \cdot 2}$ & $\begin{array}{l}\text { What were the development activities perceived as challenging by the develop- } \\
\text { ers along the system gamification? }\end{array}$ \\
\hline
\end{tabular}

Through $\mathbf{R Q}_{1 \cdot 1}$ we aim to identify which activities of the Morschheuser's method (40) should be refined to support the gamification of existing systems. We considered four types of method refinement: discard, full reuse, adaptation, and the addition of an activity not yet supported by the method. Each development activity corresponds to part of the software gamification process. For addressing $\mathbf{R Q}_{1 \cdot 1}$, we designed a self-observational study (17), named Study 1, to promote discussions on the activities currently supported by the Morschheuser's method and the required refinements (Section 3.3).

With $\mathbf{R Q}_{1 \cdot 2}$ we aim to understand the feasibility of the method. In other words, we were concerned to what extent the development teams were able to follow our method without major issues that hinder the software gamification. 
By understanding which software development activities became challenging to perform along the VazaDengue gamification, we can track if factors that are associated with these challenging activities are related or not with the method. Challenging activities are those considered hard to perform with success by developers. It may be the case that activities tend to become challenging for reasons that extrapolate the followed method, e.g., the lack of supporting tools to perform key activities such as gamification design conformance. For addressing $\mathbf{R Q}_{1 \cdot 2}$, we designed semi-structured interviews (66), named Study 2, with developers from the VazaZika gamification teams (Section 3.4).

\section{3}

\section{Study 1: A Self-Observation of the Refined Method}

In the next sections, we describe the refinements applied on the Morschheuser's method (40) along a period of 24 working months. Two researchers with practical experience in Software Engineering (especially in the management of small development teams) have contributed to a retrospective analysis aimed to track these refinements along the VazaDengue system gamification. Section 3.3.1 details the study steps. Section 3.3.2 presents the study results. Finally, Section 3.3.3 discusses threats to validity.

\subsection{1}

\section{Study Steps}

Figure 3.2 illustrates the five study steps that we defined based on previous works $(47,48)$. Due to the incremental nature of action research, Steps 1 to 4 were performed by development phase along the VazaDengue gamification. Additionally, Step 5 was designed to be performed at the end of the system gamification. We describe each step as follows.

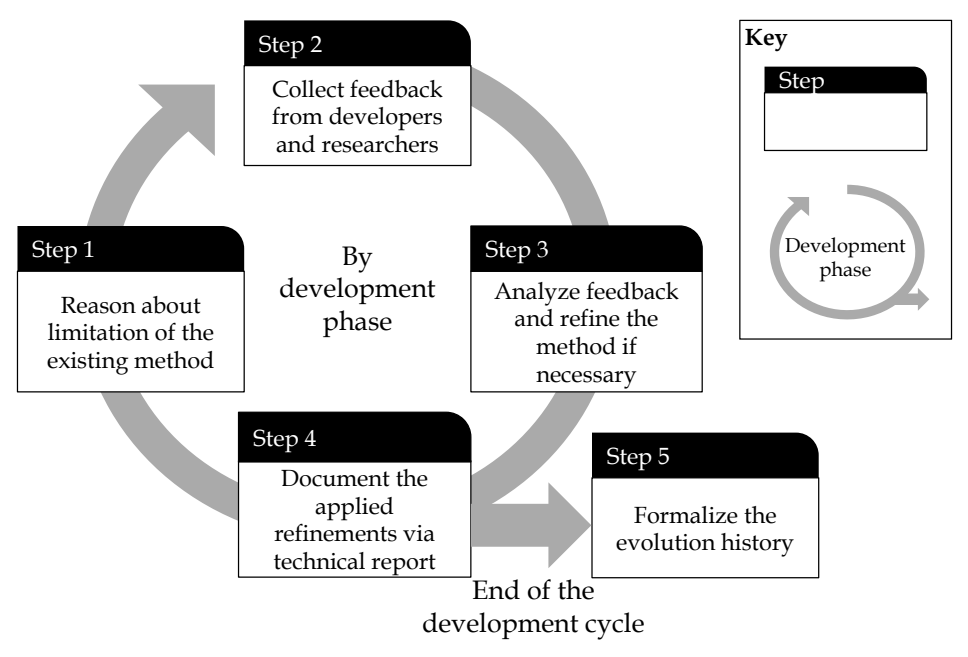

Figure 3.2: Study Steps of the Self-Observation Study 
Step 1: Reason About Limitations of the Existing Method. Two researchers reasoned about the Morschheuser's method in order to characterize to what extent each prescribed phase can support the gamification of existing systems. For this purpose, we initially observed the development context of our existing system. As aforementioned, VazaDengue was gamified by developers organized in a small and distributed development team. Based on our development context, we have discarded certain activities that do not fit the gamification of existing systems. After that, we have grouped the activities that could be adapted and reused to support the gamification of existing systems. Finally, we identified which activities were missing and, therefore, they should be added to properly support the gamification of existing systems.

Step 2: Collect Feedback from Developers and Researchers. We have conducted some meetings, face to face as far as possible, with current and former VazaDengue developers, and researchers involved during the gamification of the existing system. We aimed to capture the developers' needs that could be better addressed by the gamification method.

Step 3: Analyze Feedback and Refine the Method if Necessary. Based on the collected feedback, we were able to track which activities of the Morschheuser's method needed some type of refinement, i.e., adaptation, reuse, or discard. We were also able to identify opportunities for adding key activities to gamify existing systems. For this purpose, two researchers held several meetings aimed to validate the necessary refinements of the Morschheuser's method. Thus, for each activity included in refined method, we minimized biases and reached a consensus in a pair of researchers.

\section{Step 4: Document the Applied Refinements via Technical Re-} port. We have documented the applied refinements in four technical reports that encompass the main development phases, i.e., design, development, and testing. Each report describes the process and activities performed by developers along the VazaDengue system gamification. These reports also describe the main results obtained from each activity performed. Additionally, along with the system gamification, we managed requests (e.g., the addition of new features and bug fixes) through issues reported via GitHub. These issues contain information about architectural design and interface design decisions.

Step 5: Formalize the Evolution History. Two researchers have formalized the evolution history of our new gamification method based on milestones (60). The milestones represent a clear sequence of activities or events that incrementally build up until a specific goal is complete (60). In our case, we have taken each development phase of our refined method as a milestone because we have considered each phase as a specific goal. By phase, 
the respective activities were classified as adapted (ADP), reused (REU), added (ADD), or discarded (DIS). We preserved as much as possible the activity names assigned by the Morschheuser's method (40). An example of a classified activity is (ADP) Identify and List Objectives. Thus, we were able to define a systematic representation of how our method was incrementally refined throughout the development phases.

\subsection{2}

\section{Results and Discussions}

We discuss the main results of $\mathbf{R Q}_{1 \cdot 1}$ regarding the refinements applied on the Morschheuser's method (40) as follows.

Evolution History of the Gamification Method. We answer $\mathbf{R Q}_{1 \cdot 1}$ as follows. Figure 3.3 illustrates a overview of the evolution history of our new gamification method based on the Morschheuser's method (40). We also explain how our new gamification method was incrementally refined by each milestone as follows.

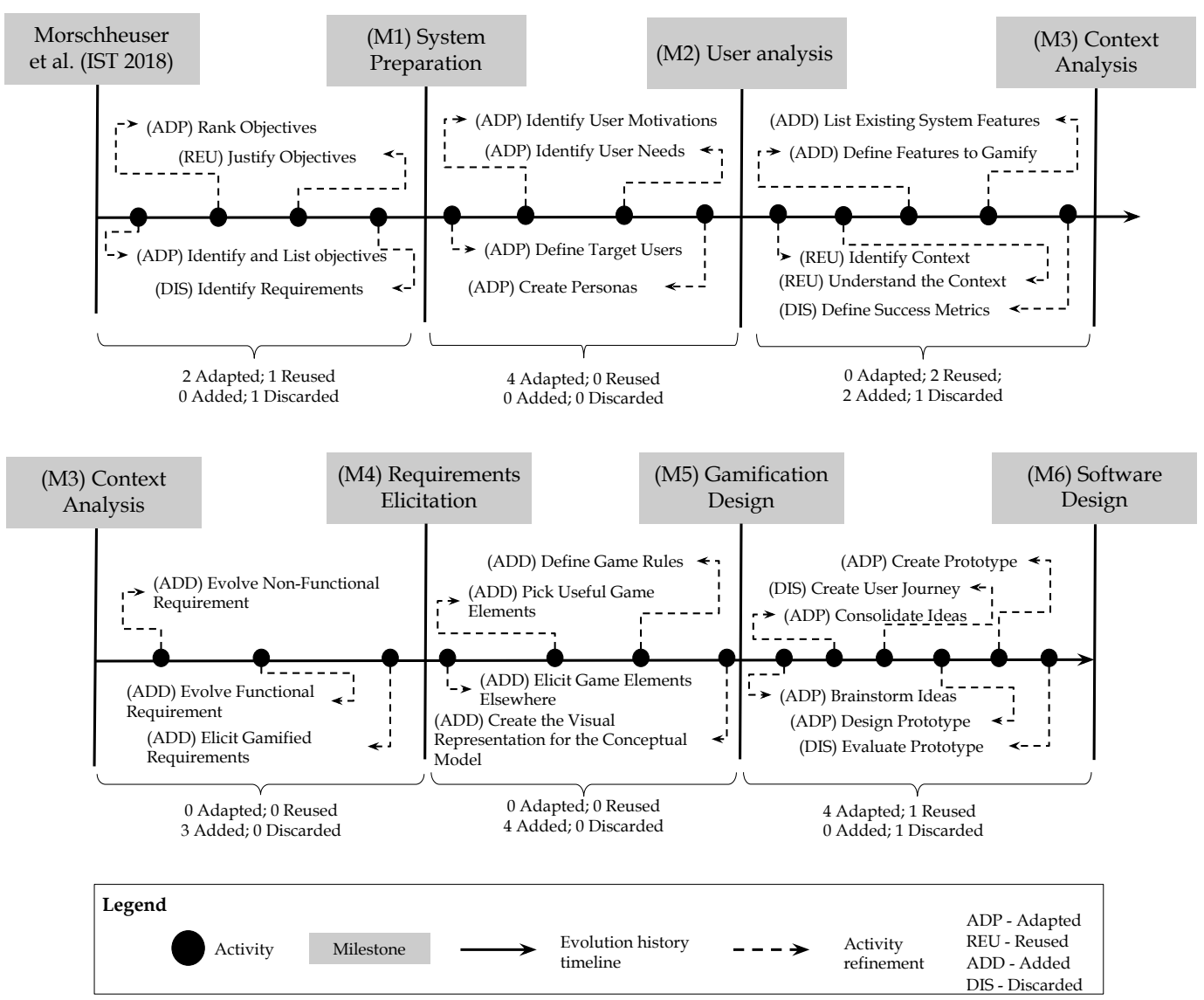

Figure 3.3: Overview of the Evolution History of the Gamification Method 
System Preparation. Figure 3.4 illustrates the refinements applied to conceive the System Preparation Phase. During this phase, we felt the need to adapt two activities of the Morschheuser's method. Adapting (ADP) Identify and List Objectives, and (ADP) Rank Objectives - The original definition of these activities did not guide the reasoning about gamification goals based on existing system goals. When gamifying systems from scratch, goals are elicited from the expectations of new users. Differently, when gamifying existing systems, it becomes necessary to discuss to what extent the system gamification affects the existing system goals. By overlooking these goals, the gamification may lead to existing system users to abandon the system usage.

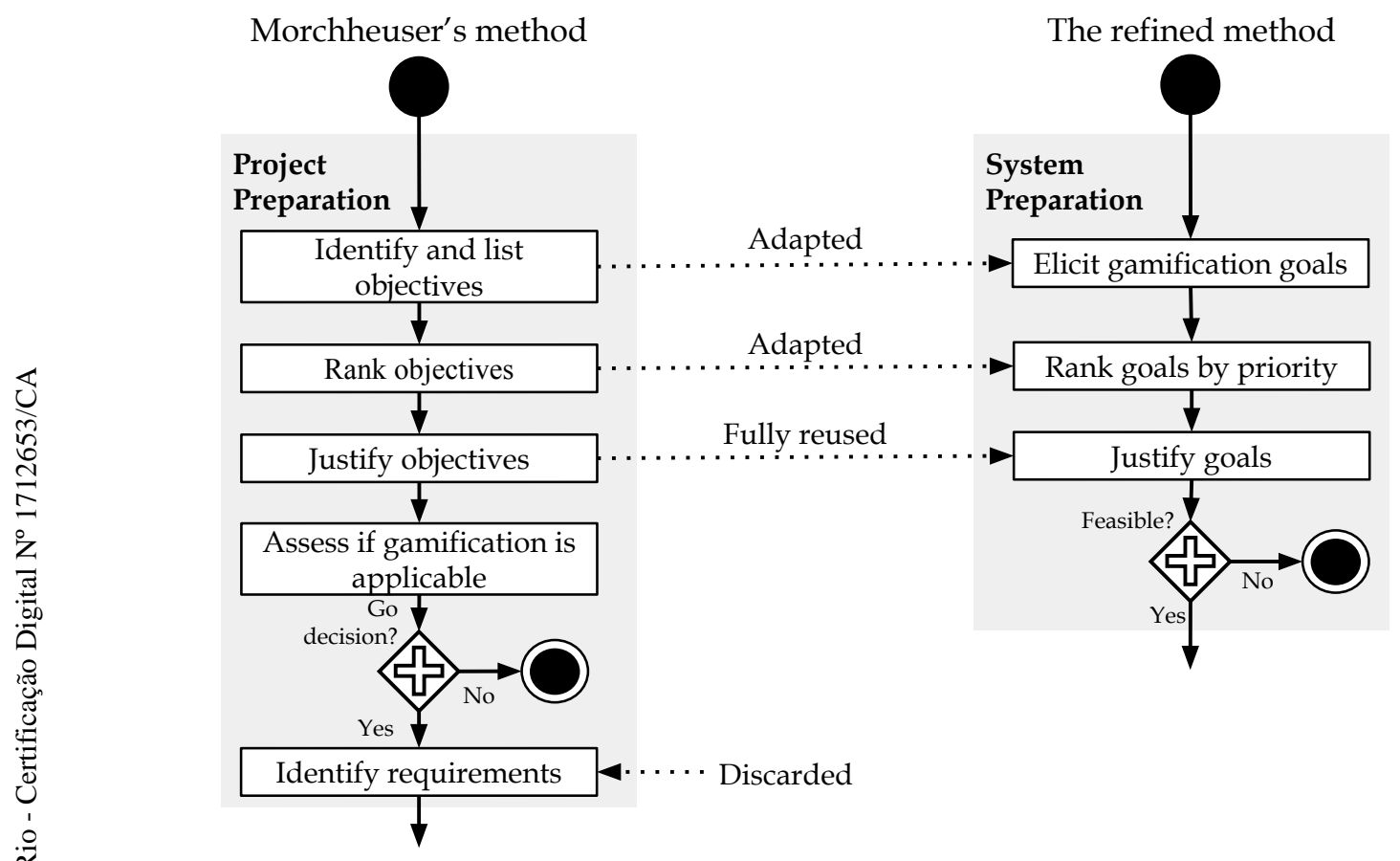

Figure 3.4: Refinements Applied in System Preparation Phase

In addition, for the first activity (Identify and List Objectives), we decided to split this activity into two other more specific activities, i.e., elicit gamification goals and rank goals by priority. We reused the (REU) Justify Objectives activity. Discarding (DIS) Identify Requirements - In the earliest gamification phases, we decided not to elicit requirements for the gamified version of our systems, because we do not consider convenient, in the systems preparation phase, to focus on the requirements elicitation. Thus, we conducted workshops with public health agents to understand their needs, and to understand how gamification could help us address these needs. In addition, we have decided to discuss the profiles of potential system users before eliciting the requirements. Thus, we decided to discard this activity at this point, but we considered to reuse this activity in future development phases. 
User Analysis. Figure 3.5 illustrates the refinements applied to conceive the User Analysis Phase. During this phase, we felt the need to adapt all activities of the Morschheuser's method. Adapting (ADP) Identify User Motivations, (ADP) Identify User Needs, (ADP) Define Target Users, and (ADP) Create Personas - The original definition of these activities did not guide the reasoning about the expectations and needs of the existing system users. When gamifying systems from scratch, this reasoning is unnecessary because there is not an existing system to use as a basis. Conversely, when gamifying existing systems, it is important to consider those who currently use the existing system. Otherwise, these users can eventually leave the system because their needs are not properly addressed anymore. Therefore, we decided to adapt all four activities to include missing reasoning. We highlight that (ADP) Identify User Motivations and (ADP) Identify User Needs were merged into a single activity called List User Needs and Motivations.

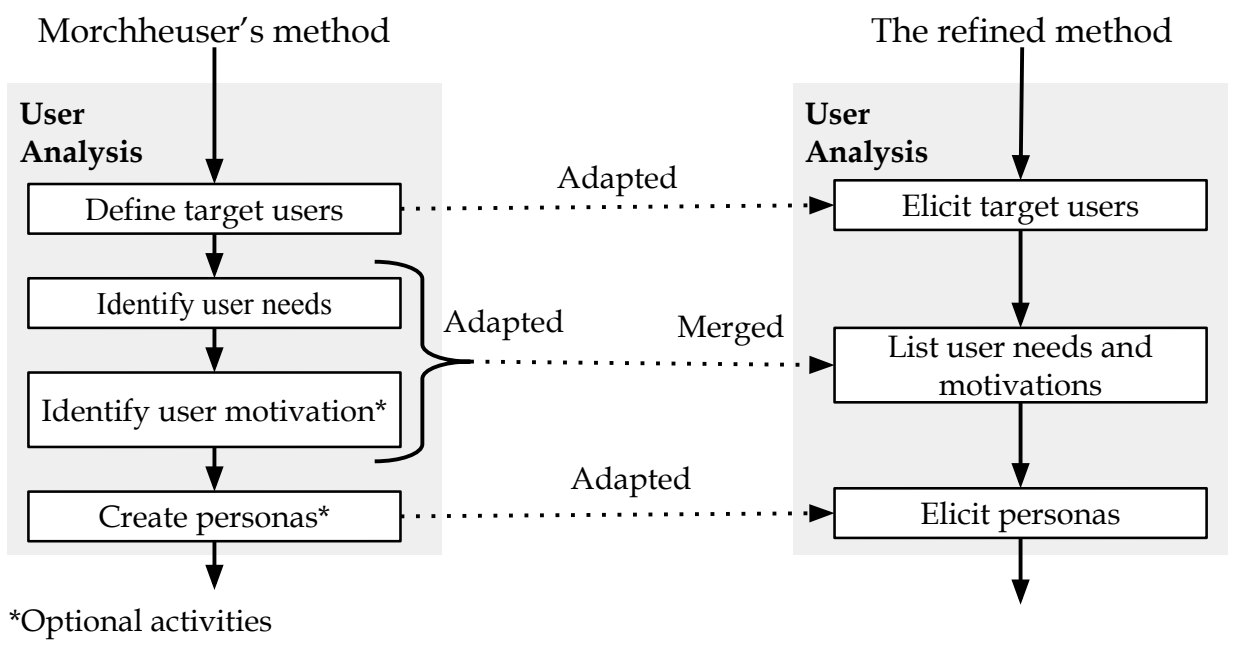

Figure 3.5: Refinements Applied in User Analysis Phase

Context Analysis. Figure 3.6 illustrates the refinements applied to conceive the Context Analysis Phase. During this phase, we decided to fully reuse two activities, add two activities and discard one activity. Reusing (REU) Identify the Context and (REU) Understand the Context - Eliciting and understanding context information, e.g., employed technologies and design decisions, is important for gamifying either systems from scratch or existing systems. Thus, we decided to fully reuse both activities. We have been motivated by the need for characterizing the limitations of an existing system regarding the planned gamification. In fact, gamifying an existing system requires understanding to what extent the incorporation of game elements and rules will affect the current development context. We highlight that both 
activities were merged into a single activity called Elicit Existing System Context.

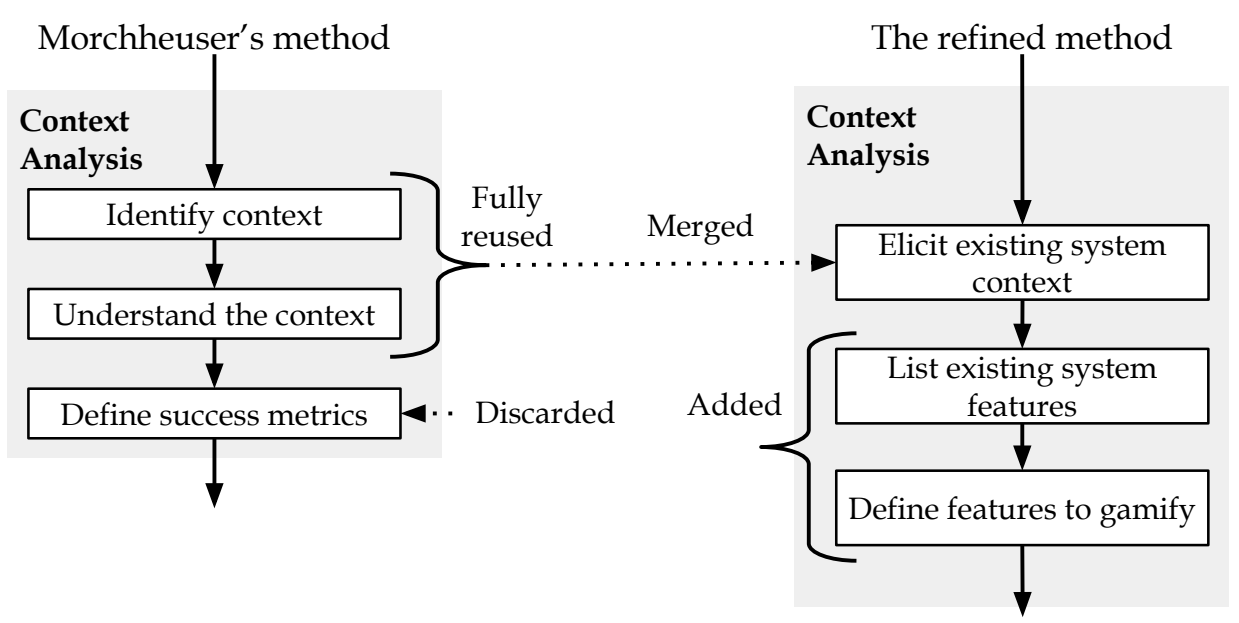

Figure 3.6: Refinements Applied in Context Analysis Phase

After performing the aforementioned activities, we felt the need to add a new activity to support the elicitation of the existing system features. Adding (ADD) List Existing System Features - In our particular case, eliciting the existing system features was necessary because the system documentation was scarce, and most of the developers involved along the system gamification were not familiar with the existing source code and system features. In addition, we decided to add a specific activity to support the definition of which existing system features should be gamified. Adding (ADD) Define Features to Gamify - We added this activity to reason about the system features that succeeded or not in their purpose. The decision by gamifying a system feature strongly depends on the gamification goals defined in the System Preparation phase. Discarding (DIS) Define Success Metrics - We decide to discard this activity because we do not consider it a priority. In addition, the system had not been deployed yet, making it impossible to compute such metrics.

Requirements Elicitation. Figure 3.7 illustrates the refinements applied to conceive the Requirements Elicitation Phase. After performing the context analysis phase, we felt the need to revisit the existing system requirements that concern the system features that could be gamified. However, the Morschheuser's method does not have a specific phase to guide developers to evolve the existing system requirements to incorporate the gamification. Adapting $(A D P)$ Identify Requirements - We adapted this activity from the System Preparation phase by transforming it into a new phase to guide the evolution of existing system functional and non-functional requirements in order to achieve the gamification goals. We called this new phase of Requirements Elicitation phase - We have designed three activities to compose this phase 
- (ADD) Evolve Functional Requirements, (ADD) Evolve Non-Functional Requirements, and (ADD) Elicit Gamified Requirements. In our case, performing these three activities have become extremely necessary. This is because of the evolution of certain existing functional requirements affected some of the system's business rules. In addition, some existing non-functional requirements have become more critical with the incorporation of gamification, such as performance and usability.

Morchheuser's method

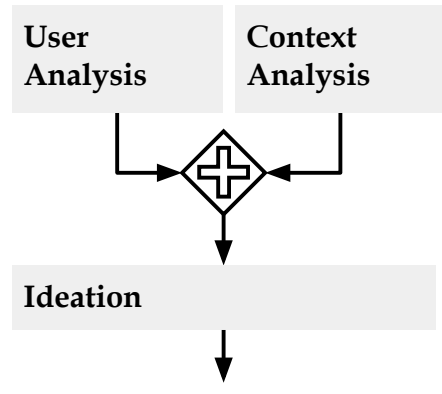

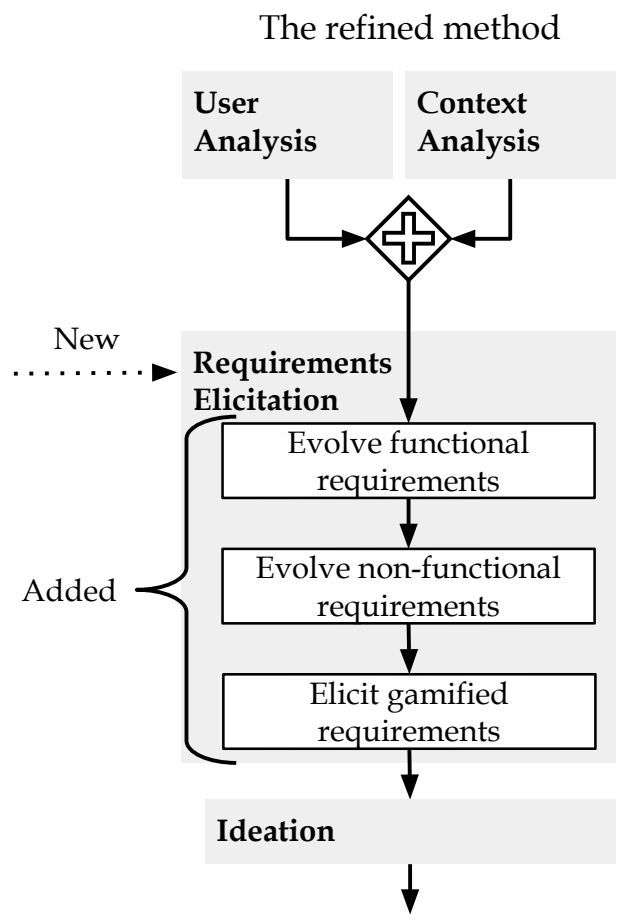

Figure 3.7: Refinements Applied in Requirements Elicitation Phase

Gamification Design. Figure 3.8 illustrates the refinements applied to conceive the Gamification Design Phase. During this phase, we were inspired by discussions provided by the original method on the difficulty of designing a gamified system. Then, we decided to formalize a specific phase that guides developers to conceive the gamification design. Due to our lack of expertise in the gamification design, we felt the need to systematically define the game elements and rules that could be incorporated into our existing system. For this purpose, we have added a new phase, called Gamification Design. We have designed four activities to compose this new phase, namely (ADD) Elicit Game Elements Elsewhere, (ADD) Pick Useful Game Elements, (ADD) Define Game Rules, and (ADD) Create the Visual Representation for the Conceptual Model. Our major goal was guiding the gamification design in its entirety, especially in the case of developers not familiar with the definition of game elements, rules, and conceptual models. We provide more details about each added activity in Section 3.5 while introducing the final version of our gamification method. 
Morchheuser's method

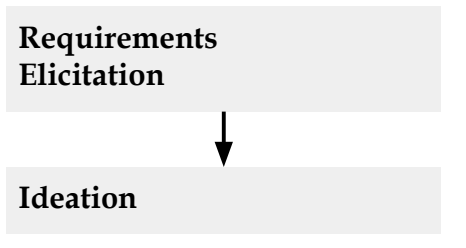

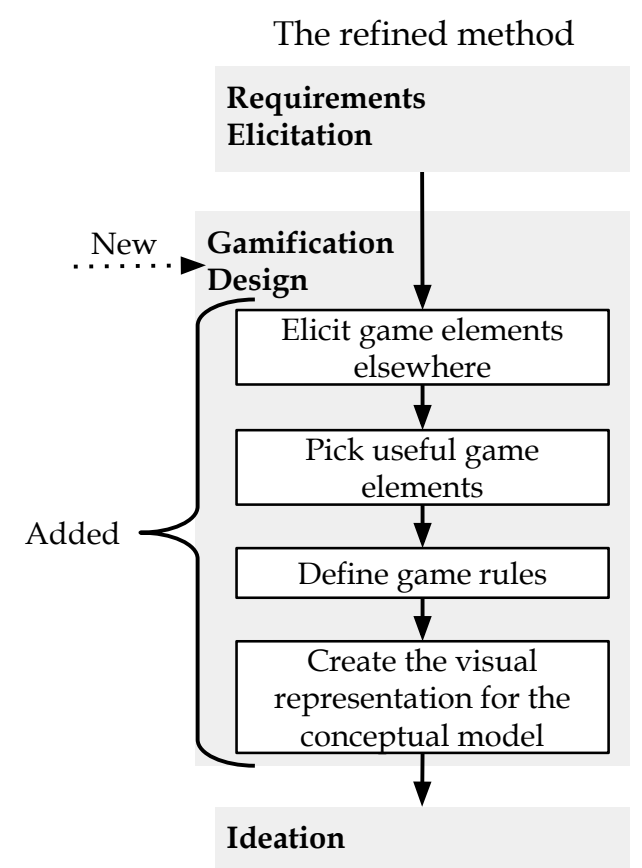

Figure 3.8: Refinements Applied in Gamification Design Phase

Software Design. Figure 3.9 illustrates the refinements applied to conceive the Software Design Phase. During this phase, we decided to adapt four activities and discard two activities. Adapting (ADP) Brainstorming Ideas and $(A D P)$ Consolidate Ideas - We changed the original purpose of both activities to focus on discussions regarding the system visual aesthetics. This phase aims to guide fruitful discussions about: (i) visual aspects that worked fine for the existing system and, therefore, they could be reused in the gamified system version; and (ii) what should be modified in order to leverage the system attractiveness and enjoyability.

Discarding (DIS) Create User Journey - We discarded this activity because the user's journey was described informally during the brainstorming activity. Adapting (ADP) Design Prototype and (ADP) Create Prototype We have adapted these activities in order to consider the user interface of the existing system, e.g., we have evaluated the visual aesthetics elements that might be reused from the existing system, before creating a new prototype. In addition, we have discarded the activity of (DIS) Evaluating the Prototype because we have conducted the evaluation along with the software design. We highlight that $(A D P)$ Brainstorming Ideas and (ADP) Consolidate Ideas were merged into a single activity called Brainstorming Ideas. 


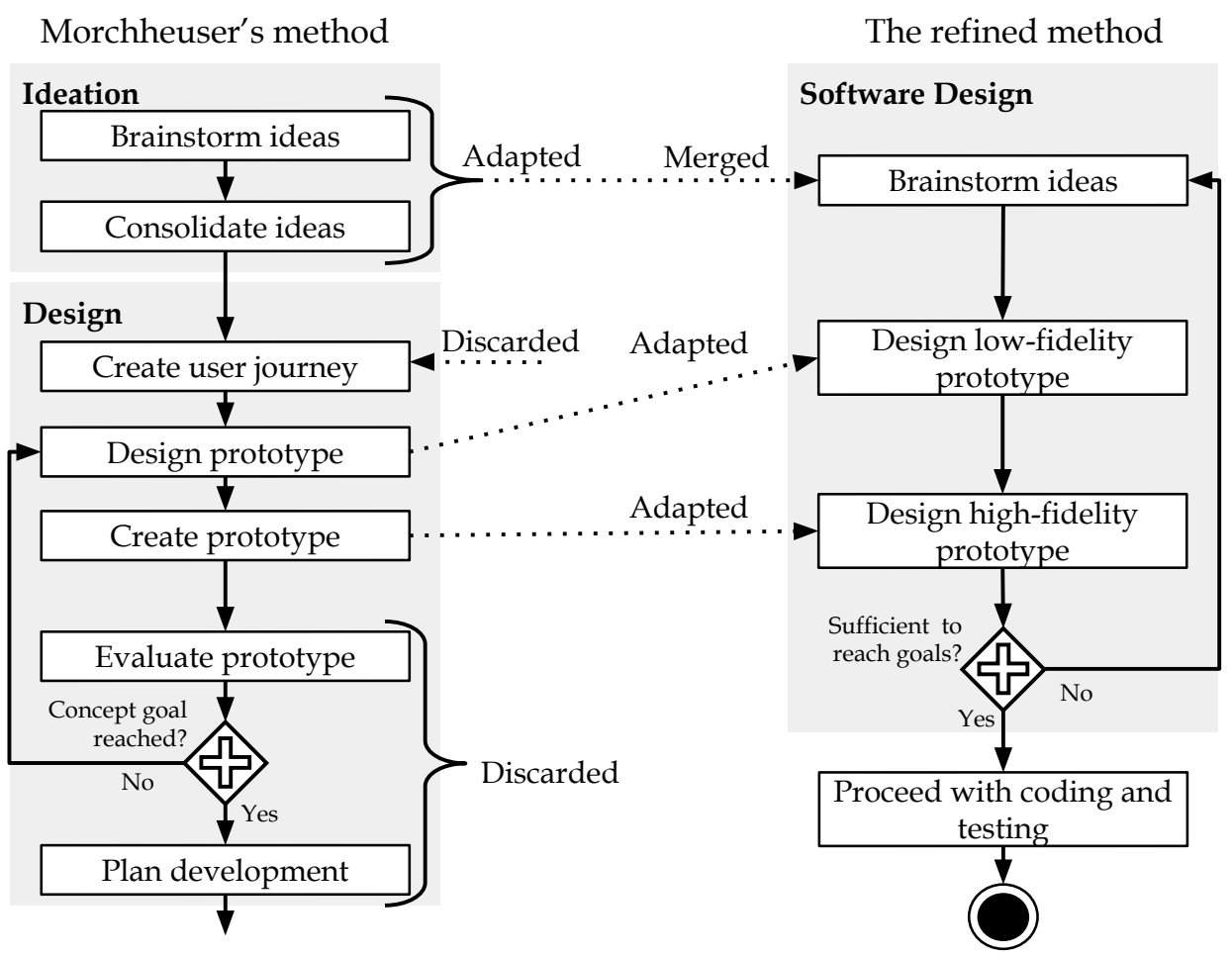

Figure 3.9: Refinements Applied in Software Design Phase

Summary of $\mathbf{R Q}_{1 \cdot 1}$. A total of 25 activities were refined from the Morschheuser's method (40) to support the gamification of existing systems. For instance, List the Existing System Features and Evolve Functional Requirements. In which, 10 activities were adapted. Three activities were fully reused by considering that they apply to the gamification of existing systems as well to the gamification from scratch. Nine new activities were introduced. Three activities were discarded, one of which was adapted to posteriori, e.g., Identify Requirements. Additionally, three mergers were performed, each merger occurred between two activities, and one activity was split into two more specific ones.

\subsection{3}

\section{Threats to Validity and Concluding Remarks}

We discuss threats to validity (66) regarding the first study as follows.

Construct Validity. We have carefully based on the participatory action research procedures to document the applied refined via technical reports. We have also conducted biweekly follow-up meetings and workshops with the developers along the gamification of our existing system. Thus, we expect to avoid the lack of observation of the researcher involved in the action 
research. For instance, during the execution of any activity, some observation may not have been captured, and some information may have not been mentioned by developers during meetings. This particular threat was also minimized through our interview-based study (Section 3.4), once we collected the developers' feedback in order to refine the gamification method whenever possible.

Internal Validity. We followed strictly the procedures to analyze the Morschheuser's method and conducting the retrospective analysis to built the evolution history map of the existing method. We have conducted the analysis in pair in order to reduce biases in the building of the evolution history map.

Conclusion Validity. We carefully performed the analysis and refinement of the Morschheuser's method. We validated all steps following our methodology in a pair. Thus, we expect to avoid an incorrect representation of the evolution history of the Morschheuser's method and interpretation of the reasons why the activities of the Morschheuser's method were refined.

External Validity. We have following the participatory action research and counted on the developers' feedback along the VazaDengue gamification to refine the Morschheuser's method. Best practices documented by the literature were employed whenever possible to incorporate gamification. Particularly, our method is independent of implementation and testing practices - its focus on gamification design makes it applicable to companies that employ varied development practices. Additionally, our method is based on the feedback of real developers and from a practical experience. Thus, we expect that the refined method is applicable to similar development contexts - i.e., small to medium-sized development teams with the support of agile practices, which represents the reality of various companies and start-ups, for instance (14). This particular threat was also partially mitigated through our interviewbased study (Section 3.4) by capturing as many limitations of our gamification method as possible via the developers' perceptions.

\section{4}

\section{Study 2: An Interview-based Experiment Report}

To answer our $\mathbf{R Q}_{1 \cdot 2}$, we performed an interview-based experience report with developers from each VazaZika development team, i.e., design, implementation, testing, and research. Our major goal was tracking the development activities that became significantly challenging along the system gamification. In totally, we applied 15 semi-structured interviews (52). The interviews were conducted when the system was about $50 \%$ completed, and they helped us to refine our method. After interviewing each VazaZika developer, we have 
applied two Grounded Theory $(\mathrm{GT})$ procedures $(8,15)$ to analyze the interviewees' responses: open coding for identifying topics of interesting from the interview data, and axial coding for grouping topics that are interrelated. Section 3.4.1 details the study steps and artifacts. Section 3.4.2 presents the results of our second study. Finally, Section 3.4.3 discusses threats to validity.

\subsection{1}

\section{Study Steps and Artifacts}

Figure 3.10 illustrates our two study phases. Phase $\mathbf{1}$ aimed to define the interview design protocol, including interview artifacts and forms. Phase 2 was proposed to guide the data analysis, from the tabulation of interview notes to the data extraction. We describe each study phase as follows.

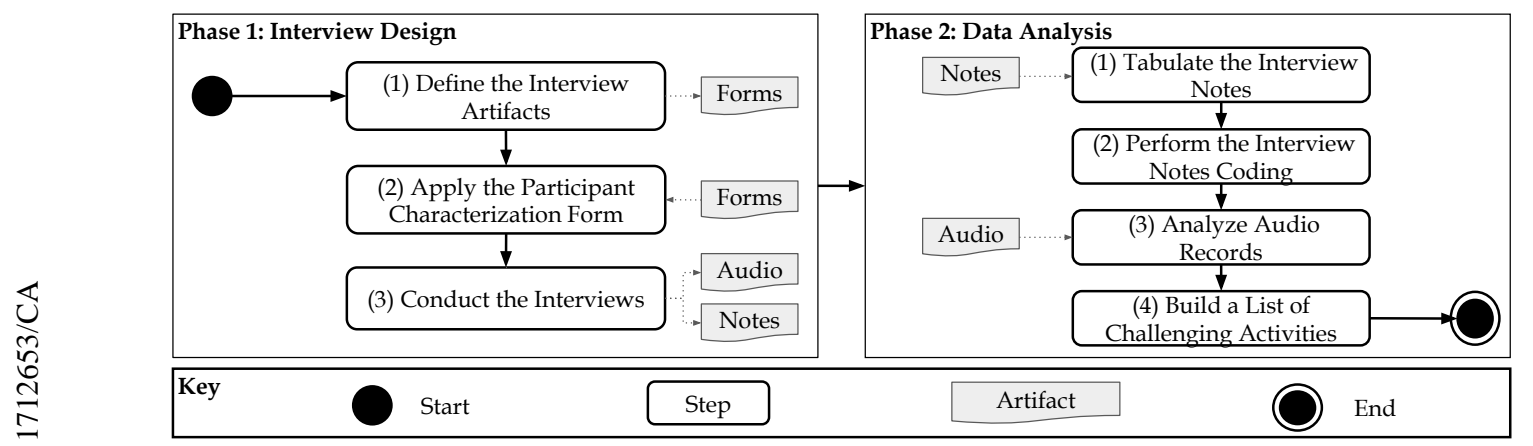

Figure 3.10: Study Steps and Artifacts of the Interview-based Study

Phase 1: Interview Design. We have designed an interview with developers from each VazaZika development team. Interviews are an effective way of understanding not easily observable phenomena such as developers' feelings and perceptions (52). We have chosen a semi-structured interview design (52) aimed at allowing high flexibility along the interviews. We explain the three steps conducted to design the interviews as follows.

Step 1 aimed to define and review the following artifacts. The Participant Characterization Form aimed to collect the developers' background, allowing us to derive the information presented in Figure 3.11. The Interview Script follows a funnel structure (52) that starts with general questions and ends with specific ones. Our seven-question script has: two questions aimed to confirm the teams in which the participant has been involved with; one question to elicit all challenging activities; and four questions to understand each challenging activity. All artifacts are presented in Appendices A and B.

Step 2 consisted of inviting all 17 developers from the four gamification teams to fill out this form. Two participants were discarded because they 
have contributed to only one development team (design, implementation, testing, and research). Thus, a total of 15 developers remained to participate as interviewees. Step 3 aimed to conduct the interviews with the 15 VazaZika developers. We strictly followed the Interview Script and were asked to avoid influencing the interviewees' responses. We have prioritized interviewing the developers through face-to-face meetings in a laboratory environment as far as possible. We have taken notes of the interviewees' responses during the interview. In addition, we asked for permission to record the interviews' audios. Each interview lasted one hour and twenty-five minutes at most.

Phase 2: Data Analysis. After interviewing each VazaZika development team, our next step consisted of analyzing the interviews data. Due to the qualitative nature of our study, we have partially relied on the well-known procedures of Grounded Theory $(\mathrm{GT})(8,15)$ to analyze the interviewees' responses. Those procedures were useful for both eliciting and understanding each difficulty faced by the developers while gamifying our existing system. We explain the four steps to conduct data analysis as follows.

Step 1 aimed to tabulate all interviewees' responses into a spreadsheet. After, we validated in pair the tabulation results. Step 2 consisted of coding the interview notes by applying two phases of data analysis GT (15) as follows. Open coding aimed to elicit the data item about challenging activities. We have identified the data from the tabulated interviews. Example of a challenging activity: choosing game elements to implement aimed at engaging users. Second, we have labeled the data item with a code. Example of code to the aforementioned challenging activity: [GRP03c] Elicit Game Elements aimed to Engage Users. Axial coding was applied for labeling groups of challenging activities with categories, such as [GRP03] Specify the Gamified Systems.

Step 3 consisted of listening to each audio record in order to validate the interview notes, correct inconsistencies and extract interviewee quotes, which help justify why an activity development become challenging. These researchers did not listen to their own interview audios. Step 4 aimed to build a list of challenging activities. For this purpose, we discarded redundant data items, refined the code and category labels, and validated the two types of relationships mentioned in Step 2. We have built a list of challenging activities that represent: each group with the respective label based. Table 3.2 introduces the list of challenging activities. 
Participant Background. Before presenting our study results, we discuss the self-assessed interviewed developers' skills collected from the Participant Characterization Form as follows. We observed that the developers have different backgrounds. Figure 3.11 summarizes the background of our 15 developers numbered from D1 to D15. In this background, we present their skills, regarding eight software engineering concepts, e.g., gamification.

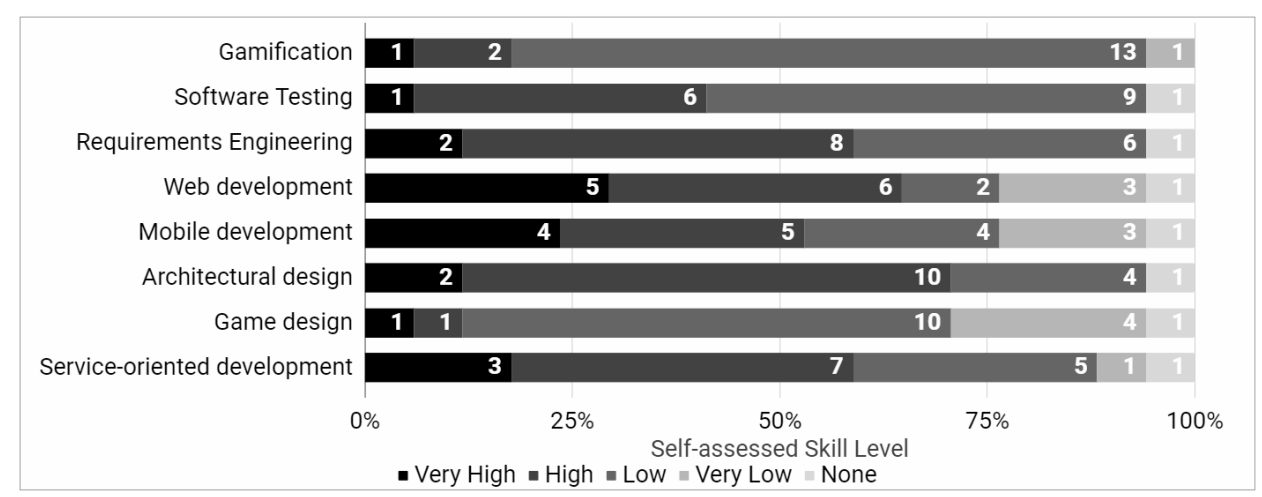

Figure 3.11: Self-assessed Developer Skills

Our results suggest that the developers have high to very high skills in basic concepts like software testing (41\%), requirements engineering (59\%), and web development (65\%). Conversely, the developers have either low, very low, or none skills in gamification (82\%) and game design (89\%). This observation has helped us in drawing the generality scope of our study results. Additionally, $41.2 \%$ of developers holds a bachelor's degree and $29.4 \%$ holds a Master's degree. Their average development experience equals six years.

\subsection{2}

\section{Results and Discussions}

In this section, we present and discuss the study results regarding $\mathbf{R} \mathbf{Q}_{1 \cdot 2}$. We discuss below the challenging activities perceived by the VazaDengue developers along the system gamification, and how the interview data supported the refinement of our gamification method.

Challenging Activities of Gamification. We answer our $\mathbf{R Q}_{1 \cdot 2}$ as follows. Table 3.2 presents all development activities perceived as challenging by the VazaZika developers along the software gamification. For each group, we provide a description, the list of challenging activities that compose the group, and when each challenging activity emerged along the gamification of the VazaDengue systems. For instance, [GPR01] is a group of challenging activities related to decision-making about the gamified systems, e.g., service decomposition. [GPR01] is composed of challenging activities such as [GPR01a] 
Define the VazaZika systems, which has emerged from the project beginning and along the project execution. In total, we have elicited 22 challenging activities, categorized into eight groups of challenging activities.

Although we have found eight groups of challenging activities in our study, only six of them are mainly related to the difficulty of gamifying an existing software system: [GRP01, GRP02, GRP03, GRP04, GRP05, GPR08]. The remaining groups are composed of challenging activities that often occur during the development of non-gamified systems. We discuss the aforementioned five groups of challenging activities as follows. For each group, we explained how the development activities that compose it was challenging. Although [GPR04, GPR08] are related to the difficulty of gamifying an existing software system, we do not describe these groups because it depends on the development techniques adopted by the VazaZika development team.

We explain the four group of challenging activities as follows. For each group we provide: (i) a discussion about the challenging activities that compose the group; (ii) context, i.e, the factors that are associated with these challenging activities along the VazaDengue gamification; and (iii) insight about how certain challenging activities helped us to identify opportunities for refining the gamification method towards a more comprehensive and lightweight one. 
Table 3.2: Groups of Challenging Activities Elicited from the Interviews [GRP01] Define the Gamified System $\quad$ [GRP02] Conceive the System Art \&

Description: Related to decision-making about the gamified systems in terms of source code organization, service decomposition, and data persistence.

Challenging activities: [GRP01a] Define the VazaZika System; [GRP01b] Model the VazaZika Web Architecture; [GRP01c] Design the Database

Emerged when: (a) from the project beginning and along the project execution; (b) along the gamification implementation; (c) after the first gamified system specification

\section{[GRP04] Implement the Gamified Sys-}

tem Design

Description: Related to the creative process of art \& design aspects (visual metaphors, colors, etc.) of the gamified system.

Challenging activities: [GRP02a] Conceive

the Systems Art \& Design

Emerged when: (a) from the project begin-

the gamification model

Description: Related to the implementation of the gamified system.

Challenging activities: [GRP04a] iOS Development; [GRP04b] Mobile Development; GRP04b] Inexperience with Hybrid Mobile Development; [GRP04c] Understand the Gamification Domain; [GRP04c] Manual Systems Deploy; [GRP04d] Synchronize System User Data

Emerged when: (a) from project beginning;

(b) from mobile implementation beginning; (c)

from implementation

system implementation

\section{GRP07] Communicate the Development Teams}

Description: Related to the communication among members of different development teams.

Challenging activities: [GRP07a] Communicate Team Members; [GRP07b] Neglect the Gamified System Specification

Emerged when: (a) from the definition of members per development team and from the project beginning; (b) from the first implementation outputs Decer by the developers to understand the VazaDengue system in terms of context, architectural design, technologies, and source code. Challenging activities: [GRP05a] Understand the VazaDengue API; [GRP05b] Under列 the System Domain

(a) along the system implementation; (b) after a development specialist VazaDengue left the project; (c) from the plementation beginning [GRP03] Specify the Gamified System

Description: Related to definition of game elements and rules to engage the users through gamification.

Challenging activities: [GRP03a] Specify the Gamified System; [GRP03b] Ensure the Gamification Design Conformance; [GRP03c] Elicit Game Elements aimed to Engage Users; [GRP03d] Insuffient Stakholders to Provide GRP03d Feedback; [GRP03e] Integrate Social Networks
into Gamified System Emerged when: (c) from project beginning, especially along the system implementation (d) from project beginning; (e) along the system implementation

[GRP06] Manage the Development

Description: Related to the management of team members tasks.

Challenging activities: [GRP06a] Assign Tasks to Team Members

Emerged when: (a) first task delays an from the project beginning

\section{GRP08] Test the Gamified System}

Description: Related to the unit test writing and execution.

Challenging activities: [GRP08a] Write Test Cases

Emerged when: (a) while changing the implementation of existing system functionalities 
[GRP01] Define the Gamified System was challenging for the developers due to several limitations of the VazaDengue existing system. Indeed, the original architecture designers acknowledged that VazaDengue was not designed to accommodate gamification features, i.e., game elements and rules. It has become evident when game elements and rules defined by the design team could not be addressed by the implementation team due to the high maintenance costs required [GRP01a]. Moreover, the naturally incremental definition of game elements and rules to be implemented by the architecture has generated additional costs to redesign the database several times [GRP01b], [GRP01c], which has delayed the implementation of game elements that inter-depend, such as team and challenges. We present a developer quote about [GRP01c] Design the Database as follows.

A major challenge was restructuring the architecture's infrastructure to accommodate gamification. - Developers 7 about [GRP01c]

Context: Along the VazaDengue gamification, the unstable definition of game elements and rules has led to several changes in the relational database model. For instance, changes in database design to optimize the management of game rules and their respective game elements. Besides that, the rotation of certain developers members of the development team has made difficult to understand the existing database and identify reuse opportunities for the new architecture's database.

Insight: The challenging activities faced in [GRP01] gave us insights of possible refinements of the Morschheuser's method, e.g., the addition of two new activities in the Context Analysis phase: (ADD) List Existing System features and (ADD) Define Features to Gamify. By complementing the discussions in Section 3.3.2, the need to adding these two activities was due to given the excess of rework in architecture changes of the existing system realized without the prior understanding of the technological, functional and architectural constraints that could be impeded to incorporate game elements and rules into the existing system.

[GRP02] Conceive the System Art \& Design was challenging due to the difficulty to design an attractive user interface that engages our stakeholders, i.e., Brazilian citizens and public health agents. In fact, various VazaZika developers struggled with defining what visual elements and metaphors (49) should compose the user interface and how to represent them [GRP02a]. Due to project budget constraints, both design and implementation teams were responsible for evaluating the user interface in terms of attractiveness. However, the lack of feedback from user interface specialists has led to rework in the 
front-end layer implementation. We present a developer quote about [GRP02a] Conceive the System Art $\&$ Design as follows.

While gamifying the existing system, it was difficult to find a trade-off between the system's serious purpose and the system's attractiveness from the viewpoint of its users. - Developers 3 about [GRP02a]

Context: The VazaZika is a healthcare system aimed to support health agents in disease prevention and control, which was at a first moment considered a too serious purpose for gamification. For instance, the variety and complexity of both game elements and rules, which made difficult to design the system that is sufficiently attractive to its users. In addition, the lack of guidelines for designing gamified system made it difficult to adopt recommended gamification practices, which led to difficulties in understanding what is necessary to gamify the system.

Insight: The challenging activities faced in [GRP02] gave us insights of refinements of the Morschheuser's method, e.g., the adaptation of three activities that compose the User Analysis phase: (ADP) Identify User Motivations, (ADP) Identify User Needs, (ADP) Define Target Users and (ADP) Create Personas to considerate the existing system users. As discussed in Section 3.3.2, this insight became more evident, due to the need to understand different needs of the existing system users and the new ones, before conceiving the system art \& design. Another insight is related with the adaptation of two activities which are part of the Software Design phase: (ADP) Design Prototype, and $(A D P)$ Create Prototype in order to consider the user interface of the existing system, along with the conceiving the system art \& design.

[GRP03] Specify the Gamified System was particularly challenging due to the constant need for validating the conformance between the game elements elicited by the design team and the ones implemented by the implementation team [GRP03b]. Misalignment between teams, due to communication noise among team members, combined with the underlying architectural constraints of VazaZika, made difficult to reason about what game elements and rules were feasible to implement and reach a satisfactory user engagement [GRP03c]. We present a developer quote about [GRP03c] Elicit Game Elements aimed to Engage Users as follows.

Elicit functional and non-functional system requirements, besides understanding what requirements should be gamified was found challengingDeveloper 11 about [GRP03c]

Context: Some of the reasons that did make [GRP03] a group of challenging activities is related to general issues of technical knowledge in gamification. 
This has caused a delayed specification of certain game elements and rules, especially those that inter-depend, such as teams and challenges.

Insight: The challenging activities faced in [GRP03] gave us insights of refinements of the Morschheuser's method, e.g., the addition of three activities that compose the Requirements Elicitation phase: (ADD) Evolve Functional Requirement, (ADD) Evolve Non-Functional Requirement, and (ADD) Elicit Gamified Requirements. By complementing the discussions in Section 3.3.2, this insight became more evident when the addition of game elements and rules, have made the specification of existing system requirements inconsistent. For instance, the requirements of reporting a mosquito breeding sites needs to be evolved to address as certain rules.

Another insight obtained through the interviews is related with the addition of a new phase, called Gamification Design which is composed of four activities: (ADD) Elicit Game Elements Elsewhere, (ADD) Pick Useful Game Elements, (ADD) Define Game Rules and (ADD) Create the Visual Representation for the Conceptual Model. This insight became more evident, due to the need to reason more specifically about the game elements that could be incorporated into the system, and what types of game rules (systemuser or element-element) could be specified to leverage the user engagement. Moreover, how these game elements and rules could be documented.

Finally, [GRP05] Understand the Existing System became challenging mostly because of the poor and outdated VazaDengue API document [GRP05a]. In fact, the API has more than 500 methods, which suggests a certain complexity for developers to understand and properly use it, especially without the documentation support. We present a developer quote about the [GRP50a] Understand the VazaDengue API as follows.

Make decisions towards the gamification of existing system and evolve a simple software infrastructure into a more complex one. - Developer 7 about

[GRP05a]

Context: Unfortunately, the documentation available for the existing system was overall poor and outdated. The lack of documentation was a real issue because the existing system' architecture was quite complex, composed of thousands of lines of code that lack comments and documented rationale. In the context, the group [GRP05a] regards the difficulty to understand how the existing system was designed by means of architecture. A key factor to that difficulty was the limited support that old team members were able to provide to new team members in understanding the existing system.

Insight: The challenging activities of [GPR05] gave us insights of refinement of the Morschheuser's method, e.g., the reuse of the activity of (REU) 
Understanding the Context. By complementing the discussions in Section 3.3.2, this insight became more evident, given the poor and outdated documentation of our existing systems making it difficult for some members of the development team to understand the existing system from requirements to implementation.

Summary of $\mathbf{R Q}_{1 \cdot 2}$. We elicited 22 challenging development activities from which 18 explicitly relate with the systems gamification. Design and development teams have the highest numbers of challenging activities. Poor design decisions, complex architecture, and lack of software documentation had a negative impact on gamification implementation.

\subsection{3}

\section{Threats to Validity}

We discuss threats to validity (66) regarding the second study as follows.

Construct Validity. We designed the Participant Characterization Form aimed to capture the interviewees' expertise in basic software engineering activities from requirements elicitation to testing. We then minimize threats regarding the interviewees' sampling variety. In addition, we have interviewed only developers engaged with at least two development teams aimed to avoid a poor elicitation of challenging activities. Thus, we expect to interviewed developers that faced challenges in varied software engineering activities, from requirements elicitation to testing. We designed our interview protocol based on the funnel structure aimed to avoid missing relevant information about the challenging activities during the interviews. Thus, we have conducted a more flexible interview starts with general questions and ends with specific ones.

Internal Validity. We conducted each interview in isolation in order to make interviewees comfortable with reporting their perceptions about challenging activities. We also have recorded interview audios in order to complement the interviews notes and avoid missing data. We preferred face-to-face interviews rather than online aimed to control the interviewees' attention whenever possible. The interviewers were trained to strictly follow the Interview Script and were asked to avoid influencing the interviewees' responses.

Conclusion Validity. We have partially relied on our data analysis protocol on GT (15). We aimed to reduce the inherent subjectivity of coding interview notes. We analyzed all data in a pair to minimize biases and reach a consensus about the elicited challenging development activities. Although the researcher that coded the interviews was also an interviewee, four other 
researchers have validated the coding - only one was not an interviewee due to the limited set of interviewees. We have analyzed challenges regarding the gamification of both mobile and web applications to make our findings varied.

External Validity. We have interviewed 15 developers only, but they mostly lacked gamification expertise. It might have boosted the relevance of the elicited challenges. Since developers with expertise in gamification may face different challenges from those that have been elicited. From these 15 developers, we have recruited interviewees engaged with two or more development teams: design, implementation, testing, and research. We expect that our challenges encompass varied software engineering activities, from requirements elicitation to testing. Therefore, we elicited challenges with different natures during the gamification process. Most interviewees showed inexperience with gamification. Although it might have biased the reported perceptions of challenging activities analyzing the interviewees' background has helped us characterize the generalization scope of our study results according to the expertise of the developers.

\section{5}

\section{A Method for Guiding the Gamification of Existing Software Systems}

Our two empirical studies enabled us to derive our method aimed to guide the gamification of existing software systems. Figure 3.12 illustrates the phases and activities of our refined method; it also depicts their relationships. The figure relies on the Business Process Model and Notation (BPMN) (43) and it represents the following six method phases: 1) System Preparation consists of preparing the environment for gamifying the existing system; 2) User Analysis aims to elicit potential system users based on the existing system users; 3) Context Analysis aims to characterize the existing system domain; 4) Requirements Elicitation aims to refine existing requirements and defining gamification-specific requirements; 5) Gamification Design aims to design the conceptual gamification model; and 6) Software Design aims to design and prototype the system. We do not describe the Proceed with Coding and Testing activity because it depends on the development techniques adopted by companies and developers. We also illustrate the challenging development activities of each phase with a star. We explain each method phase as follows. 

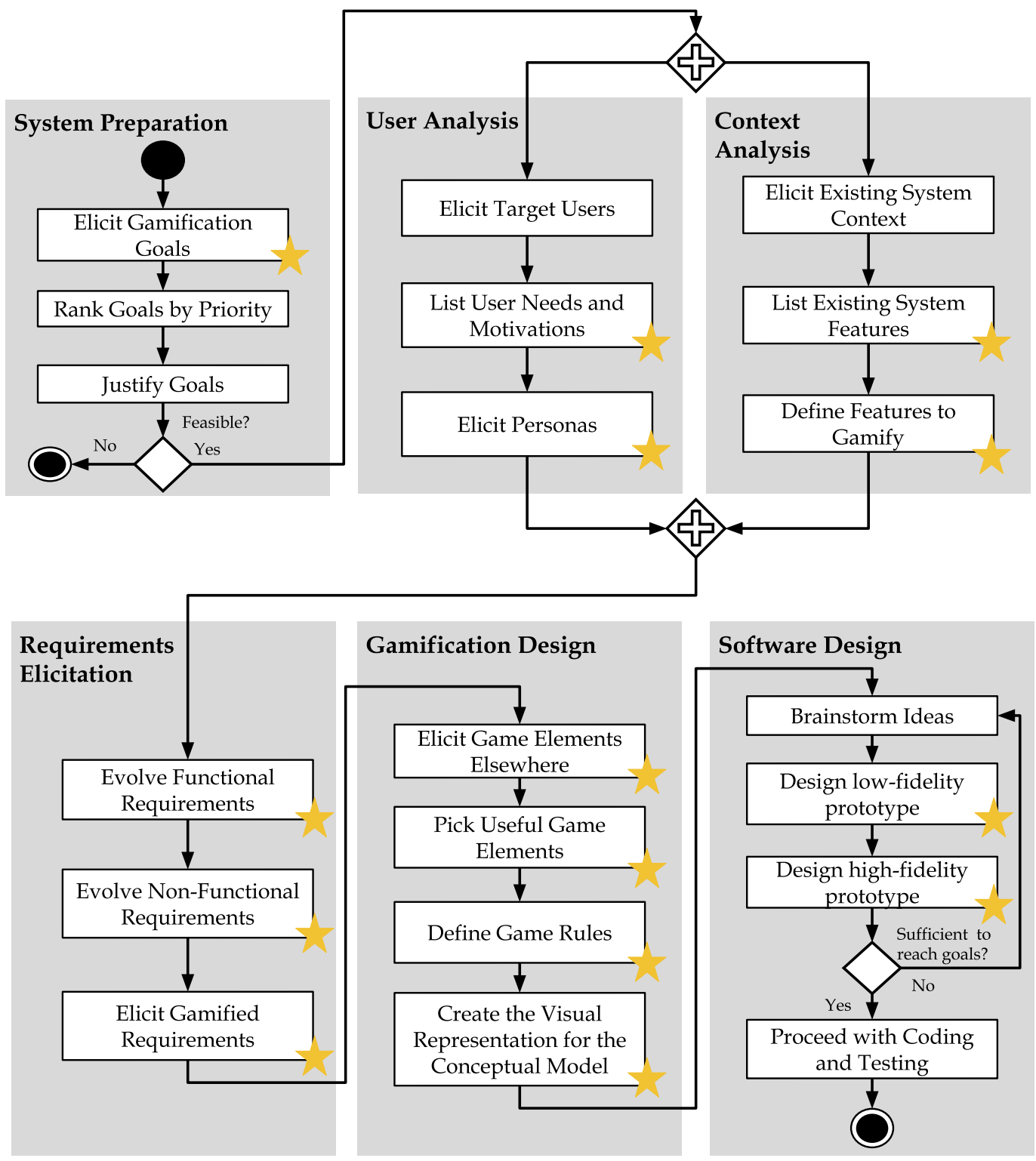
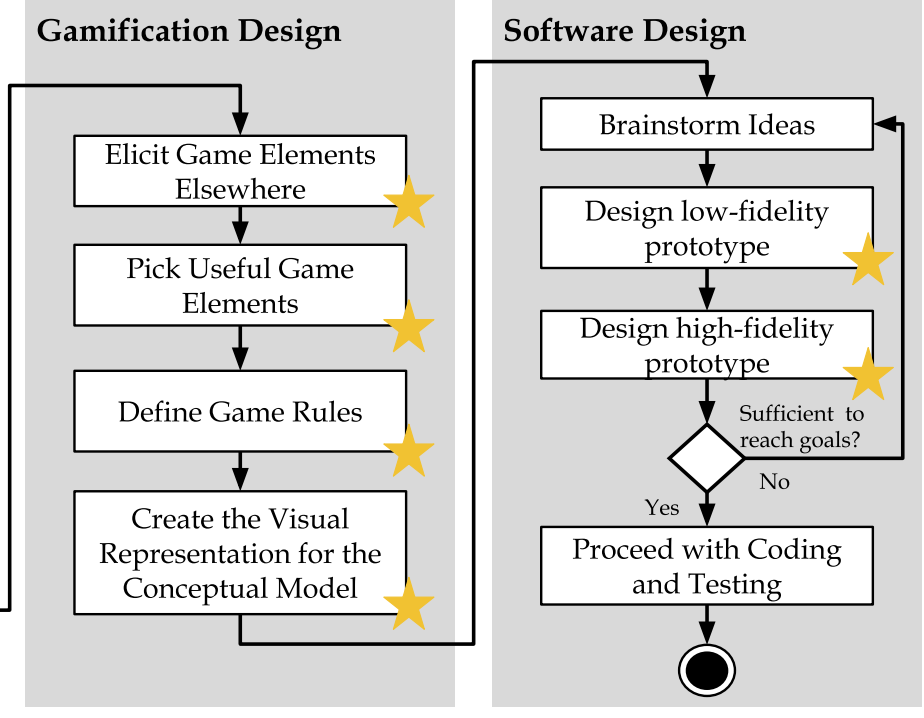

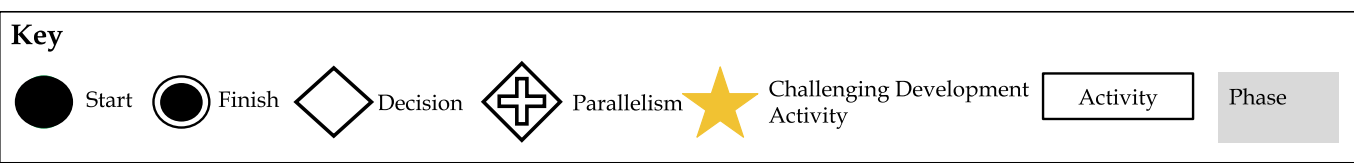

Figure 3.12: A Method for Gamifying Existing Systems

System Preparation. The first phase aims at promoting discussions about the goals that developers expect to accomplish when gamifying the existing system. A gamification goal is any concrete need for making the system enjoyable and challenging for its users. In the specific case of VazaZika, we have tried to answer questions such as How do mosquito-borne diseases spread in economically emerging countries such as Brazil?, How do citizens and public health agents contribute to the disease prevention?, and What tasks are critical 
to the disease prevention and, therefore, should be constantly performed by the citizens? This phase consists of three activities described as follows.

- Elicit Gamification Goals consists of listing what the existing users and potentially new users should expect from the gamified version of the existing system. We recommend the developers to meet internally and promote workshops with existing and new system stakeholders, such as (but not limited to) health authorities, institutions, and the system users. Our experience in gamifying VazaZika has benefited from meetings with health agents (18) and other types of stakeholders.

- Rank Goals by Priority consists of ranking the elicited gamification goals by priority. Each software project has particular priorities. We recommend the developers to define a prioritization criterion. In the VazaZika case, rewarding the reports of mosquito breeding sites had the highest priority. That is because, without these reports, the public health agents cannot prevent the disease outbreaks.

- Justify Goals means documenting the rationale behind each goal. A well-documented rationale can help to understand the enjoyability and the effort required to incorporate gamification into the existing system. If the system gamification is sufficiently justified, then the developers can proceed with the next phase. Otherwise, it may be the case that gamifying the existing system is not actually the best solution to leverage the user experience. We recommend the constant support of system stakeholders, as we had from the health authorities (18).

User Analysis. The second phase aims to characterize the users that interacted with the existing system. While gamifying VazaZika, we aimed to address questions like What were the VazaDengue users? This phase also aims to reason about additional users that could be interested in the gamified system. In the VazaZika case, we tried to answer questions like Who would be the potential users of the gamified system? and Is there any chance of losing users after the existing system is gamified? This phase has the three following activities.

- Elicit Target Users consists of listing the candidate users of the gamified system. We recommend the developers to first list the current users of the existing system. Thus, developers can consider the risks of these users leaving the system after gamifying the existing system.

- Elicit User Needs and Motivation consists of listing the needs by candidate system user. We recommend the developers to meet with the 
stakeholders and ask them about their practical needs, but also track the motivations behind the user interaction with the existing system.

- Elicit Personas consists of summarizing the lists of target users, needs, and motivation into personas (24). Personas are mechanisms for abstracting user profiles in terms of human characteristics, such as age, sex, and professional background. We recommend describing the daily routine of each persona aimed to highlight the context in which they would be engaged with the system features.

Context Analysis. The third phase aims to characterize the context in which the existing system was developed. Context includes the human resources and technologies employed for developing the system. While gamifying VazaZika, we tried to answer questions like What development process has guided the VazaDengue development? and What technological constraints affected the system development? Our experience suggests that the clearer the context analysis, the easier is for developers to cope with challenges along with the system gamification. This phase consists of the three following activities.

- Elicit Existing System Context consists of documenting any context information, e.g., employed technologies and design decisions. While gamifying VazaZika, an incomplete context elicitation has led to excessive rework. For instance, poor design decisions led to database and web service redesign too many times.

- Elicit Existing System Features consists of listing the main features that constitute the existing system. Our experience shows that, especially if the existing system documentation is scarce or outdated, the feature elicitation is essential to perform the next activity.

- Define Features to Gamify means selecting the existing system features that should be gamified. We recommend asking the system stakeholders about: (i) system features that succeeded in their purpose without gamification; and (ii) system features that failed in their purpose and could be gamified.

Requirements Elicitation. The fourth phase has the purpose of systematically documenting the functional, non-functional, and gamification-specific requirements of the gamified systems. This phase consists of three activities described as follows. 
- Evolve Functional Requirements (FR) consists of refining the FR elicited for the existing system. In contrast to eliciting requirements for a non-existing system, there are features that developers should consider before gamifying the system. In the VazaZika case, we reused the elicited personas for refining the FR. We elicited five FR, e.g., The citizen can report mosquito breeding sites through text, pictures, and geolocation data.

- Evolve Non-functional Requirements (NFR) means refining the NFR elicited for the existing system. In the VazaZika case, these requirements have significantly changed. For instance, both performance and availability have become critical due to the addition of gamification features. Such addition has increased the number of web requests. We recommend to consider the technological constraints for performing this activity. We elicited six NFR, e.g., The system must inter-operate through a shared communication protocol.

- Elicit Gamified Requirements complements the two previous activities by specifying the gamification-specific requirements. These requirements encompass the features that emerged from the incorporation of game elements and rules into the existing system. We elicited four gamification-specified requirements. An example of requirement is: The citizen can perform tasks either alone or as part of a team.

Gamification Design. The fifth phase has the major goal of building the gamification conceptual model to be incorporated into the existing system. For building this conceptual model, developers have to carefully define the game elements and rules they aim to implement in the existing system. During the VazaZika gamification, we have debated questions like What game elements could help us in leveraging the enjoyability and challenge levels of VazaDengue?, How should these game elements interact for realizing our gamification goals?, and How the system users should interact with these game elements? This phase consists of the four following activities.

- Elicit Game Elements Elsewhere means searching for game elements to incorporate into the existing system. For gamifying VazaZika, we tabulated the game elements used by 10 successful gamified systems we are familiar with, e.g., Duolingo and Waze. We present more details in our previous work (18). We recommend this activity for developers without experience with gamification.

- Pick Useful Game Elements means picking game elements that will help in achieving the gamification goals. 
- Define Game Rules aims at defining how the system users and game elements should interact into the system.

- Create the Visual Representation for the Conceptual Model aims to document the conceptual model based on the picked game elements and defined game rules. We strongly recommend a careful modeling of the relationships between game elements and rules, so that developers can avoid rework while gamifying a system.

Software Design. The sixth phase consists of defining the aesthetics of the gamified system. While gamifying VazaZika, we have tried to answer questions like What aesthetics elements may be reused from the existing system? and What changes should we apply for incorporating game elements into the existing system interface? This phase has the three following activities.

- Brainstorming Ideas aims at promoting discussions regarding the gamified system aesthetics. In VazaZika, we have designed different interfaces for the mobile and the web application. We recommend the developers to list all ideas and ask the stakeholders' opinions about color schemes, layout items, and screen navigation preferences.

- Design Low-Fidelity Prototypes consists of elaborating either manual or tool-supported interface drafts. When gamifying a system with many applications, we recommend to design similar drafts that share elements, so that users can easily migrate across applications.

- Design High-Fidelity Prototypes consists of drawing high-fidelity interface prototypes. We recommend to validate and refine these prototypes with stakeholders.

\section{6}

\section{Limitations of the Proposed Method}

We are aware of a few limitations of our method, which are either related to development activities that we decided to omit from the method on purpose (Expected Limitations), or related to aspect observed through the empirical validation of the proposed method (Observed Limitations). We summarize the major limitations for both types as follows.

Expected Limitations. In an intentional way, we decided that our method would not guide developers along the system coding and testing. This decision was taken because coding and testing practices vary a lot across software 
projects, development teams, and organizations. In the particular case of the VazaDengue system gamification, we have followed agile practices, for instance, the use of version control systems and bi-weekly follow-up meetings. Thus, although the Morschheuser's method that we have refined (40) has prescribed activities for writing, validating, and testing code, we have omitted these activities from our method.

Nevertheless, we acknowledge that full support for development teams to gamify their existing systems would require at least a general view of how coding and testing would look like. In fact, we observed two groups of challenging development activities that are strongly related to coding, i.e., [GPR04], and testing, i.e., [GPR06]. One opportunity for improving our method would be to propose a guide to the test and development practices we use in our particular context. Another opportunity would be to propose a guide with different techniques that support the developers in evaluating the prototypes with the stakeholders. For instance, usability testing (2).

Observed Limitations. Through our empirical studies, we observed that certain activities of our method may not have been addressed in the most appropriate manner. For instance, the techniques that we used to characterize the system users, i.e., Personas, may not have been sufficient to represent the means of how potential users would interact with the system. The literature reports other techniques with a similar purpose, e.g., user journey (13) and empathy map (44). One opportunity for improving our method would be to adapt the user analysis phase to include the empathy map technique (44). Empathy map aims to create an empathy degree of developers with the target system users. Thus, this technique could support the developers to better characterize the target users regarding their needs and motivations (44).

Another limitation of our current method is related to the visual representation of the relationships between the system users, game elements and rules through the gamification model. This is because the gamification model may not be the best option to systematically represent these relationships. Due to the existence of other notations better known by developers. For instance, the literature reports other techniques with a similar purpose, e.g., decision trees (36), storyboard (30), and use-case modeling to support the specification and the gamification design $(9,29)$. One opportunity for improving our method would be to adapt the gamification design phase to provide one of the aforementioned techniques for representing the relationships between the system users, game elements and rules. 


\section{7}

\section{Summary}

In this chapter, we report on the refinement of an existing method aimed to gamify software systems from scratch (40). With this purpose, we conducted a participatory action research. Our aim was analyzing and refining the existing method to guide developers on performing key activities to gamify their existing systems. For that, we incrementally refined the existing method according to the needs of gamifying an existing system. We also present the evolution history of refinements that we have conducted to building our method. As a result, our resulting method adapts ten activities from the existing method to particularities of gamifying existing systems; one activity was fully reused from that method; and nine new activities were introduced in order to guide developers in revisiting existing requirements and system features, for instance. Our method successfully supported the VazaDengue gamification. We expect our method is applicable to existing systems being gamified by developers with limited experience and following agile development practices (56) (as in the VazaDengue case).

An artifact that is essential to the software gamification is the so-called gamification model (63). This model can be derived with the application of our gamification method. Along VazaZika gamification, we did not find gamification models that target mosquito-borne diseases as VazaZika does. Moreover, many of the resulting gamification models for healthcare domains are not explicitly defined, thereby making their reuse quite challenging. To address this gap, the next chapter introduces and empirically assesses a gamification model for guiding developers teams in gamifying their existing healthcare systems that share similar goals with VazaZika. 


\section{A Gamification Model to Prevent Mosquito-borne Diseases}

Gamifying a software system consists of the incorporation of game elements and rules into systems to engage users with system features (12). Also, consist in defining a conceptual gamification model and incorporating it into the system (12). Gamification models are intended to make the use of a system more attractive and enjoyable, thereby promoting user engagement (63). This model defines how system users and game elements interact through welldefined game rules (63). An example of game elements are the point, i.e., an unit of reward that system user earns, and ranking policy, i.e., how to rank system user by performance. Examples of game rules are a system user earns points after completing a given task and, as a complement the system users the point count earned by a given user for determining the user ranking $(18,61)$.

Promoting user engagement is particularly important in certain healthcare domains (54), such as the prevention of mosquito-borne diseases $(18,61)$. Healthcare systems of this domain also largely depend on the wide engagement of health agents and authorities (58). In most cases, the citizens have to report mosquito breeding sites so that the public health agents can cope with these sites. Unfortunately, this modus operandi has been shown ineffective to prevent diseases. Indeed, citizens are poorly motivated to constantly report mosquito breeding sites in healthcare systems $(18,64)$. More critically, disseminating the use of healthcare systems, like any other software system, is quite hard (18). Thus, proposing attractive and enjoyable systems is a key to the success of these systems in practice. Aimed to leverage the user engagement, gamification models play an essential role (63).

Existing gamification models for healthcare domains are focused on non-borne diseases such as diabetes (6). However, they are not explicitly defined, thereby making their reuse quite challenging (61). More critically, these gamification models are not focused on the constant report and validation of health issues, as well as the cooperation of citizens and health agents, which is essential to prevent mosquito-borne diseases such as Dengue, Zika, and Chikungunya (27). We struggle with the lack of gamification models when gamifying a healthcare system for preventing these diseases (Chapter 3 ). Thus, well-defined and evaluated gamification models for the domain of mosquito- 
borne disease prevention are desired to gamify certain existing systems (61).

This chapter introduces and assesses a conceptual gamification model for healthcare systems in the specific domain of mosquito-borne disease prevention. Our gamification model is composed of 12 game elements and 16 game rules. We have incorporated this model into an existing healthcare system (VazaZika, in our case). We have evaluated our gamification model through an experiment with 20 citizens focused on the VazaZika mobile application. We evaluated six aspects concerning the incorporation of our gamification model into the VazaZika healthcare system: (i) user interface; (ii) ease of use; (iii) fun; (iv) motivation; (v) potential for the constant use of key system features; and (vi) potential for disseminating the system use among citizens. Our results suggest that our gamification model has resulted in an easy-to-use system with the potential of truly engaging users with critical healthcare-related features.

The study reported in this chapter corresponds to the extension of our paper accepted in the 1st International Workshop on Software Engineering for Healthcare (SEH) (61). The remainder of this chapter is organized as follows. Section 4.1 introduces and describes our gamification model built by following our method described in Chapter 3. Section 4.2 introduces the study goal and research questions regarding the assessment of our gamification model through the VazaZika mobile application. Section 4.3 details the study steps and artifacts. Section 4.5 presents the study results and discussions. Section 4.6 discusses additional evaluations and the potential reuse of our gamification model. Section 4.7 discusses threats to the study validity. Finally, Section 4.8 summarizes this chapter and introduces the following chapter.

\section{1}

\section{Design of the Conceptual Gamification Model}

In the particular context of the VazaDengue gamification, the development team had little experience with software gamification $(18,61)$. Therefore, a gamification model serving our specific system domain would be ideal to support the gamification of our existing system. Unfortunately, we do not found any gamification model in the literature. Thus, we decided to propose our gamification model in order to support the VazaDengue system gamification. We expected that the proposed gamification model would assist other development teams in gamifying their healthcare systems, in particular for the mosquito-borne diseases domain.

We have followed our gamification method presented in Chapter 3 to build our gamification model. Our model aims at (i) addressing the need for constantly reporting mosquito breeding sites, (ii) promoting the collaborative 
work of citizens towards the disease prevention, and (iii) promoting a fruitful competition among citizens. Healthcare systems that share these gamification goals could eventually benefit from reusing our model. The model consists of 12 game elements and 16 rules. We detail each step followed to build the gamification model as follows.

Gamification Goals. Along the System Preparation phase (Section 3.5), we derived six gamification goals, which are ordered by descending priorities. Table 4.1 summarizes the gamification goals as follows.

Table 4.1: Gamification Goals

\begin{tabular}{ll} 
ID & Gamification Goals \\
\hline G1 & $\begin{array}{l}\text { Promote constant report of mosquito breeding sites, so that tracking disease outbreaks and } \\
\text { eliminating mosquito breeding sites become easier for the health agents }\end{array}$ \\
G2 & $\begin{array}{l}\text { Promote reports in all Brazilian locations through game elements and rules that engage citizens } \\
\text { with different profiles to contribute critical-related healthcare tasks }\end{array}$ \\
G3 & $\begin{array}{l}\text { Promote tasks with varied purpose, difficulty, and user engagement } \\
\text { G4 }\end{array}$ \\
Provide tasks and challenges to be performed individually and in teams by citizens, in order to \\
spread the systems' user base
\end{tabular}

Personas. In the User Analysis phase (Section 3.5), we conducted meetings and workshops with the Brazilian public health agents. We aimed at characterizing the existing system users and the potential new ones. We have elicited a total of four personas associated with different user profiles. For this purpose, three software engineers have met in different days to reason about possible users and their interactions with the system. We illustrate the personas as follows. Persona 1: Laura is 18 years old, she loves playing games, and she lives in a community affected by many disease cases. Persona 2: Daniel is 34 years old, he got Zika six months ago, he has noticed several mosquito breeding sites in his neighborhood, and he is afraid his kids get Zika too. Persona 3: Kellen is 14 years old, she is socially engaged, she would like to report mosquito breeding sites in her community. Persona 4: Pedro is 45 years old, he is newstand owner, he is recently aware of several mosquito breeding sites in the neighborhood of his newsstand.

Personas are useful means to describe the needs of potential system users (24). We have taken advantage of the data richness documented through four elicited personas to defined which system features should be implemented and the user interaction should be taken. Moreover, we defined how these features should be gamified in order to reward and stimulate users to constantly use these features along time. Thus, we defined the game rules that could structure the user interaction with the features, especially by means of rewarding users after using a given system feature. 
System Requirements. In the Requirements Elicitation phase, we have documented the functional, non-functional, and gamification-specific requirements to incorporate game elements and rules into our existing system. We emphasize that characterizing personas considerably helped to evolve our existing system requirements. By defining personas to the potential system users, we tried to understand the possible interactions of a given user with the gamified system. After conducting various brainstorming meetings with both software engineers and public health agents, we have elicited 15 requirements that if not satisfied would prevent the achievement of the six gamification goals. Table 4.2 lists the VazaZika system requirements, which are classified into functional (FR), gamification-specific (GR), and non-functional requirements (NR). We also exemplify certain system requirements as follows.

Table 4.2: List of VazaZika FR, GR, and NR

\begin{tabular}{|c|c|c|c|}
\hline ID & Requirement Description & System & Goals \\
\hline FR1 & $\begin{array}{l}\text { The citizen can report mosquito breeding sites through text, } \\
\text { pictures, and geolocation data }\end{array}$ & Mobile & $1,2,3$ \\
\hline FR2 & $\begin{array}{l}\text { The citizen can monitor the report status (treated report, veri- } \\
\text { fied report, and report under analysis) in real time }\end{array}$ & Mobile, Web & 1 \\
\hline FR3 & $\begin{array}{l}\text { Both citizen and health agent can visualize mosquito-breeding } \\
\text { sites by location through a dynamic map }\end{array}$ & Mobile, Web & 1,2 \\
\hline FR4 & $\begin{array}{l}\text { The citizen can share a report of mosquito breeding site via social } \\
\text { networks like Twitter and Facebook }\end{array}$ & Mobile & $1,2,3$ \\
\hline FR5 & $\begin{array}{l}\text { The health agent can view and manage a list of reports by } \\
\text { location and status }\end{array}$ & Web & 1,2 \\
\hline GR1 & $\begin{array}{l}\text { The citizen can track his/her progress while performing tasks in } \\
\text { the systems }\end{array}$ & Mobile, Web & 1 \\
\hline GR2 & $\begin{array}{l}\text { The citizen can engage with teams of citizens from different } \\
\text { locations }\end{array}$ & Mobile & $1,2,3,4$ \\
\hline GR3 & The citizen can perform tasks either alone or as part of a team & Mobile & $1,2,3,4$ \\
\hline GR4 & $\begin{array}{l}\text { The citizen can perform an individual task at a time or multiple } \\
\text { tasks together }\end{array}$ & Mobile & 1,3 \\
\hline NR1 & $\begin{array}{l}\text { The system must have an acceptable usability that satisfies the } \\
\text { citizen expectations }\end{array}$ & Mobile, Web & $1,2,3$ \\
\hline NR2 & $\begin{array}{l}\text { The system must inter-operate through a shared communication } \\
\text { protocol }\end{array}$ & Mobile, Web & $1,2,3,4$ \\
\hline NR3 & $\begin{array}{l}\text { The system must implement a security layer for authenticating } \\
\text { both citizens and health agents }\end{array}$ & Mobile, Web & 1,2 \\
\hline NR4 & $\begin{array}{l}\text { The system must be adaptable according to the user natural } \\
\text { language }\end{array}$ & Mobile & 1,2 \\
\hline NR5 & $\begin{array}{l}\text { The system must support a reasonable set of Google Android } \\
\text { operating system (OS) versions }\end{array}$ & Mobile & 1,2 \\
\hline NR6 & $\begin{array}{l}\text { The system must be easily portable from Google Android OS to } \\
\text { Apple iOS and vice-versa }\end{array}$ & Mobile & 1,2 \\
\hline
\end{tabular}

An example of an evolved functional requirement is (FR1) The citizen can report mosquito breeding sites through text, pictures, and geolocation data. By defining the gamification-specific requirements, we thought how the game elements and rules would contribute to satisfy the needs of the elicited personas and help us achieve the main gamification goals. For instance, (GPR4) The citizen can perform an individual task at a time or multiple tasks together incorporates a game element that better engages the user with the system features, i.e., team. Consequently, it has helped us in achieving two gamification goals, i.e., G1 and G3. By adding this game element, we 
observed that certain existing non-functional requirements became critical, e.g., performance and availability.

Game Elements. We systematically followed the Gamification Design phase in order to decide which game elements and rules could be included in our gamification model (Section 3.5). We searched for successful and well-known gamified systems. We selected systems from different domains to increase the chance of reusing elements and rules that have been successfully independent of the domain. We have chosen to search systems from other domains rather than gamified systems in the healthcare domain, due to the lack of explicit definition of their gamification models, especially because the existing gamification model does not focus on assisting the prevention of mosquito-borne diseases. Thus, our goal was to identify the game elements and rules of these systems to propose our gamification model. Table 4.3 shows the ten gamified systems, which we categorize by the game elements that they implement. The first column lists the ten systems. The second and third columns respectively present the domain and the related game elements of each system.

\begin{tabular}{|c|c|c|}
\hline System & Domain & Game Elements \\
\hline Duolingo & $\begin{array}{l}\text { A real-world application that assigns badges to users that } \\
\text { complete activities and challenges while learning a new } \\
\text { language }\end{array}$ & $\begin{array}{l}\text { Point, Badge, Ranking, Social } \\
\text { sharing, Avatar, Chat, Level, } \\
\text { Social activity, Comment, and } \\
\text { Notification }\end{array}$ \\
\hline Facebook & $\begin{array}{l}\text { A popular free social networking that allows registered } \\
\text { users to create profiles, upload photos and video, send } \\
\text { messages and keep in touch with friends, family and col- } \\
\text { leagues }\end{array}$ & $\begin{array}{l}\text { Social sharing, Vote, Chat, } \\
\text { Team, Social activity, and } \\
\text { Challenge }\end{array}$ \\
\hline Foursquare & $\begin{array}{l}\text { A social check-in that rewarding people for exploring new } \\
\text { locations or returning to locations }\end{array}$ & Point, Badge, and Ranking \\
\hline GitHub & $\begin{array}{l}\text { A web-based version-control and collaboration system for } \\
\text { software developers }\end{array}$ & Vote \\
\hline Nike+ Running & $\begin{array}{l}\text { An application that assigns points and badges to users } \\
\text { according to the distance run by them indoors, e.g., on } \\
\text { treadmills, or outdoors. Also, provide a ranking based on } \\
\text { the user's friends list }\end{array}$ & $\begin{array}{l}\text { Point, Badge, Ranking, Social } \\
\text { sharing, Level, and Notification }\end{array}$ \\
\hline Stack Overflow & $\begin{array}{l}\text { A popular system for developers sharing knowledge } \\
\text { through questions and answers. In Stack Overflow, the sys- } \\
\text { tem users earn points and badges by performing a variety } \\
\text { of tasks, such as (i) asking and answering questions, (ii) } \\
\text { commenting on answers and questions provided by other } \\
\text { users, and (iii) up and down voting existing questions and } \\
\text { answers }\end{array}$ & Point, Badge, and Vote \\
\hline Steam & $\begin{array}{l}\text { This system is a combination of a gaming environment } \\
\text { with a game virtual store. Users can buy video games, } \\
\text { manage wish lists, interact with other users through a } \\
\text { social network and follow a news feed. Playing games, } \\
\text { interacting with people, and participating in campaigns } \\
\text { via virtual store gives points and badges to users }\end{array}$ & $\begin{array}{l}\text { Badge, Social sharing, Avatar, } \\
\text { Chat, Team, Social activity, } \\
\text { Challenge, and Comment }\end{array}$ \\
\hline Swarm & $\begin{array}{l}\text { A location-based social network that rewarding their user } \\
\text { with points for each check-in and badges for new types of } \\
\text { location or checking in more often than your friends }\end{array}$ & $\begin{array}{l}\text { Point, Badge, Ranking, Social } \\
\text { Sharing, Vote, Avatar, Chat, } \\
\text { Level, and Team }\end{array}$ \\
\hline Uber & $\begin{array}{l}\text { An application for drivers to keep them on the road } \\
\text { for a longer period of time each day. The application } \\
\text { sets arbitrary earnings goals that provide achievements } \\
\text { when satisfied. The app provides feedback for drivers and } \\
\text { game elements like badges and bonuses for hitting certain } \\
\text { milestones }\end{array}$ & $\begin{array}{l}\text { Point, Vote, Level, Challenge, } \\
\text { and Comment }\end{array}$ \\
\hline Waze & $\begin{array}{l}\text { A location-based application that provides users with traf- } \\
\text { fic information through maps, promoting the participation } \\
\text { of the entire application community in a collaborative way }\end{array}$ & $\begin{array}{l}\text { Point, Ranking, Avatar, and } \\
\text { Team }\end{array}$ \\
\hline
\end{tabular}

Table 4.4 lists ten systems categorized by the game elements they implement (columns two to 14). We observed that points and badges are the most frequent game elements, implemented by $70 \%$ and $60 \%$ of the systems. This result confirms some discussions presented in the literature $(12,68)$. We 
have selected 12 out of the 13 game elements elicited. We decided not to select chat to design our gamification model.

Table 4.4: Game Elements in Existing Systems (and Selected Game Elements)

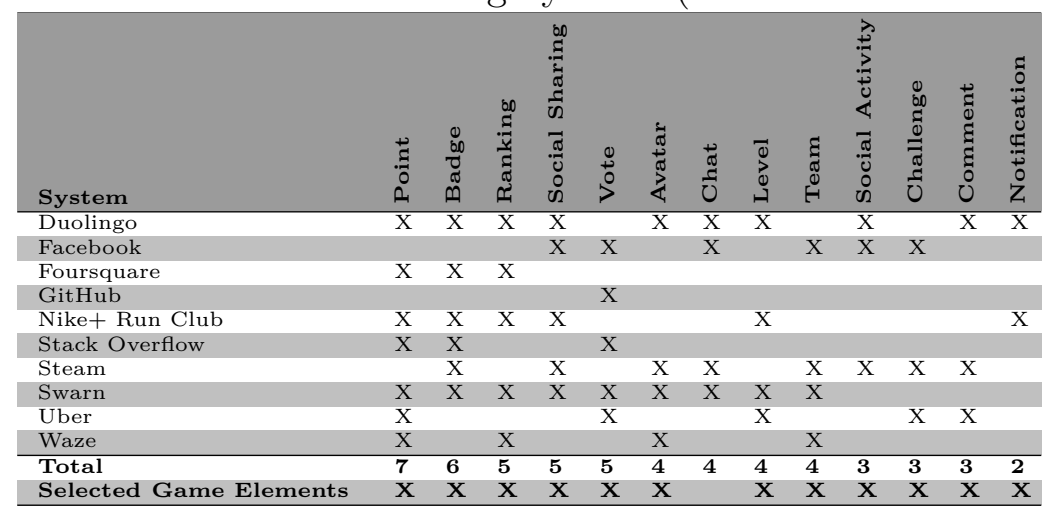

Regarding the game rules, we observed that the ranking policies of many systems, e.g., Stack Overflow, rely on the point count. Additionally, most systems such as Duolingo and Waze provide system users with varied badges. Table 4.5 describes the selected 12 game elements. By rewarding the citizens for performing critical-related healthcare tasks, such as reporting and validating mosquito breeding sites. Thus, we expected to achieve the VazaZika system gamification goals as described in Table 4.1.

Table 4.5: Game Elements Incorporated into our Gamification Model

\begin{tabular}{|c|c|}
\hline Game Element & Purpose \\
\hline Avatar: representation of the citizen (12) & $\begin{array}{l}\text { Aimed at immersing the citizen into the sys- } \\
\text { tem, so that the citizen feels part of the system }\end{array}$ \\
\hline Badge: special reward assigned to a citizen (68) & $\begin{array}{l}\text { Aimed to recognize the citizen skills regarding } \\
\text { specific tasks performed through the system }\end{array}$ \\
\hline Challenge: set of tasks that share a purpose (68) & $\begin{array}{l}\text { Aimed at challenging the citizen to perform } \\
\text { important tasks through the system }\end{array}$ \\
\hline Comment: text feedback given by a citizen (68) & $\begin{array}{l}\text { Aimed at manifesting the citizen opinion } \\
\text { about a task }\end{array}$ \\
\hline Level: control of the citizen progress (68) & $\begin{array}{l}\text { Usually aimed at unlocking new tasks as the } \\
\text { citizen accumulates rewards }\end{array}$ \\
\hline Notification: feedback on citizen actions (68) & $\begin{array}{l}\text { Aimed at alerting the citizen about completed } \\
\text { actions and earned rewards }\end{array}$ \\
\hline Point: a unit of reward assigned to a citizen (68) & $\begin{array}{l}\text { Aimed at rewarding the citizen after complet- } \\
\text { ing tasks through the system }\end{array}$ \\
\hline Ranking: a sorted list of citizens (68) & $\begin{array}{l}\text { Aimed at promoting a comparison and compe- } \\
\text { tition among citizens }\end{array}$ \\
\hline Social activity: registry of citizen actions (68) & $\begin{array}{l}\text { Aimed at summarizing the actions, e.g., com- } \\
\text { pleted tasks, performed by the citizens }\end{array}$ \\
\hline Social sharing: action report via social media (68) & $\begin{array}{l}\text { Aimed at promoting the system use outside } \\
\text { the system, i.e., in external social networks }\end{array}$ \\
\hline Team: group of citizens that share a task (68) & $\begin{array}{l}\text { Aimed at promoting the collectivism in the } \\
\text { realization of tasks through the system }\end{array}$ \\
\hline Vote: validation of a completed task (68) & $\begin{array}{l}\text { Aimed at confirming or refuting that a task } \\
\text { was correctly performed through the system }\end{array}$ \\
\hline
\end{tabular}

Game Rules. Table 4.6 lists the game rules incorporated into our gamification model. R1, R2, R8, and R13-R16 define how the citizens interact with system. For instance, the citizens earn points after reporting a mosquito breeding site. It aims at acknowledging the citizen so that he feels encouraged 
to report sites again. The remainder rules define relations between a pair of game elements, which determines how one element affects another. For instance, points assigned to a citizen count on the citizen ranking. In the table, we inform the gamification goals addressed by game rules.

Table 4.6: Game Rules and Goals They Help in Addressing Gamification

\begin{tabular}{|c|c|c|}
\hline ID & Game Rule & Goals \\
\hline R1 & Citizens can edit their avatar, and create new challenges and teams & 3,4 \\
\hline $\mathrm{R} 2$ & $\begin{array}{l}\text { The citizen can engage with existing Challenges, provide comments on citizens' } \\
\text { actions, perform social sharing of his own actions, and vote for mosquito } \\
\text { breeding sites reported by other citizens }\end{array}$ & $1,2,4$ \\
\hline R3 & Edit avatar and create challenges and teams generate notifications & 1,2 \\
\hline $\mathrm{R} 4$ & $\begin{array}{l}\text { Avatar editing and the creation of challenges and teams by citizens update the } \\
\text { social activity }\end{array}$ & $1,2,4$ \\
\hline R5 & $\begin{array}{l}\text { Engaging with either challenges, comments, social sharing, or voting updates } \\
\text { the social activity }\end{array}$ & $1,2,4$ \\
\hline $\mathrm{R} 6$ & $\begin{array}{l}\text { Engaging with either challenges, comments, social sharing, or voting generates } \\
\text { badges }\end{array}$ & $1,2,4$ \\
\hline $\mathrm{R} 7$ & $\begin{array}{l}\text { Engaging with either challenges, comments, social sharing, or voting generates } \\
\text { notifications }\end{array}$ & $1,2,4$ \\
\hline $\mathrm{R} 8$ & Notifications inform the citizen & 1 \\
\hline R9 & $\begin{array}{l}\text { After either engaging a challenge or performing comments, social sharing, and } \\
\text { voting, points are generated }\end{array}$ & $1,2,4$ \\
\hline R10 & Points counts control the ranking of citizens & $1,2,4$ \\
\hline R11 & Points of a citizen control his progression along the game levels & 3,4 \\
\hline $\mathrm{R} 12$ & The citizen level unlocks specific citizen actions in the system & 3,4 \\
\hline R13 & The health agent can edit his avatar & 5 \\
\hline R14 & $\begin{array}{l}\text { Notifications inform the health agent that a report was updated by the citizen } \\
\text { according to the agent's vote }\end{array}$ & $1,3,5$ \\
\hline R15 & $\begin{array}{l}\text { The health agent can vote about the quality of information of the reported } \\
\text { mosquito breeding sites }\end{array}$ & $1,5,6$ \\
\hline R16 & $\begin{array}{l}\text { The health agent can comment about the quality of information of the reported } \\
\text { mosquito breeding sites }\end{array}$ & $1,5,6$ \\
\hline
\end{tabular}

Relationships Between Elements and Rules. The gamification model supports developers and stakeholders in understanding how the game elements and game rules interrelate in a system (12). Figure 4.1 shows our gamification model, which incorporates all 12 game elements (Table 4.5) and 16 game rules (Table 4.6) with the purpose of engaging users with healthcarerelated tasks, especially for preventing mosquito-borne diseases. Continuous arrows represent the relations between the system and their users (SU) and dotted arrows represent the relations between a pair of game elements (EE). 


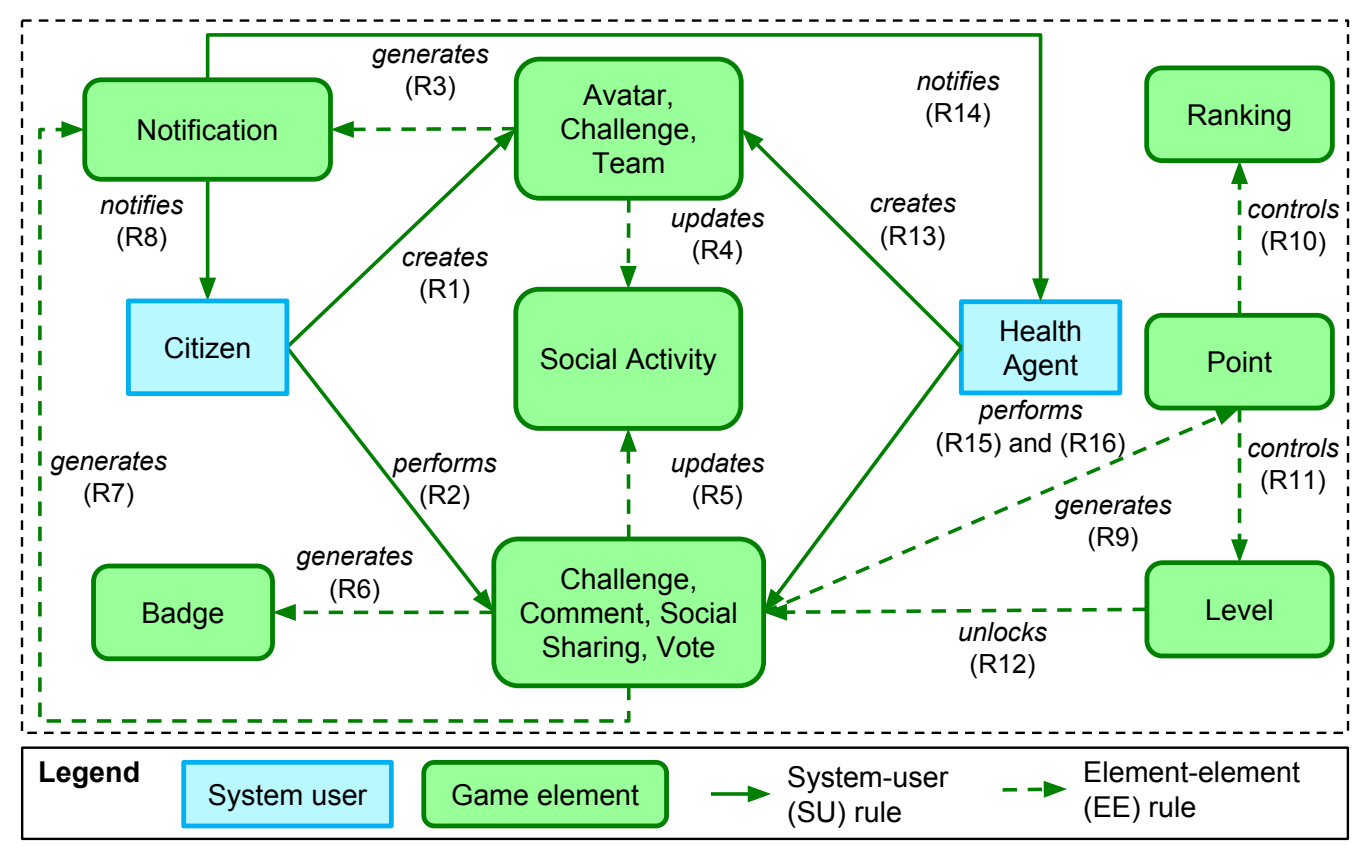

Figure 4.1: The Designed Conceptual Gamification Model

\section{2}

\section{Goal and Research Questions}

Based on guidelines provided by Wohlin et al. (66), we defined our study goal as follows: analyze the gamification model that supported the gamification of a healthcare system; for the purpose of understanding to what extent the gamification model has helped to achieve the system gamification goals; with respect to (i) user interface, (ii) ease of use, (iii) fun, (iv) motivation, (v) potential for the constant use of key system features, and (vi) potential for disseminating the system use among citizens; Our analysis is from the viewpoint of Brazilian citizens with varied background; in the context of VazaZika mobile application. We chose to conduct our study using the mobile application because of it better supports the configuration of our study. For instance, the feature of reporting a mosquito breeding site in a simulated environment was only possible to exploit through mobile application rather than the web application that would not make possible this simulation. Table 4.7 list our six research questions (RQs). We detail each RQ as follows.

Through $\mathbf{R Q}_{1}$ we aim to identify opportunities for improving the interface to make citizens more comfortable with using the VazaZika mobile application if users. Additionally, we aim to understand to what extent the game elements incorporated by VazaZika have been perceived by the citizens. Thus, we can have a clear understanding of the interface attractiveness and how the 
Table 4.7: Research Questions of the Empirical Study

\begin{tabular}{ll}
$\mathrm{RQ}$ & Description \\
\hline $\mathrm{RQ}_{1}$ & $\begin{array}{l}\text { What are the positive and negative aspects of the gamified mobile } \\
\text { application user interface? }\end{array}$ \\
$\mathrm{RQ}_{2}$ & How easy was it for the citizen to use the gamified mobile application? \\
$\mathrm{RQ}_{3}$ & $\begin{array}{l}\text { How fun and motivate was it for the citizen to use the gamified mobile } \\
\text { application? }\end{array}$ \\
$\mathrm{RQ}_{4}$ & $\begin{array}{l}\text { What is the correlation between ease of use and user fun, and user } \\
\text { motivation for the gamified mobile application? }\end{array}$ \\
$\mathrm{RQ}_{5}$ & How often citizens would use the gamified mobile application again? \\
$\mathrm{RQ}_{6}$ & $\begin{array}{l}\text { How often citizens would recommend the gamified mobile application to } \\
\text { friends? }\end{array}$
\end{tabular}

game elements have contributed to such attractiveness. We decided to assess the gamification model through the user interface because most game elements and rules are explicit in the user interface itself. Thus, by providing opinions about the user interface, users are implicitly assessing the model. $\mathbf{R Q}_{2}$ aims to understand if the incorporation of game elements and rules into VazaZika has contributed to build an easy-to-use application. In this case, certain game elements may hinder application usage, even though they make the system enjoyable and challenging. These cases would be opportunities for refining our gamification model by adapting it to the user needs.

$\mathbf{R Q}_{3}$ aims to capture whether the game elements and rules incorporated by VazaZika help promote a constant report and validation of mosquito breeding sites. A poor citizen's fun and motivation imply a defect in the gamification model and a need for refinement. We measured the user fun and motivation by capturing the citizen perception through a closed form question, in a five-point Likert scale (32). With $\mathbf{R Q}_{4}$ we aim to understand if there is any correlation between the ease of use and either fun or motivation provided by our gamification model. It might be the case that, the harder it is to use the mobile application, the lower is the user fun and user motivation of gamified mobile application. In this case, it would be necessary to refine our model in order to make it easier while enjoyable and challenging.

Through $\mathbf{R Q}_{5}$ we aim to know how often citizens feel motivated to use the VazaZika again. This information is quite relevant because one of our major goals with the VazaDengue gamification was to leverage user engagement. Although there may be some bias in the citizen's responses, this question may guide an understanding of what extends citizens feel motivated. We assume that the higher the number of citizens motivated to use the application again, the more these citizens would contribute to disease prevention. $\mathbf{R Q}_{6}$ we aim to assess another major gamification goal, i.e., the potential for disseminating the 
gamified mobile application use across citizens. Thus, we could leverage the disease prevention by potentially increasing the number of reports of mosquito breeding sites in different locations. In summary, we expect that a high number of citizens recommending the mobile application to their friends can make VazaZika popular and useful to the public health agents.

\section{3}

\section{Study Steps and Artifacts}

Figure 4.2 illustrates our seven study steps encapsulated in four phases, which we describe as follows.

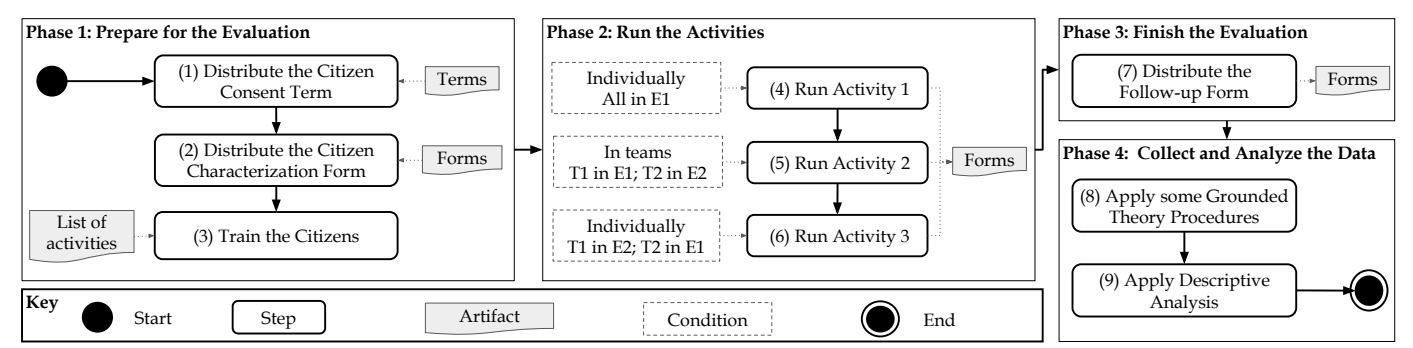

Figure 4.2: Study Phases and Artifacts

Phase 1: Prepare for the Evaluation. Through the Consent Form, Step 1 consisted of collecting permission to anonymously collect experiment data of the citizens that participated in the experiment. Step 2 aimed at collecting the citizen background, e.g., age, sex, and highest education degree, via the Characterization Form. All citizens were asked to use their mobile devices for installing and using the VazaZika mobile application. Step 3 aimed at instructing in the experiment procedures. We spent about 10 minutes explaining the experiment artifacts and five minutes answering general questions about the experiment.

Phase 2: Run the Activities. We have distributed the List of Experiment Activities to all citizens before proceeding with Steps 4 to 6. We defined three activities that encapsulate a disjoint set of system features. Two out of three activities are individual and one has to be performed by citizens collaboratively. We also distributed the Activity Experiment Form composed of open and closed questions. The latter rely on five-point Likert scales (32). Each form should be filled right after completing an activity. Steps 4, 5, and 6 were designed to perform Activities 1 to 3 in this order (Section 4.4 describes the environment settings). Phase 3: Finish the Evaluation. Step 7 aimed at collecting data about the citizen's experience with the experiment via the Follow-up Form. This form was distributed for each citizen after all citizens 
have completed Activity 3. All artifacts of this study are presented in Appendices $\mathrm{D}, \mathrm{E}, \mathrm{F}, \mathrm{G}$, and $\mathrm{H}$.

Phase 4: Collect and Analyze Data. We have conducted the experiment data analysis in two steps. In Step 8, we have applied some Grounded Theory (GT) (8) procedures for coding and classifying the data provided by citizens in the form of open questions. We performed the open coding for labeling the interface aspects mentioned by citizens. An example of a group is (ASP10) Information Presentation. After that, we performed the axial coding for grouping the labeled aspects in two layers: (i) quality attribute in accordance with the ISO 9126 norm (31) and (ii) positive, i.e., praises, versus negative, i.e., criticism, mentions. In Step 9, we have performed the descriptive analysis (66) for the form of closed questions.

\section{4}

\section{Citizen Characterization and Environment Settings}

Table 4.8 lists the 20 citizens that participated in our experiment (C01 to $\mathrm{C} 20$ ). We have elicited the following data by citizen: Age, Sex, highest education degree (Degree), use of mobile applications in hours by week (Mobile), and use of video games in hours by week (Games). Our citizen sample is quite diverse. The average age equals 23 years old. They spend about 29 and 14 hours by week with mobile devices and games. Finally, 40\% hold a high school (HS) degree and 55\% hold a Bachelor (BS) degree.

Table 4.8: Summary of the Citizen Background

\begin{tabular}{lrllrr||lrllrr}
\hline ID & Age & Sex & Degree & Mobile & Games & ID & Age & Sex & Degree & Mobile & Games \\
\hline C01 & 28 & Male & BS & 20 & 0.5 & C11 & 30 & Male & Spec & 14 & 8 \\
C02 & 23 & Male & BS & 35 & 7 & C12 & 23 & Male & BS & 15 & 2 \\
C03 & 22 & Male & HS & 24 & 0 & C13 & 22 & Male & BS & 50 & 42 \\
C04 & 20 & Male & HS & 25 & 10 & C14 & 21 & Female & BS & 28 & - \\
C05 & 24 & Male & HS & 30 & 10 & C15 & 20 & Male & BS & 25 & 8 \\
C06 & 20 & Male & BS & 80 & 80 & C16 & 30 & Male & BS & 15 & 0 \\
C07 & 22 & Male & BS & 35 & 35 & C17 & 20 & Male & HS & 21 & 4 \\
C08 & 19 & Male & HS & 24 & 6 & C18 & 28 & Male & BS & 20 & 0 \\
C09 & 21 & Male & HS & 50 & 20 & C19 & 23 & Male & HS & 38 & 25 \\
C10 & 27 & Male & BS & 20 & 6 & C20 & 20 & Male & HS & 28 & - \\
\hline
\end{tabular}

Table 4.9 presents our crossover study design (66). We defined two geographically distant environments, i.e., E1 and E2. We also split the total of 20 citizens into two groups, so that each group could perform certain experiment activities separately. We have defined three experiment activities as follows. Activity 1: Citizens create and edit their user profiles individually. Activity 2: Citizens engage with a challenge in order to report mosquito breeding sites collaboratively. Activity 3: Citizens validate the mosquito breeding sites reported by colleagues individually. Each activity encompasses the user interaction with a different set of game elements (second column). 
The input of Activity 3, i.e., the reports of mosquito breeding sites provided by citizens), is produced along with Activity 2. Thus, there is a dependency between Activities 2 and 3. If we have allowed the group that reported sites in E1 to validate the reports also in E1 (same applies to E2), there would be a bias in Activity 3 (report validation). That is because citizens reporting sites in E1 already know where the reports were made. Our crossover study design aimed to mitigate this bias by exchanging the environment of the two citizens after Activity 2 has ended.

Table 4.9: Crossover Study Design

\begin{tabular}{c|l|l|lr}
\hline \multirow{2}{*}{ Activity } & \multicolumn{1}{c}{ Game Elements } & \multicolumn{2}{c}{ Game Rules } & Ell \\
E2 & Citizens & - \\
\hline $\mathbf{1}$ & Avatar, social activity, notification & R1, R3-4 & 10 Citizens & 10 Citizens \\
\hline $\mathbf{2}$ & $\begin{array}{l}\text { Badge, challenge, point, social ac- } \\
\text { tivity, team, level, ranking, notifi- } \\
\text { cation }\end{array}$ & R2, R4-7, R9-10, R12 & & \\
\hline & $\begin{array}{l}\text { Badge, comment, level, point, } \\
\text { ranking, social sharing, vote, noti- } \\
\text { fication }\end{array}$ & R2, R6, R9-10 & Citizens & 10 Citizens \\
\hline
\end{tabular}

\section{5}

\section{Results and Discussions}

This section presents our study results. We discuss each of the six evaluated aspects of our gamification model as follows.

User Interface. Figure 4.3 illustrates how part of the user interface of the VazaDengue mobile application has evolved, thereby constituting the VazaZika interface. Figures 4.3(a) and 4.3(b) regard the main application screen. They compare the map of reported mosquito breeding sites before and after the incorporation of the following game elements: Avatar (Profile) and Teams. We show these elements in screen bottom corner, as indicated in Figure 4.3(b). The Teams feature appears in the main screen in order to stimulate the report of various mosquito breeding sites in teams of citizens. Indeed, engaging as many citizens as possible to report sites is essential to the success of the public health agents' work. The Avatar feature also appears in the main screen in order to make citizens immersed into the application purposes. Figures 4.3(c) and 4.3(d) regard the main application feature: the report of mosquito breeding sites. Based on the demand of our stakeholders, mostly public health agents, we have added an option for citizens to report photos of the reported sites. Thus, we expect to help agents in accurately finding the reported sites. 


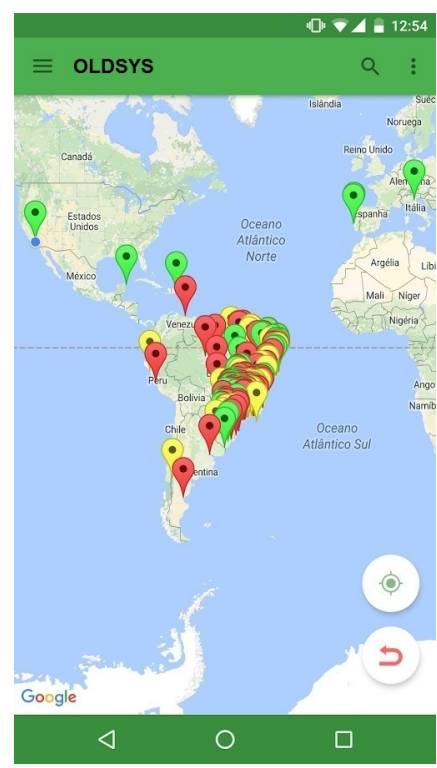

4.3(a): VazaDengue's map

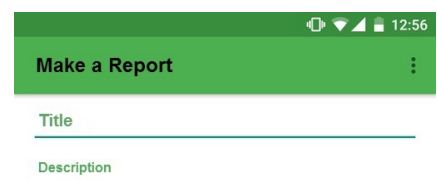

Report Type

Mosquito breeding site

Is the site located in a public area?

No

Where did you find the site?

Aquarium

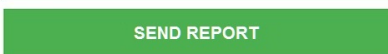

$\triangleleft$

4.3(c): VazaDengue's report

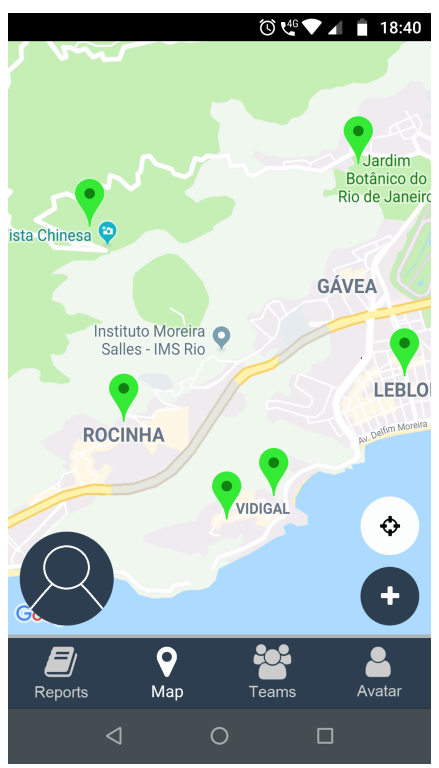

4.3(b): VazaZika's map

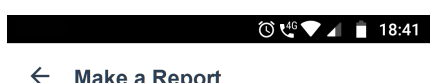

$\leftarrow$ Make a Report

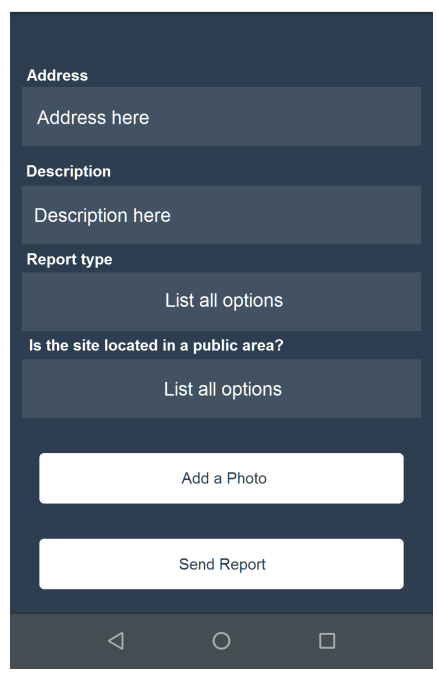

4.3(d): VazaZika's report

Figure 4.3: Sample of the Evolution of the Mobile Application's Interface

Table 4.10 summarizes the citizens' perception about the user interface aimed to answer $\mathbf{R Q}_{1}$. After performing each activity, we asked all citizens to list at least three positive and three negative aspects of the user interface. We expected that game elements and rules incorporated by our model are satisfactorily accepted by citizens in terms of how they are displayed in the user interface. The first column lists the groups of aspects based on the ISO 25010 quality attributes of the second column. The third and fourth columns count the number of citizens that provided positive and negative mentions to each quality attribute. We have found 13 quality attributes grouped in five groups: ability to capture the citizen attention to the system (GRP01); ability 
to be properly understood (GRP02); ability to respond the citizen requests in a satisfactory time (GRP03); ability to represent information in a satisfactory manner (GRP04); and easiness to use the system (GRP05). Quality attributes marked have received both positive and negative by the same citizen.

Table 4.10: Quality Attributes Mentioned by Citizens About the User Interface

\begin{tabular}{|c|c|c|c|c|}
\hline Group & Quality & Attribute & Positive & Negative \\
\hline \multirow{6}{*}{ (GRP01) Attractiveness } & (ASP01) & Accessibility & 1 & 0 \\
\hline & (ASP02) & Color Scheme* & 4 & 4 \\
\hline & (ASP03) & Design Minimalism & 3 & 0 \\
\hline & (ASP04) & Fun & 4 & 0 \\
\hline & (ASP05) & Interface Simplicity & 10 & 0 \\
\hline & (ASP06) & Visual Aesthetics* & 6 & 10 \\
\hline \multirow[t]{2}{*}{ (GRP02) Comprehensibility } & (ASP07) & Intuitiveness & 7 & 0 \\
\hline & (ASP08) & Understandability & 5 & 3 \\
\hline (GRP03) Efficiency & (ASP09) & Efficiency* & 5 & 12 \\
\hline $\begin{array}{l}\text { (GRP04) Information Presenta- } \\
\text { tion }\end{array}$ & (ASP10) & Information Presentation* & 7 & 10 \\
\hline \multirow[t]{3}{*}{ (GRP05) Usability } & (ASP11) & Easiness to Access Specific Feature & 4 & 1 \\
\hline & (ASP12) & Easiness to Use* & 10 & 1 \\
\hline & (ASP13) & Interface Navigation* & 7 & 2 \\
\hline
\end{tabular}

The results presented in Table 4.10 reveal some interesting findings regarding $\mathbf{R Q}_{1}$. We have found that most quality attributes (69\%) had more positive than negative mentions. The two attributes with most positive mentions are Interface Simplicity (ASP04) and Easiness to Use (ASP12). In summary, we conclude that the VazaZika mobile application is easy to interact with. Surprisingly, only a few quality attributes (ASP01, ASP03, ASP04, ASP05, and ASP07) had no negative mention. Visual Aesthetic (ASP06), Efficiency (ASP09), and Information Presentation (ASP10). In order to complement our understanding of the user interface from the viewpoint of citizens, we have asked the citizens to mark the game elements they have perceived. More than $50 \%$ of citizens perceived all 12 game elements incorporated by VazaZika, except Vote (45\%), Comment (25\%), and Notification (25\%).

The results of $\mathbf{R Q}_{1}$ reveal opportunities to improve Activity 3, i.e., a feature of validating reports of mosquito breeding sites, with respect to the user interface. We have found the quality attributes Color Scheme, Visual Aesthetics, and Information Presentation were the most criticized by the citizens. A solution for improving the Color scheme would be using brighter or bolder colors, aimed at further attracting the citizens, especially the younger ones - since our current color scheme is composed by a majority of dark tones.

With respect to Visual aesthetics and Information presentation, we emphasize that Activity 3 depends on Votes and Comments, which were rarely perceived by citizens. We could make these game elements more evident to users. For example, we could increase the icons size, use vivid colors, and add notifications to emphasize the need for using them. 
Summary of $\mathbf{R Q}_{1}$. Citizens mentioned 13 quality attributes of the VazaZika user interface. Most mentions are positive and praise the interface simplicity and easiness to use. Many game elements, including Avatar and Social Sharing, were perceived by at least $50 \%$ of citizens. The main improvement opportunities identified are: using brighter or bolder colors (interface-related), and better presenting the key game elements for validating reports of mosquito breeding sites (e.g., vote and comment).

Ease to Use. We answer $\mathbf{R Q}_{2}$ as follows. After performing each experiment activity (Activities 1 to 3 ), we asked the citizens to indicate how much they agree with the following sentence: I found it easy to perform this activity. Table 4.11 presents our study results regarding $\mathbf{R Q}_{2}$. The second to fourth columns present the percentages for the VazaZika ease of use, according to the responses of the 20 citizens. Considering both Strongly agree and Agree, we observed that at least $55 \%$ of citizens found easy to performed the experiment tasks. Additionally, only a few citizens ( $5 \%$ at most by activity) found very hard to perform the experiment activities.

Table 4.11: Citizens Perception About Ease to Use

\begin{tabular}{lrrrr} 
Perception & Activity 1 & Activity 2 & Activity 3 & All \\
\hline Strongly agree & $\mathbf{5 0 \%}$ & $5 \%$ & $25 \%$ & $27 \%$ \\
Agree & $40 \%$ & $\mathbf{5 0 \%}$ & $\mathbf{3 5 \%}$ & $\mathbf{4 2 \%}$ \\
Neutral & $0 \%$ & $15 \%$ & $30 \%$ & $15 \%$ \\
Disagree & $5 \%$ & $25 \%$ & $5 \%$ & $12 \%$ \\
Strongly disagree & $5 \%$ & $5 \%$ & $5 \%$ & $5 \%$ \\
\hline
\end{tabular}

We asked the citizens to justify their perception on the VazaZika ease of use. About $45 \%$ of citizens associated game elements incorporated by the system with ease of use. The mentioned elements are Vote and Social sharing. This result is expected because both game elements are explicit in the VazaZika interface, and the users can interact with them directly through the system, contrary to subtle game elements such as Comment. This is different from Ranking and Point, which are perceived after a user action performs in the system. Regarding the citizens that mentioned game elements, $78 \%$ have found VazaZika is (very) easy to use.

I found the system easy to use, especially because the voting feature is easy to use - Citizen 10 about votes

I found it easy to share my actions via social networks [...] - Citizen 11 about social sharing 
Regarding the aspect of ease of use, our gamification model showed to be promising. The results show that, for Activity 3 (validating mosquito breeding sites) certain involved game elements (Vote and Social sharing) might have contributed to the ease of use. Similar reasoning is valid for the game rules $(R 1, R 2, R 8$, and $R 13-R 16)$ that represent the relations between the system and their users. These results also suggest that for critical healthcarerelated features, e.g., reporting mosquito breeding sites that were performed collaboratively through Activity 2, Challenge and Team and their game rules, in general, do not affect negatively the ease of use of the system.

However, by summing the answers Neutral, Disagree and Strongly disagree, we observed that $45 \%$ of citizens not found it easy to perform Activity 2. This might be explained due to the difficulty imposed by the gamification mechanics incorporated into the gamified application. In this case, the citizen should meet with other citizens and create a team. They join an existing challenge and invite a rival team to take part in the challenge (report the highest amount of mosquito breeding sites). We emphasize that in our study we evaluated only challenges performed in team rather than individual challenges.

Our results about $\mathbf{R Q}_{2}$ point out many opportunities for enhancing the ease of use through our gamification model. Our results suggest that Challenge and Team are game elements that users found a little hard to interact with. This observation is especially valid in the context of reporting of mosquito breeding sites (Activity 2). Thus, we could improve our gamification model by reducing the complexity of the gamification mechanism. For instance, after creating a team and entering a challenge, the gamified application could automatically select or recommend a rival team. This would reduce the necessary steps to start challenges performed by teams. Thus, it is necessary to revisit the game rules of our gamification model to make the association with challenges and teams simpler and rewarding.

Summary of $\mathbf{R Q}_{2}$. At least $55 \%$ of the citizens have found the VazaZika ease to use. Additionally, a half of citizens have found the incorporated game elements and rules are ease of use. Regarding improvement opportunities, we observed that the game rules of the gamification model must be simplified with respect to challenges and teams.

User Fun and Motivation. We answer $\mathbf{R Q}_{3}$ as follows. We asked the citizens how much they agree with this sentence: I found it fun to perform this activity. The second to fourth columns of Table 4.12 present the percentages of fun. By 
considering both Strongly agree and Agree, up to $65 \%$ of citizens have found fun to perform the activities. Unfortunately, most citizens (55\%) stayed in the borderline for Activity 1. This observation is expected because Activity 1 is too simple (avatar creation and edition). Fortunately, only a few citizens ( $5 \%$ at most) had no fun in performing some activity.

Table 4.12: Citizens Perception About User Fun

\begin{tabular}{lrrrr} 
Perception & Activity 1 & Activity 2 & Activity 3 & All \\
\hline Strongly agree & $15 \%$ & $30 \%$ & $10 \%$ & $18 \%$ \\
Agree & $15 \%$ & $\mathbf{3 5 \%}$ & $\mathbf{3 5 \%}$ & $28 \%$ \\
Neutral & $\mathbf{5 5 \%}$ & $20 \%$ & $30 \%$ & $\mathbf{3 5 \%}$ \\
Disagree & $10 \%$ & $15 \%$ & $25 \%$ & $17 \%$ \\
Strongly disagree & $5 \%$ & $0 \%$ & $0 \%$ & $2 \%$ \\
\hline
\end{tabular}

Regarding the aspect of user fun, we can conclude that the game elements involved in the Activity 1 (Avatar, Social activity, and Notification) and game rules $(R 1, R 3, R 4)$ were not sufficient to achieve a satisfactory user fun. One solution would be to assign Points and Badges even for profile creation and editing (this is because points and badges are in the activities considered most fun by citizens). For Activity 2, certain game elements (Challenge and Team) and game rules (R2, R3, $R 5-R \%, R 9$ ) were sufficient to provide fun for $55 \%$ of citizens. This can be explained because the game elements Challenge and Team and their related game rules promote the collaboration between citizens to perform certain activities on the gamified mobile application. That was the case of reporting mosquito breeding sites collaboratively by teams, that made the Activity 2 more fun than Activities 1 and 3.

For Activity 3, by summing Strongly agree and Agree, specific game elements (Comment, Social sharing, and Vote), and rules (R2, R6, R9) provided fun for $45 \%$ of citizens. However, we observed that $25 \%$ of citizens did not find fun to perform Activity 3. This might be explained due to inefficient use of Notifications during Activity 3. One solution would be to provide incentive notifications, e.g., Congratulations! You were able to validate a report of mosquito breeding sites! Continue to validate mosquito outbreaks and help build a healthier city for everyone. Besides, we could assign additional points to the citizens who most validate reports of mosquito breeding sites per week.

We also asked the citizens to indicate how much they agree with this sentence: I felt motivated to perform this activity again. The second to fourth columns of Table 4.13 present the percentages for the citizen motivation. By considering both Strongly agree and Agree, we observed that up to $65 \%$ of citizens felt motivated to perform the activities again. Most citizens (60\%) stayed in the borderline for Activity 1. More critically, we have found that 
$40 \%$ of citizens did not feel motivated to repeat Activity 3 (by considering both Disagree and Strongly disagree).

Table 4.13: Citizens Perception About User Motivation

\begin{tabular}{lrrrr} 
Perception & Activity 1 & Activity 2 & Activity 3 & All \\
\hline Strongly agree & $5 \%$ & $25 \%$ & $5 \%$ & $12 \%$ \\
Agree & $20 \%$ & $30 \%$ & $25 \%$ & $25 \%$ \\
Neutral & $\mathbf{6 0 \%}$ & $\mathbf{3 5 \%}$ & $30 \%$ & $\mathbf{4 2 \%}$ \\
Disagree & $15 \%$ & $0 \%$ & $\mathbf{3 5 \%}$ & $17 \%$ \\
Strongly disagree & $0 \%$ & $10 \%$ & $5 \%$ & $5 \%$ \\
\hline
\end{tabular}

As far as user motivation is concerned, we observed that similarly to user fun, the game elements involved in Activity 1 (Avatar, Social activity, and Notification) and rules $\left(R 1, R 3, R_{4}\right)$ were not sufficient to achieve a satisfactory user motivation. For Activity 2, by summing Strongly agree and Agree, the results suggest that Challenge and Team have made the Activity 2 more motivating than Activities 1 and 3 for $55 \%$ of citizens. However, we observed a considerable number of Neutral (35\%) that indicates an improvement opportunity. A solution would be to add to the application a tutorial on how important it is to prevent mosquito-borne diseases via reporting. An example of a tutorial would be how the reports will help public health agents to ensure the quality of life of the population. The same rationale applies to other activities, especially Activity 1 (which obtained $60 \%$ of Neutral answers).

However, for Activity 3 although the specific game elements Comment, Social sharing, and Vote have provided good user fun, we observed that for $40 \%$ of citizens (by summing Disagree and Strongly disagree) the feature of validating reports of mosquito breeding sites has not sufficiently motivated citizens. The results of $\mathbf{R Q}_{3}$ about user motivation suggest an opportunity to improve our gamification model to make Activity 3 more motivating for citizens. Thus, similarly to user fun, we could increase the user motivation by providing more notifications and assigning additional points to citizens who most validate reports of mosquito breeding sites per week.

Summary of $\mathbf{R Q}_{3}$. Our results suggest that citizens are motivated to use the mobile application again. This result implies that our gamification model has promoted a satisfactory user engagement in terms of user fun and user motivation. Regarding improvement opportunities, we observed that user fun and motivation can be improved by providing additional points and badges as well as using incentive notifications. 
Correlation Between Ease of Use, User fun, and User Motivation. We assessed the user fun and motivation in order to address $\mathbf{R Q}_{4}$ as follows. We hypothesize that $\mathbf{H A}_{1}$ : There is a strong correlation between ease of use and fun. The null hypothesis is $\mathbf{H A}_{0}$ : There is no strong correlation between ease of use and fun. Additionally, we hypothesize that $\mathbf{H B}_{1}$ : There is a strong correlation between ease of use and motivation. The null hypothesis is $\mathbf{H B}_{0}$ : There is no strong correlation between ease of use and motivation. We have applied the Shapiro-Wilk test (57) to assess our data distributions. We have confirmed that our data is not normally distributed. Thus we decided to compute the Spearman's rank correlation coefficient (66). We considered a confidence interval of $95 \%$ ( $p$-value $<0.05$ ). As a result, we obtained a $p$-value $<0.05$ for Activities 2 and 3. Thus, the computed correlation has statistical significance for both activities.

Table 4.14 presents the correlation results. The first column lists the experiment activities. The second column presents the correlation between ease of use and fun. The third column presents the correlation between ease of use and motivation. We have categorized the correlation values according to a previous work (53): Very strong relationship (0.8 to 1.0 or -0.8 to -1.0 ); Strong relationship ( 0.6 to 0.8 or -0.6 to -0.8 ); Moderate relationship (0.4 to 0.6 or -0.4 to -0.6 ); Weak relationship ( 0.2 to 0.4 or -0.2 to -0.4 ); and Weak or no relationship (0.0 to 0.2 or 0.0 to -0.2 ).

Table 4.14: Spearman's Rank Correlation Results

\begin{tabular}{|l|rl|rl|}
\hline \multirow{2}{*}{ Activity } & \multicolumn{2}{|c|}{$\begin{array}{c}\text { Correlation(Ease, Fun) } \\
\text { Correlation }\end{array}$} & Category & Correlation(Ease, Motivation) \\
& Correlation & Category \\
\hline 1 & 0.3487773 & Weak & -0.0748679 & Weak \\
\hline 2 & 0.6512982 & Strong & 0.7672592 & Strong \\
\hline All & 0.6454658 & Strong & 0.5762920 & Moderate \\
\hline
\end{tabular}

Our results confirm $\mathrm{HA}_{1}$ for Activities 2 and 3. Thus, reporting and validating reports of mosquito breeding sites are both easy and fun to perform. Conversely, we reject $\mathrm{HA}_{1}$ (and confirm $\mathrm{HA}_{0}$ ) for Activity 1. It indicates an opportunity for making funnier and more challenging the avatar feature. We also confirmed $\mathrm{HB}_{1}$ for Activity 2, i.e., the report feature. This observation is relevant because the report feature is essential to support disease prevention. Unfortunately, we rejected $\mathrm{HB}_{1}$ (and confirmed $\mathrm{HB}_{0}$ ) for Activities 1 and 3 . We point out the moderate correlation between ease of use and motivation for Activity 3. These observations suggest improvements in Activities 1 and 3 .

The obviousness of Activity 1 made it very little or nothing motivating. However, Activity 1 is essential, because it opens doors for the user experience 
in the gamified application. Thus, since the positive correlations indicate that the easier, more fun and motivating and vice versa, one solution would be to add other game elements and rules in this activity. Regarding Activity 3, we could assign additional points and special badges to citizens who constantly validate reports of mosquito breeding sites. This improvement is necessary because the activity of validating report of mosquito breeding sites helps Brazilian public health agents to prioritize the control of reports of mosquito breeding sites since the validated location of the mosquito breeding site can guide most of the agents' daily work. The results of $\mathrm{RQ}_{4}$ complements the findings of $\mathrm{RQ}_{3}$ about the user fun and motivation of each activity and the need to improve Activities 1 and 3 .

Summary of $\mathbf{R Q}_{4}$. The activities of reporting and validating reports of mosquito breeding sites are both easy and fun to perform. Reports of mosquito breeding sites are both easy and motivation to perform. Regarding improvement opportunities, we observed that new game elements and game rules should be added in our gamification model to further promote citizens' motivation and fun.

Potential for the Constant Use. We answer $\mathbf{R Q}_{5}$ as follows. By the end of the experiment, we asked all citizens to inform whether they would use the VazaZika application again. As aforementioned (Section 4.2), we consider that the higher the number of citizens motivated to use again the application, the higher is the user engagement provided by the application. Table 4.15 presents the results of user engagement $\left(\mathrm{RQ}_{5}\right)$. The first column lists the four background characteristics under analysis. The second column lists the variations by characteristic. The third column presents the absolute and relative number of variations. The fifth and sixth columns present the rate of citizens motivated to use VazaZika again. Two out of 20 citizens did not respond about the use of video games in hours by week. We marked the data affected by this phenomenon in Table 4.15 with an "*". Overall, regardless the variations by characteristic, the citizens are highly motivated to use the VazaZika application. We present some citizen quotes about the user interface.

I found the system easy to use due to the interface simplicity - Citizen C05 about the user interface Validating the reported mosquito breeding sites was easy for me - Citizen C16 about validate activity 
Table 4.15: Constant Use and and System Dissemination

\begin{tabular}{|c|c|c|c|c|c|c|c|}
\hline Characteristics & Variations & & Number of Citizens & \multicolumn{2}{|c|}{ Use Again? } & \multicolumn{2}{|c|}{ Recommend? } \\
\hline \multirow{3}{*}{ Age } & $15-20$ & 6 & $30 \%$ & 5 & $83 \%$ & 4 & $67 \%$ \\
\hline & $21-25$ & 9 & $45 \%$ & 9 & $100 \%$ & 8 & $89 \%$ \\
\hline & $26-30$ & 5 & $25 \%$ & 5 & $100 \%$ & 5 & $100 \%$ \\
\hline \multirow{2}{*}{ Sex } & Male & 19 & $95 \%$ & 18 & $95 \%$ & 16 & $84 \%$ \\
\hline & Female & 1 & $5 \%$ & 1 & $100 \%$ & 1 & $100 \%$ \\
\hline \multirow{3}{*}{ Degree } & High school & 8 & $40 \%$ & 8 & $100 \%$ & 7 & $88 \%$ \\
\hline & $\mathrm{BS}$ & 11 & $55 \%$ & 10 & $91 \%$ & 9 & $82 \%$ \\
\hline & Specialization & 1 & $5 \%$ & 1 & $100 \%$ & 1 & $100 \%$ \\
\hline \multirow{2}{*}{ Mobile } & $\{$ Min, Mean $\}$ & 13 & $65 \%$ & 12 & $92 \%$ & 11 & $85 \%$ \\
\hline & $\{$ Mean, Max & 7 & $35 \%$ & 7 & $100 \%$ & 6 & $85 \%$ \\
\hline \multirow{2}{*}{ Game } & $\{$ Min, Mean $\}$ & 13 & $65 \%$ & 12 & $92 \%$ & 11 & $85 \%$ \\
\hline & $\{$ Mean, Max $\}$ & $*_{5}$ & $29.4 \%$ & $*_{5}$ & $100 \%$ & $*_{5}$ & $100 \%$ \\
\hline
\end{tabular}

Regarding Age (15-20), we observed a slightly lower rate (83\%) that suggests we should improve the VazaZika user interface for younger citizens. This might have been caused due to a serious user interface of the gamified mobile application. In fact, our color scheme does not refer to a flashy application, the majority of the screens use colors with dark tones. In this case, we could use brighter or bolder colors for elements to which we want to draw attention $(23,2)$. In addition, Visual Aesthetics resembles an information system, i.e., with few animations. In this case, in order to engage younger citizens to use the VazaZika again, aspects of the user interface related to Visual Aesthetics (ASP06) and Information Presentation (ASP10) presented in $\mathbf{R Q}_{1}$ could be improved. For instance, the addition of more representative icons and the use of a textual language more fun $(23,2)$.

Regarding Degree, we observed that citizens with High school were more motivated to use VazaZika again. Citizens with Bachelor degree presented a slightly lower rate (91\%) that also suggests an opportunity to improve the user interface. This might have been caused due to the complexity of certain activities, e.g., Activity 2 that is performed collaboratively using Challenge and Team, requiring more time to be accomplished. In this case, we could create challenges with a more specific goal. For instance, some team members before starting the Activity 2 are responsible for indicating at least 3 locations likely to have mosquito breeding sites. While other members are responsible for conducting the search in the indicated location. Thus, citizens can continue to report mosquito breeding sites collaboratively, but with a specific goal.

Summary of $\mathbf{R Q}_{5}$. Our results suggests that citizens are highly motivated to use the VazaZika mobile application again. This result implies a satisfactory user engagement with the application. The main improvement opportunities are: (i) using brighter or bolder colors for elements to which we want to draw attention and adding of more representative icons and 
the use of a textual language more fun (interface-related); and (ii) game elements and rules for reporting mosquito breeding sites (e.g., challenge and team) must be simplified through the interface and the addition of new game rules to our gamification model.

Potential for Disseminating. We answer $\mathbf{R Q}_{6}$ as follows. After performing all of the experiment activities (Activities 1 to 3), we asked the citizens whether they would recommend the VazaZika mobile application to their friends. Data in Table 4.15 summarizes the results collected from the citizens in the seventh and eighth columns. We present some citizen quotes about the user interface.

The application is a fun way to fight against mosquito breeding sites - Citizen

I found it very cool to compete with my friends - Citizen C13

As a result, we observed that most citizens would recommend the application to friends. However, in a particular case, the recommendation rates where lower than average: Age (15-20). This result sums up with the previous observations of $\mathrm{RQ}_{5}$ that the application requires some changes to be more attractive and enjoyable to citizens. One solution would be to add a new feature that allows the citizens to share the gamified mobile application to new users, e.g., a "download now" banner. Giving rewards for sharing that on social networks, such as Twitter and Facebook, we could motivate the user much more to disseminate the application.

Summary of $\mathbf{R Q}_{6}$. Our results also suggest that citizens are highly motivated to recommend the VazaZika mobile application with friends. This result implies a potential dissemination of the application with citizens. The main improvement opportunity is: adding new features into gamified application, and new game rules to our gamification model. 


\section{6}

\section{Towards a Holistic Assessment of Our Conceptual Gamification Model}

The evaluation of our gamification model presented in Section 4.5 was conducted only from the viewpoint of Brazilian citizens. We recognize that to fully evaluating our gamification model, make it necessary for conducting an additional evaluation from the viewpoint of public health agents. Since they are one of the stakeholders of our gamification model. Therefore, we emphasize that one of our ongoing work is to conduct a similar evaluation to that presented in this chapter, but with the participation of public health agents.

Another aspect of this additional evaluation is to evaluate the incorporation of our model into the VazaZika web application already implemented. By evaluating the incorporation of our model in both mobile and web applications, we can provide a more holistic assessment to understanding to what extent our model has helped to achieve the system gamification goals with respect to all six aspects evaluated in this chapter.

Potential Reuse for Gamifying Similar Healthcare Systems. We expect our gamification model has the potential to be further reused and adapted to similar healthcare systems in the domain of mosquito-related borne diseases prevention. In fact, in economically emerging countries such as Brazil, the existing healthcare systems for mosquito-related diseases prevention could incorporate our gamification model to promote a constant engagement of citizens and health public agents in preventing and combating diseases such as Dengue, Zika, and Chikungunya (27). We exemplify how an existing healthcare system could incorporate our gamification model as follows.

ContraDengue $^{1}$ is a mobile application developed by the government of Minas Gerais in order to allow the citizens report potential mosquito breeding sites, diseases cases, and make comments through Twitter or via email using the application. This information reported by the citizens is filtered and sent to the dengue control team, culminating in the collaboration of the government and the population in combating of Dengue, Zika, and Chikungunya. The ContraDengue application could implement our gamification model in order to incorporate all gamification goals reported in Table 4.1. For instance, the application could add game elements and rules to promote the constant report of mosquito breeding sites, so that tracking disease outbreaks and eliminating mosquito breeding sites become easier for the health agents.

\footnotetext{
${ }^{1}$ http://itunes.apple.com/br/app/contradengue/id487338743?mt=8
} 


\section{7 \\ Threats to Validity}

We discuss threats to the study validity (66) as follows.

Construct Validity. We carefully designed our study artifacts prior to the evaluation run. These artifacts include the study protocol (goal, research questions, and metrics) and the survey forms. Thus, we expect to avoid changing the study procedures as we run the experiment and analyzed the data. The forms were written by two researchers and validated by other two researchers. The validation has occurred in at least two rounds. We have designed the experiment in a crossover design (66) manner aimed to maximize the participation of each citizen. Especially, we designed experiment activities that involved all elements and rules of our gamification model. We know that assessing the gamification model through the user interface may be not the ideal means for capturing the effectiveness of all game elements and rules of our model. It is not trivial to fully assess the model in engaging user with the key system features. That is because, for instance, some game elements and rules incorporated by the system are not explicit to the system user through the system interface. However, assessing the user interface may reveal key aspects of the model, especially with respect to those game elements and rules that are visible and the user can directly interact with.

Internal Validity. We have followed strict procedures for running the experiment with citizens, so that all citizens could have a similar experience with the gamified application. We have collected the citizen background prior to the field experiment. Two instructors were trained and followed the field experiment, one per location. The citizens of one location were physically isolated from the ones of the other location in order to reduce biases in the validation of mosquito breeding sites. All citizens were trained about the experimental procedures. Additionally, we have addressed the doubts of citizens whenever possible.

Conclusion Validity. We carefully performed the quantitative and qualitative data analyses. We tabulated and validated all the extracted data in a pair. Thus, we expected to avoid missing and incorrect data. The analysis followed guidelines of descriptive data analysis (66). We computed the data distribution before applying the correlation tests. Thus, we aimed to mitigate statistical analysis biases. The qualitative data analysis was also well performed. We followed two Grounded Theory procedures (8): open and axial coding. All coding was performed by one researcher and validated by another researcher. We have solved ties and treated divergences through discussions. 
External Validity. We have counted on the participation of 20 Brazilian citizens in our experiment aimed to evaluate the VazaZika mobile application. Our citizen set is limited but diversified. Our application implements 12 game elements (e.g., points and rankings) and 16 game rules. The incorporated game elements are popularly adopted by successful gamified systems such as Duolingo and Waze. The same reasoning applies to the game rules, which have been inspired by these systems.

\section{8}

\section{Summary}

This chapter aimed at introducing and assessing a gamification model for gamifying healthcare systems in the domain of mosquito-borne disease prevention. For this purpose, we introduce our gamification model that is resulting from our gamification method presented in Chapter 3. Our gamification model aimed at: (i) addressing the need for constantly reporting mosquito breeding sites; (ii) promoting the collaborative work of citizens towards the disease prevention; and (iii) promoting a fruitful competition among citizens. We empirically evaluated our gamification model with 20 citizens by assessing the VazaZika mobile application under six aspects: (i) user interface; (ii) ease of use; (iii) fun; (iv) motivation; (v) potential for the constant use of key system features; and (vi) potential for disseminating the system use among citizens.

Our results suggest that our model is promising with respect to all these six aspects. These findings suggest our gamification model has the potential of truly engaging users with critical healthcare-related features, e.g., mosquito breeding site report and validation. We expect our gamification model has the potential to be further reused and adapted to similar healthcare systems in the domain of mosquito-borne disease prevention. In the next chapter, we revisit the main Master's dissertation contributions and present new challenges and opportunities for improvement and future work that have emerged along the studies conducted in the context of this Master's dissertation. 


\section{5}

\section{Conclusion and Future Work}

In this Master's dissertation, we have exploited software gamification in the context of a healthcare software system. Software gamification consists of using game elements (e.g., points) and rules into conventional software systems for engaging users with key system features (12). Particularly, we have conducted a series of empirical studies aimed to leverage the current software engineering practices for supporting the gamification of existing systems. In fact, there is an increasing demand for gamifying systems that were previously implemented without gamification in mind $(55,58)$.

Unfortunately, there is no systematic method aimed to guide development teams in gamifying their existing systems. Thus, developers may struggle with performing key gamification activities, just as it happened to us while gamifying the VazaDengue healthcare system. Additionally, there are only a few gamification models aimed to guide the incorporation of game elements and rules into existing systems that actually need to be boosted through gamification. This is the case of healthcare systems for preventing mosquito-borne diseases, such as Zika, Dengue, and Chikungunya (27). Such lack of supporting gamification models has led us to rework when gamifying VazaDengue.

Aimed to address the aforementioned limitations, this dissertation presented two complementary empirical studies. Our first study consisted of a participatory action research aimed to refine an existing gamification method (40) in order to properly support the gamification of existing systems. This action research was composed of a self-observational study (17) and an interviewbased study (66). With this research, we expected to collect as much evidence as possible to refine, validate, and demonstrate the feasibility of our method in a real gamification context (the VazaDengue case).

Our second study aimed to evaluate a gamification model designed to support the engagement of users with the prevention of mosquito-borne diseases. This model was incorporated by the gamified version of VazaDengue. We have performed a controlled experiment with 20 Brazilian citizens to understand how promising is our gamification model in engaging people with key healthcare activities, such as reporting mosquito breeding sites.

This chapter summarizes the major contributions of this Master's dis- 
sertation. We discuss how we have contributed to the Software Engineering community through a novel method and a new gamification model for a particular domain of healthcare systems (Section 5.1). We also have the potential of our work in contributing to the Brazilian public healthcare policies (Section 5.2). Finally, we provide the community with a variety of suggestions for future work (Section 5.3) based on the contributions of this dissertation.

\section{1}

\section{Contributions to Software Engineering Community}

This dissertation targeted an emerging problem in software engineering: the gamification of existing software systems. We employed our best effort in contributing to assets and insights for both researchers and practitioners. To the best of our knowledge, we performed the very first studies aimed to: (i) introduce a systematic method to guiding development teams along the gamification of existing systems based on an empirical methodology; (ii) reveal the development activities that become challenging along the gamification of existing software systems based on a practical experience (with the VazaDengue system, in our case); and (iii) introduce a gamification model aimed to guide the incorporation of game elements and rules into healthcare systems aimed to prevent mosquito-borne diseases, such as Zika, Dengue, and Chikungunya. We summarize each contribution as follows.

Contribution 1: A refined method to support the gamification of existing systems. A gamification method, as any other, aims to guide developers to perform systematically a set of activities along specific phases during software gamification. For this purpose, we built a new gamification method based on successive experience-based refinements. In total, we refined 25 activities from a previously proposed method to meet the key needs of gamifying an existing system. Our method successfully supported the VazaDengue gamification. By introducing a new gamification method, we expect to guide development teams in gamifying their existing systems. Thus, developers, who face problems to know what to do and when each activity needed to be performed, can use our method as a guide, similarly to was the done in the VazaDengue gamification.

Contribution 2: An experience report of gamifying an existing system. By reporting our experience with the incorporation of game elements and rules into an existing system from this nature, we aim to provide the software engineering research community with a better understanding about the gamification process of an existing system. Especially, we aim to reveal how challenging the gamification of an existing system might be, from the early 
requirements elicitation to the system implementation and testing.

Contribution 3: A conceptual gamification model to healthcare systems. Conceptual gamification model aims to define the interactions of system users and game elements into the system through game rules $(18,61)$. The definition of a gamification model guides developers to reason about how game elements and rules should be incorporated into the gamified system. In this context, to the best of our knowledge, we defined the first gamification model for guiding the gamification of the healthcare systems in the domain of prevention of mosquito-borne diseases. We built our model based on our gamification method. Our model has successfully guided the incorporation of game elements and rules into VazaDengue healthcare system in practice. Especially, through an empirical study with 20 citizens, we confirmed that the gamification model that underlies our mobile application actually engages users with potential system dissemination. We expected that other researchers or developers could extend our gamification model by adding up rules for other stakeholders, such as institutions and health authorities. We also expect that our model could guide the gamification of similar healthcare systems (Section 4.6).

\section{2}

\section{Contribution to the Brazilian Public Healthcare Policies}

This dissertation also targeted supporting the Brazilian public healthcare policies: a gamified healthcare system to engage citizens with the prevention of mosquito-borne diseases. We employed our best effort to leverage the Brazilian citizen's engagement with critical healthcare-related features, e.g., reporting mosquito breeding sites. We have incorporated 12 game elements and 16 rules into an existing healthcare system called VazaDengue (17). As a result, we have developed and introduced the VazaZika healthcare system (a gamified version of the VazaDengue).

VazaZika aims to address the need for constantly reporting mosquito breeding sites, promoting the collaborative work of citizens towards the disease prevention, promoting a fruitful competition among citizens, and improving the quality of reported mosquito breeding sites through game elements and rules that reward citizens by reporting valid information. We summarize our contribution to the Brazilian public healthcare policies as follows.

Contribution 1: VazaZika gamified healthcare system to engage citizens with disease prevention. The citizen engagement in reporting mosquito breeding sites is hard to achieve but essential in preventing disease outbreaks. By evolving an existing healthcare system, we contribute with a new pub- 
lic healthcare solution. This solution combines gamification and geolocation to leverage the citizen engagement to support the prevention and control of mosquito-borne diseases such as Zika, Dengue, and Chikungunya. In addition, the solution provides different types of feedback to citizens: 1) about the actions taken by public health agents regarding the status of the mosquito breeding sites; and 2) about feedback about the information quality of the reported mosquito breeding sites.

\section{3}

\section{Future Work}

New challenges and opportunities for improvement have emerged along the studies conducted in the context of this dissertation. Based on them, we present further directions for future work as follows.

Future work 1: Conducting empirical studies in industrial settings. Our gamification method was built on practical experience along gamifying an existing system. However, we do not know the possible effects of our method in industrial settings. Future work could explore the application of our method in other system domains, as well as organizations with different settings and from different countries. Given the context of our VazaZika research project, the developer's expertise in software gamification as well as the employed development practices may have affected the perception of the key activities required for gamifying existing systems. Thus, our method certainly suffers from these influences. Thus, there are many possibilities for conducting case studies in industrial settings in order to further refine and improve our method.

Future work 2: Guiding developers along with the implementation and testing of gamified systems. Our gamification method aims to guide the developers to gamify their existing systems from the system preparation to software design. However, our gamification method does not provide support for activities of implementation and testing of gamified systems. Thus, future work could extend our gamification method to guide developers along with the activities for writing, validating and testing source code.

Future work 3: Improving software engineering practices for gamifying existing systems. From our empirically-derived knowledge on the gamification of existing systems, we observed that the gamification design inspection and implementation are two of the most critical software engineering phases along the gamification of existing systems. Thus, future work could provide better support for developers along these two specific phases.

Future work 4: Extending the current knowledge on gamification-driven 
challenging activities. Unfortunately, the challenging activities elicited from our interview-based study reflect a very specific practical experience. Due to the limited context in which challenging activities have been derived, the practical experience of the VazaZika developers may have represented a limited spectrum on software gamification. Thus, future work could extend the current knowledge on gamification-driven activities with professional developers that already gamified existing systems. By understanding what development activities were challenging along the gamification of different existing systems, we will able to better understand the different natures of challenging activities along the gamification of existing systems.

Future work 5: Extending the conceptual gamification model. From our experimental study with citizens, we observed different opportunities for improving our conceptual gamification model in terms of certain aspects. Thus, future work could improve our model based on the limitations observed in the study with citizens. For instance, the addition of new game rules to interact with the Avatar game element could lead to a better engagement of citizens. Currently, our model aims to assist two stakeholders, i.e., citizens and public health agents. Thus, another future work could extend our gamification model by adding up game elements and rules for other stakeholders, such as health institutions and authorities. Our model targets the domain of mosquito-borne diseases prevention, in particular diseases transmitted by the Aedes aegypti such as Zika, Dengue, and Chikungunya. Thus, future work could extend our gamification model to support other disease types, such as Malaria. Malaria is an infectious disease transmitted by the Anopheles mosquito, whose prevention requires other activities than reporting and validation of mosquito breeding sites, e.g., monitoring the treatment of the disease.

Future work 6: Assessing the conceptual gamification model with public health agents. Our conceptual gamification model aims to assist two stakeholders, i.e., citizens and public health agents. However, we do not conduct an assessment from the viewpoint of public health agents. Thus, future work could conduct an assessment similar to the experimental study presented in Chapter 4 of our gamification model with public health agents. 


\section{Bibliography}

[1] AlLAM, A.; KOSTOVA, Z.; NAKAMOTO, K. ; SCHULZ, P. J.. The effect of social support features and gamification on a Web-based intervention for rheumatoid arthritis patients: Randomized controlled trial. Journal of Medical Internet Research (JMIR), 17(1):e14, 2015.

[2] BARBOSA, S.; SILVA, B.. Interação Humano-Computador. Elsevier, 1st edition, 2010. (In Portuguese).

[3] BARCELLOS, C.; QUITÉRIO, L. A.. Environmental surveillance in health in Brazil's Unified Health System. Revista de Saúde Pública (RSP), 40(1):170-177, 2006.

[4] BOSU, A.; CORLEY, C.; HEATON, D.; CHATTERJI, D.; CARVER, J. ; KRAFT, N.. Building reputation in stackoverflow: An empirical investigation. In: PROCEEDINGS OF THE 10TH INTERNATIONAL CONFERENCE ON MINING SOFTWARE REPOSITORIES (MSR), p. 8992, 2013.

[5] BRENDER, J.; AMMENWERTH, E.; NYKÄNEN, P. ; TALMON, J.. Factors influencing success and failure of health informatics systems. Methods of Information in Medicine, 45(1):125-136, 2006.

[6] CAFAZZO, J.; CASSElMAN, M.; HAMMING, N.; KATZMAN, D. ; PALMERT, M.. Design of an mHealth app for the self-management of adolescent type 1 diabetes: A pilot study. Journal of Medical Internet Research (JMIR), 14(3):e70, 2012.

[7] CODECO, C.; CRUZ, O.; RIBACK, T.; DEGENER, C.; GOMES, M.; VILLELA, D.; BASTOS, L.; CAMARGO, S.; SARACENI, V.; LEMOS, M. C. ; COELHO, F.. InfoDengue: A nowcasting system for the surveillance of Dengue fever transmission. BioRxiv, p. 1-24, 2016.

[8] CORBIN, J.; STRAUSS, A.. Basics of Qualitative Research: Techniques and Procedures for Developing Grounded Theory. Thousand Oaks, 3rd edition, 2008. 
[9] DE LOPE, R.; MEDINA-MEDINA, N.. Using UML to model educational games. In: PROCEEDINGS OF THE 8TH INTERNATIONAL CONFERENCE ON GAMES AND VIRTUAL WORLDS FOR SERIOUS APPLICATIONS (VS-GAMES), p. 1-4, 2016.

[10] DE MELLO, R.; UCHÔA, A.; OLIVEIRA, R.; TENORIO, D.; FONSECA, B.; GARCIA, A. ; DE MELLO, F.. Investigating the social representations of code smell identification: A preliminary study. In: 12TH INTERNATIONAL WORKSHOP ON COOPERATIVE AND HUMAN ASPECTS OF SOFTWARE ENGINEERING (CHASE), p. 1-8. IEEE, 2019.

[11] DE OLIVEIRA JÚNIOR, J.; TUBELO, R.; GRADELLA, G.; PADILHA, J.; ZANATTA, E. J.; PORTELlA, F.; DE OlIVEIRA, A. E.; PINTO, M. E. ; DAHMER, A.. Informational design applied to graphical interface development of a serious game intending to fight Aedes aegypti. Brazilian Journal of Telehealth, 4(2):246-254, 2016. (In Portuguese).

[12] DETERDING, S.; DIXON, D.; KHALED, R. ; NACKE, L.. From game design elements to gamefulness: Defining gamification. In: PROCEEDINGS OF THE 15TH INTERNATIONAL TECHNOLOGY CONFERENCE (MINDTREK), p. 9-15, 2011.

[13] DETERDING, S.; BJÖRK, S. L.; NACKE, L. E.; DIXON, D. ; LAWLEY, E.. Designing gamification: Creating gameful and playful experiences. In: PROCEEDINGS OF THE 31ST CONFERENCE ON HUMAN FACTORS IN COMPUTING SYSTEMS (CHI): EXTENDED ABSTRACTS, p. 3263-3266, 2013.

[14] DYBÅ, T.; DINGS $\varnothing Y R$, T.. Empirical studies of agile software development: A systematic review. Information and software technology, 50(9-10):833-859, 2008.

[15] EASTERBROOK, S.; SINGER, J.; STOREY, M.-A. ; DAMIAN, D.. Selecting empirical methods for software engineering research. In: GUIDE TO ADVANCED EMPIRICAL SOFTWARE ENGINEERING, p. 285311. Springer, 2008.

[16] ELDEN, M.; CHISHOLM, R.. Emerging varieties of action research: Introduction to the special issue. Human Relations, 46(2):121-142, 1993.

[17] EMERSON, R.; FRETZ, R. ; SHAW, L.. Participant observation and fieldnotes. Handbook of Ethnography, p. 352-368, 2001. 
[18] FERNANDES, E.; UCHÔA, A.; SOUSA, L.; OLIVEIRA, A.; DE MELLO, R.; BARROCA, L. P.; CARVALHO, D.; GARCIA, A.; FONSECA, B. ; TEIXEIRA, L.. VazaZika: A software platform for surveillance and control of mosquito-borne diseases. In: PROCEEDINGS OF THE 16TH INTERNATIONAL CONFERENCE ON INFORMATION TECHNOLOGY: NEW GENERATIONS (ITNG), p. 1-4, 2019.

[19] FERNANDES, E.; UCHÔA, A.; BIBIANO, A. C. ; GARCIA, A.. On the Alternatives for Composing Batch Refactoring. In: PROCEEDINGS OF THE 3RD INTERNATIONAL WORKSHOP ON REFACTORING (IWOR), p. 1-4. IEEE, 2019.

[20] FERREIRA, I.; FERNANDES, E.; CEDRIM, D.; UCHÔA, A.; BIBIANO, A. C.; GARCIA, A.; CORREIA, J. L.; SANTOS, F.; NUNES, G.; BARBOSA, C.; FONSECA, B. ; DE MELLO, R.. The buggy side of code refactoring: Understanding the relationship between refactorings and bugs. In: PROCEEDINGS OF THE 40TH INTERNATIONAL CONFERENCE ON SOFTWARE ENGINEERING: COMPANION PROCEEEDINGS, p. 406-407. ACM, 2018.

[21] FIORINI, S.; SOUSA, L.; CEDRIM, D.; GARCIA, A.; MUCHALUAT-SAADE, D. C.; MORAES, I. ; FRAJHOF, L.. Vigilância entomológica da Dengue, Zika e Chikungunya: Uma soluçao baseada em redes sociais e dispositivos móveis. In: PROCEEDINGS OF THE 16TH WORKSHOP ON MEDICAL INFORMATICS (WIM), p. 2567-2576, 2016. (In Portuguese).

[22] FONSECA, M.; DOS SANTOS JÚNIOR, G.; FONTES, L. ; SOUSA, T.. Zika Gamification: Mobile application for endemic disease control agents training. In: PROCEEDINGS OF THE 17TH WORKSHOP ON MEDICAL INFORMATICS (WIM), p. 1921-1930, 2017. (In Portuguese).

[23] GARRETT, J.. The Elements of User Experience: User-Centered Design for the Web and Beyond. New Riders, 2nd edition, 2010.

[24] GRUDIN, J.; PRUITT, J.. Personas, participatory design and product development: An infrastructure for engagement. In: PROCEEDINGS OF THE 7TH PARTICIPATORY DESIGN CONFERENCE (PDC), p. 144-152, 2002.

[25] GUERRA, E.; FORNARI, G.; COSTA, W.; PORTO, S.; CANDIA, M. ; DA SILVA, T.. An approach for modularizing gamification con- 
cerns. In: PROCEEDINGS OF THE 17TH INTERNATIONAL CONFERENCE ON COMPUTATIONAL SCIENCE AND ITS APPLICATIONS (ICCSA), p. 635-651, 2017.

[26] GUSTAFSSON, A.; KATZEFF, C. ; BANG, M.. Evaluation of a pervasive game for domestic energy engagement among teenagers. Computers in Entertainment (CIE), 7(4):54:1-54:19, 2009.

[27] GYAWALI, N.; BRADBURY, R. ; TAYLOR-ROBINSON, A.. The global spread of Zika virus: Is public and media concern justified in regions currently unaffected? Infectious Diseases of Poverty (IDP), 5(1):37:1-37:6, 2016.

[28] HANLON, J.. Five years ago, stack overflow launched. then, a miracle occurred. Available at Stack Overflow Blog: https://stackoverflow.blog/2013/09/16/five-years-ago-stack-overflowlaunched-then-a-miracle-occurred/, 2013.

[29] HERZIG, P.; AMELING, M. ; SCHILL, A.. A generic platform for enterprise gamification. In: PROCEEDINGS OF THE 10TH WORKING CONFERENCE ON SOFTWARE ARCHITECTURE (WICSA), p. 219-223, 2012.

[30] HSU, S.; CHANG, J.-W. ; LEE, C.-C.. Designing attractive gamification features for collaborative storytelling websites. Cyberpsychology, Behavior, and Social Networking, 16(6):428-435, 2013.

[31] ISO/IEC. Iso/iec 25010 - systems and software engineering - systems and software quality requirements and evaluation (square) - system and software quality models. Technical report, International Organization for Standardization, Geneva, Switzerland, 2011.

[32] JAMIESON, S.. Likert scales: How to (ab) use them. Medical Education, 38(12):1217-1218, 2004.

[33] JIN, Y.; YANG, X.; KULA, R.; CHOI, E.; INOUE, K. ; IIDA, H.. Quick trigger on stack overflow: A study of gamification-influenced member tendencies. In: PROCEEDINGS OF THE 12TH INTERNATIONAL CONFERENCE ON MINING SOFTWARE REPOSITORIES (MSR), p. 434437, 2015.

[34] KARDAN, A.; ARANI, A.. A novel gamification-based architecture for web environments. In: PROCEEDINGS OF THE 2ND INTERNATIONAL CONFERENCE ON WEB RESEARCH (ICWR), p. 125-130, 2016. 
[35] LIMA, T.; BARBOSA, B.; NIQUINI, C.; ARAÚJO, C. ; LANA, R.. Playing against dengue design and development of a serious game to help tackling Dengue. In: PROCEEDINGS OF THE 5TH INTERNATIONAL CONFERENCE ON SERIOUS GAMES AND APPLICATIONS FOR HEALTH (SEGAH), p. 1-8, 2017.

[36] MARACHE-FRANCISCO, C.; BRANGIER, E.. Process of gamification: From the consideration of gamification to its practical implementation. In: PROCEEDINGS OF THE 6TH INTERNATIONAL CONFERENCE ON ADVANCES IN HUMAN ORIENTED AND PERSONALIZED MECHANISMS, TECHNOLOGIES, AND SERVICES (CENTRIC), p. 126131, 2013.

[37] MARTINS, J.; BEZERRA, C. ; UCHÔA, A.. Analyzing the impact of inter-smell relations on software maintainability: An empirical study with software product lines. In: PROCEEDINGS OF THE 15TH BRAZILIAN SYMPOSIUM ON INFORMATION SYSTEMS (SBSI), p. 1-8. ACM, 2019.

[39] MORA, A.; RIERA, D.; GONZÁLEZ, C. ; ARNEDO-MORENO, J.. Gamification: A systematic review of design frameworks. Journal of Computing in Higher Education (JCHE), 29(3):516-548, 2017.

[40] MORSCHHEUSER, B.; HASSAN, L.; WERDER, K. ; HAMARI, J.. How to design gamification? A method for engineering gamified software. Information and Software Technology (IST), 95:219-237, 2018.

[41] MUNTEAN, C. I.. Raising engagement in e-learning through gamification. In: PROCEEDINGS OF THE 6TH INTERNATIONAL CONFERENCE ON VIRTUAL LEARNING (ICVL), p. 1-7, 2011.

[42] O'SULLIVAN, T.; CORNEIL, W.; KUZIEMSKY, C. ; LANE, D.. Citizen participation in the specification and mapping of potential disaster assets. In: PROCEEDINGS OF THE 10TH INTERNATIONAL CONFERENCE ON INFORMATION SYSTEMS FOR CRISIS RESPONSE AND MANAGEMENT (ISCRAM), p. 890-895, 2013.

[43] OMG. Business Process Model and Notation (BPMN). Technical report, Object Management (OMG), Inc., 01 2011. version 2.0.

[44] OSTERWALDER, A.; PIGNEUR, Y.. Business model generation: A handbook for visionaries, game changers, and challengers. John Wiley \& Sons, 1st edition, 2010. 
[45] PEDREIRA, O.; GARCÍA, F.; BRISABOA, N. ; PIATTINI, M.. Gamification in software engineering: A systematic mapping. Information and Software Technology (IST), 57:157-168, 2015.

[46] PEREIRA, P.; DUARTE, E.; ReBelO, F. ; NORIEGA, P.. A review of gamification for health-related contexts. In: PROCEEDINGS OF THE 4TH INTERNATIONAL CONFERENCE ON DESIGN, USER EXPERIENCE AND USABILITY (DUXU), p. 742-753, 2014.

[47] PeTersen, K.; GenCEL, C.; ASGHARI, N.; BACA, D. ; BeTZ, S.. Action research as a model for industry-academia collaboration in the software engineering context. In: PROCEEDINGS OF THE 14TH INTERNATIONAL WORKSHOP ON LONG-TERM INDUSTRIAL COLLABORATION ON SOFTWARE ENGINEERING (WISE), p. 55-62, 2014.

[48] POLO, M.; PIATTINI, M. ; RUIZ, F.. Using a qualitative research method for building a software maintenance methodology. Software: Practice and Experience (S:P\&E), 32(13):1239-1260, 2002.

[49] REFAIE, E. E.. Understanding visual metaphor: The example of newspaper cartoons. Visual Communication, 2(1):75-95, 2003.

[50] RODRIGUES, L. F.; COSTA, C. ; OLIVEIRA, A.. Gamification: A framework for designing software in e-banking. Computers in Human Behavior, 62:620-634, 2016.

[51] ROJAS, J. M.; WHITE, T.; CLEGG, B. ; FRASER, G.. Code Defenders: Crowdsourcing effective tests and subtle mutants with a mutation testing game. In: PROCEEDINGS OF THE 39TH INTERNATIONAL CONFERENCE ON SOFTWARE ENGINEERING (ICSE), p. 677-688, 2017.

[52] RUNESON, P.; HÖST, M.. Guidelines for conducting and reporting case study research in software engineering. Empirical Software Engineering (EMSE), 14(2):131-164, 2009.

[53] SALKIND, N.. Exploring Research. Pearson Education, 8th edition, 2012.

[54] SARDI, L.; IDRI, A. ; FERNÁNDEZ-ALEMÁN, J. L.. A systematic review of gamification in e-health. Journal of Biomedical Informatics, 71:31-48, 2017.

[55] SCHACHT, M.; SCHACHT, S.. Start the game: Increasing user experience of enterprise systems following a gamification mechanism. In: SOFTWARE FOR PEOPLE, p. 181-199. Springer, 2012. 
[56] SCHWABER, K.; BEEDLE, M.. Agile software development with Scrum. Prentice Hall, 2002.

[57] SHAPIRO, S.; WILK, M.. An analysis of variance test for normality (complete samples). Biometrika, 52(3/4):591-611, 1965.

[58] SWACHA, J.. Gamification in enterprise information systems: What, why and how. In: PROCEEDINGS OF THE 11TH FEDERATED CONFERENCE ON COMPUTER SCIENCE AND INFORMATION SYSTEMS (FEDCSIS), p. 1229-1233, 2016.

[58] SOUSA, L.; DE MELLO, R.; CEDRIM, D.; GARCIA, A.; MISSIER, P.; UCHÔA, A.; OLIVEIRA, A. ; ROMANOVSKY, A.. VazaDengue: An information system for preventing and combating mosquitoborne diseases with social networks. Information Systems (IS), 75:2642, 2018.

[60] TAUSWORTHE, R.. The work breakdown structure in software project management. Journal of Systems and Software (JSS), 1:181186, 1979.

[61] UCHÔA, A.; FERNANDES, E.; FONSECA, B.; DE MELLO, R.; BARBOSA, C.; NUNES, G.; GARCIA, A. ; TEIXEIRA, L.. On gamifying an existing healthcare system: Method, conceptual model and evaluation. In: PROCEEDINGS OF THE 1ST INTERNATIONAL WORKSHOP ON SOFTWARE ENGINEERING FOR HEALTHCARE (SEH), p. 1-8, 2019.

[62] UCHÔA, A.; FERNANDES, E.; BIBIANO, A. C. ; GARCIA, A.. Do coupling metrics help characterize critical components in componentbased spl? an empirical study. In: PROCEEDINGS OF THE 5TH WORKSHOP ON SOFTWARE VISUALIZATION, EVOLUTION AND MAINTENANCE (VEM), p. 36-43, 2017.

[63] WERBACH, K.; HUNTER, D.. For the win: How game thinking can revolutionize your business. Wharton Digital Press, 1st edition, 2012.

[64] WINTER, A.; HAUX, R.; AMMENWERTH, E.; BRIGL, B.; HELLRUNG, N. ; JAHN, F.. Health information systems. In: HEALTH INFORMATION SYSTEMS, p. 33-42. Springer, 2010.

[65] WITT, M.; SCHEINER, C. ; ROBRA-BISSANTZ, S.. Gamification of online idea competitions: Insights from an explorative case. Proceedings of the 41st Annual Meeting of the Society for Computer Science (INFORMATIK), p. 392-406, 2011. 
[66] WOHLIN, C.; RUNESON, P.; HÖST, M.; OHLSSON, M.; REGNELL, B. ; WESSLÉN, A.. Experimentation in Software Engineering. Springer Science \& Business Media, 1st edition, 2012.

[67] ZICHERMANN, G.; LINDER, J.. Game-based Marketing: Inspire Customer Loyalty through Rewards, Challenges, and Contests. John Wiley \& Sons, 2010.

[68] ZICHERMANN, G.; CUNNINGHAM, C.. Gamification by Design: Implementing Game Mechanics in Web and Mobile Apps. O'Reilly Media, 2011.

[69] ZUCKERMAN, O.; GAL-OZ, A.. Deconstructing gamification: Evaluating the effectiveness of continuous measurement, virtual rewards, and social comparison for promoting physical activity. Personal and Ubiquitous Computing, 18(7):1705-1719, 2014. 


\section{A}

\section{Appendix A: Participant Characterization Form}

This appendix presents the participant characterization form used in the study reported in Chapter 3. 


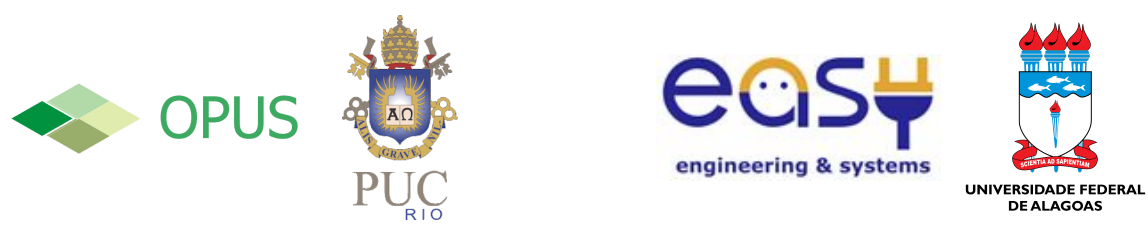

Participant Characterization Form

This questionnaire aims at characterizing the interviewees of a study about challenging activities faced during gamification of the VazaZika software gamification, which comprises a Web and two mobile applications. Besides the basic personal data of interviewees, we collect the interviewees' background about experience in software development and the development activities that they have participation either before or during the VazaZika gamification.

All data will be analyzed by the study conductors only. Your answers will be exclusively used for the study purposes, and your identity will be kept anonymous. By filling this form, we assume that you have accepted participating as an interviewee of our study and agree with our terms, as described in the Consent Form which you have signed.

Thank you in advance for your participation!

\section{Personal Data}

1. Full name:

2. Highest education level: ( ) High school ( ) BS ( ) MSc ( ) PhD ( ) Postdoc ( )

3. Are you currently working with software development in the industry?

( ) Yes ( ) No

\section{General Experience}

4. Years of experience with software development (academia and industry):

5. Number of software projects you have worked on: 

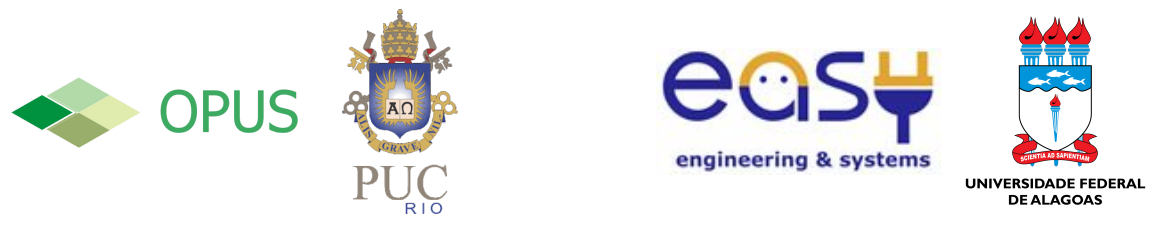

\section{Background}

6. How do you classify your level of knowledge with respect to the following techniques?
a. Gamification
( ) Very high
( ) Very low
( ) None
( ) High
( ) Low

b. Software Testing
( ) Very high
( ) Very low
( ) None
( ) High
( ) Low

c. Requirements Engineering
( ) Very high
( ) Very low
( ) High
( ) Low
( ) None

d. Web development
( ) Very high
( ) Very low
( ) None
( ) High
( ) Low

e. Mobile development
( ) Very high
( ) Very low
( ) None
( ) High
( ) Low
f. Architectural design
( ) Very high
( ) Very low
( ) High
( ) Low 


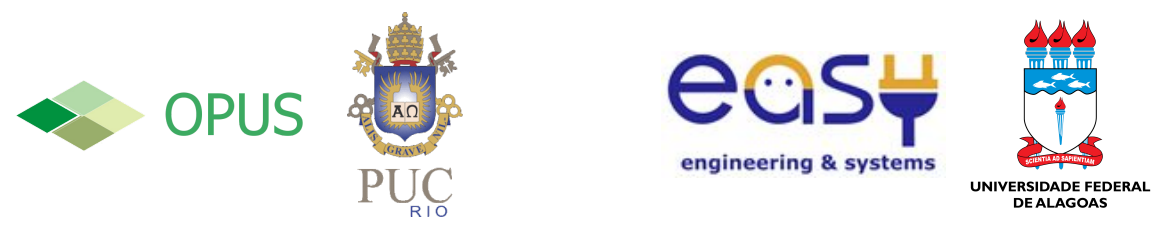
g. Game design
( ) Very high
( ) Very low
( ) None
( ) High
( ) Low

h. Service-oriented development
( ) Very high
( ) Very low
( ) None
( ) High
( ) Low

7. Regarding the VazaDengue and VazaZika projects, please tick the software development phases that you have been involved in?

\begin{tabular}{|l|c|c|}
\hline \multicolumn{1}{|c|}{ Phases } & VazaDengue & VazaZika \\
\hline Idealization & {$[$ ] } & [ ] \\
\hline Requirement elicitation & {$[$ ] } & {$[$ ] } \\
\hline Gamification design & {$[$ ] } & {$[$ ] } \\
\hline Architectural design & {$[$ ] } & {$[$ ] } \\
\hline Web back-end development & {$[$ ] } & {$[$ [ ] } \\
\hline Web front-end development & {$[$ ] } & {$[$ ] } \\
\hline Mobile back-end development & {$[$ ] } & {$[$ ] } \\
\hline Mobile front-end development & {$[$ ] } & {$[$ ] } \\
\hline Testing & {$[$ ] } & \\
\hline
\end{tabular}


B

\section{Appendix B: Interview Script}

This appendix presents the interview script used in the study reported in Chapter 3. 


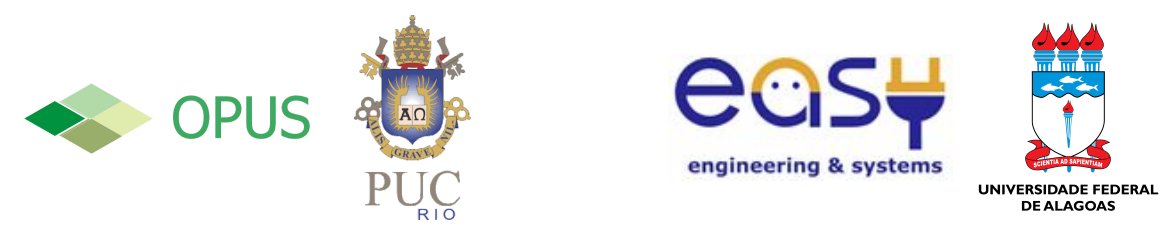

Interview Script

1. Participant Characterization

A. How long have you been involved with the VazaZika project since its start?

B. What phases of the VazaZika gamification you have been involved in?

\section{General question}

C. Did you face any challenge while participating in the gamification of VazaZika?

\section{Specific questions per challenging activity}

D. Along the VazaZika gamification, when did you have to face this challenging activity?

E. Did you find any solution for this challenging activity?

F. What techniques you have applied to address this challenging activity?

G. For each technique, why did you decide to use those techniques?

\section{Retrospective question per challenging activity}

Analyzing in retrospect your participation in gamification of VazaZika...

H. Do you think you could have applied an alternative solution?

I. Would you use other techniques than the applied ones? 
C

\section{Appendix C: Elicited Gamified Systems}

This appendix presents the list of elicited gamified systems reported in Chapter 4. 

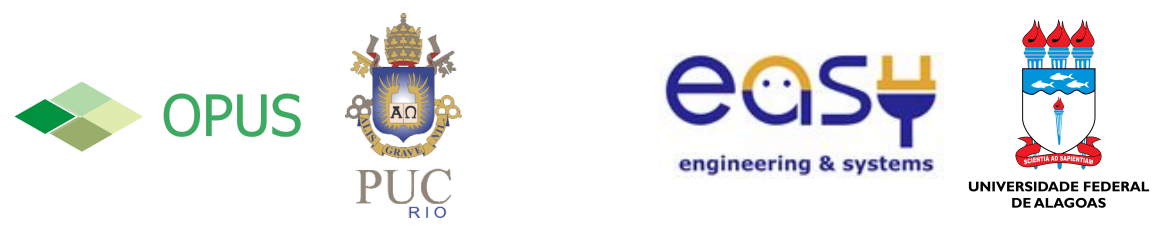

\section{ELICITED GAMIFIED SYSTEMS}

\begin{tabular}{|l|l|}
\hline \multicolumn{1}{|c|}{ System } & \multicolumn{1}{c|}{ Link } \\
\hline Duolingo & https://www.duolingo.com \\
\hline Facebook & https://www.facebook.com \\
\hline Foursquare & https://foursquare.com \\
\hline GitHub & https://github.com \\
\hline Nike+ Running & https://www.nike.com.br/corrida/nrc \\
\hline Stack Overflow & https://stackoverflow.com \\
\hline Steam & https://store.steampowered.com \\
\hline Swarm & https://www.swarmapp.com \\
\hline Uber & https://www.uber.com \\
\hline Waze & https://www.waze.com \\
\hline
\end{tabular}


D

\section{Appendix D: Consent Form}

This appendix presents the consent form used in the study reported in Chapter 4. 


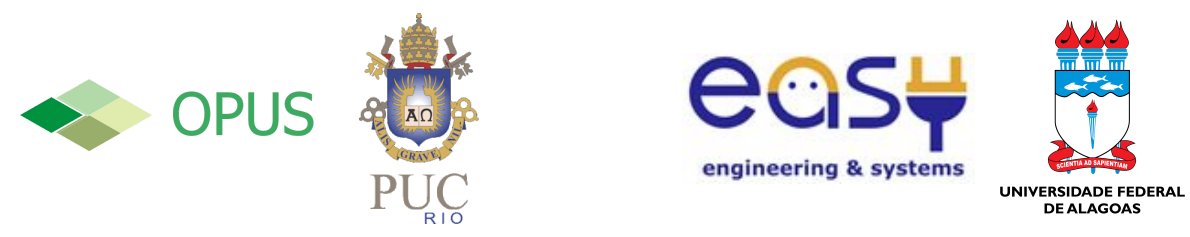

\title{
CONSENT FORM
}

You are invited to participate in an experiment conceived in the context of the research project entitled "Leveraging Gamification and Social Networks for Improving Prevention and Control of Zika". By participating in the experiment, you will be one of the first users of the VazaZika application, and you will help us in extracting the first experiment results about the application. This experiment is proposed by Pontifical Catholic University of Rio de Janeiro (PUC-Rio) in collaboration with Federal University of Alagoas (UFAL). Along the experiment, you will use the VazaZika application to help in combating diseases such as Zika, Dengue, and Chikungunya. In the experiment, researchers from PUC-Rio and UFAL will collect data about your profile and your use experience with VazaZika in the UFAL facilities.

If you agree in participating in the experiment, you will use VazaZika before others and contribute with the research conducted by PUC-Rio and UFAL. You are allowed to ask any researcher responsible for the experiment to address your eventual doubts. You participate as a volunteer and refusing to participate will not cost you any penalty or loss. You can interrupt your participation at any time during the experiment conduction, if you want it. Participating in the experiment does not cause any harm to your physical and moral integrity. Your sensitive information will be kept anonymous and it will be shared with third-parties only under your explicit consent.

This consent form is printed in two copies: one copy will be stored by the researchers responsible for the experiment of the Informatics Department at PUC-Rio; the other copy will be given to you for your records. Data and artifacts used by this research will be stored by the researchers for a period equals five (5) years and, after this period, data and artifacts will be destroyed. If you have any questions about the experiment, please send an email to one of the researchers in up to fifteen (15) working days after the experiment conduction in UFAL.

\author{
Anderson Gonçalves Uchôa - auchoa@inf.puc-rio.br \\ Eduardo Fernandes - emfernandes@inf.puc-rio.br \\ Alessandro Fabricio Garcia - afgarcia@inf.puc-rio.br \\ Baldoino Fonseca dos Santos Neto - baldoino@ic.ufal.br
}




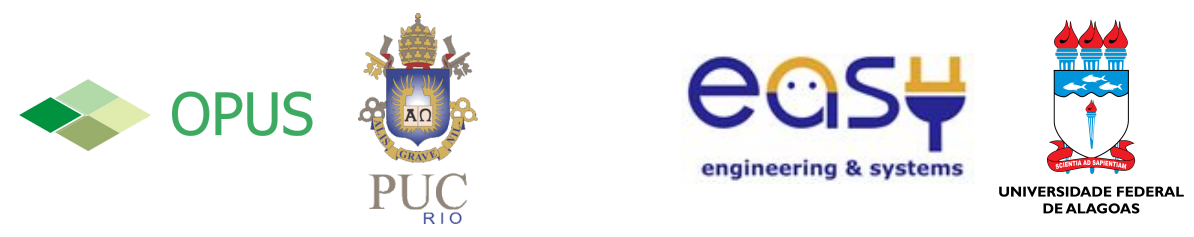

CONSENT FORM

$\mathrm{I}$,

was clearly and detailedly informed about the goals of the experiment proposed in the context of the project "Leveraging Gamification and Social Networks for Improving Prevention and Control of Zika" and I have clarified my doubts. I know that I have up to fifteen (15) working days to ask for additional information about the experiment and to interrupt my participation in the experiment, if I want it. I declare that I freely agree to take part in the proposed experiment. I have received a copy of this consent term, which I was responsible to fully read and comprehend. 
E

\section{Appendix E: Participant Characterization Form}

This appendix presents the participant characterization form used in the study reported in Chapter 4. 


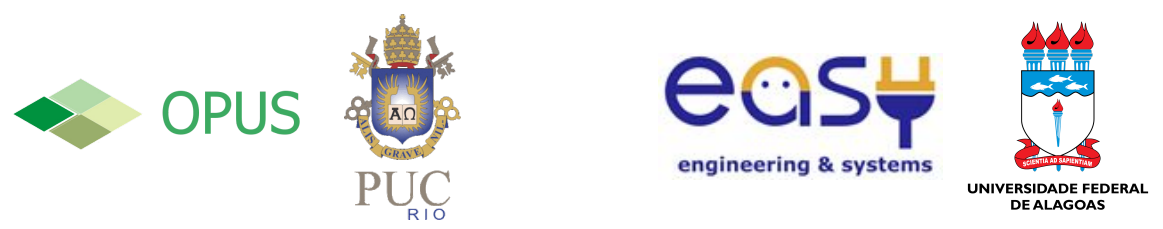

PARTICIPANT CHARACTERIZATION FORM

The seven questions below will help us in understanding who you are. Your answers will be kept anonymous. In 5 minutes, you will help us a lot in our research. Thanks for participating!

1. What is your name?

2. How old are you? ___ years

3. Which is your sex? ( ) Male ( ) Female

4. Which is your highest instruction level?

( ) Elementary school

( ) High school

( ) Specialization in

( ) Undergraduation in

( ) Master in

( ) Doctorate in

( ) Post Doctorate in

5. How many you spent by week in average with:

a. Using mobile devices (e.g., smartphones and tablets)? ___ hours

b. Browsing the Internet? ___ hours

c. Playing video games in computer, mobile device, etc.? __ hours

6. List the applications for mobile devices that you use the most.

7. Would you like to combat diseases like Dengue and Zika?
( ) Strongly agree
( ) Agree
( ) I neither agree nor disagree
( ) Disagree
( ) Strongly disagree 
$\mathbf{F}$

Appendix F: List of Experiment Activities

This appendix presents the list of experiment activities used in the study reported in Chapter 4. 


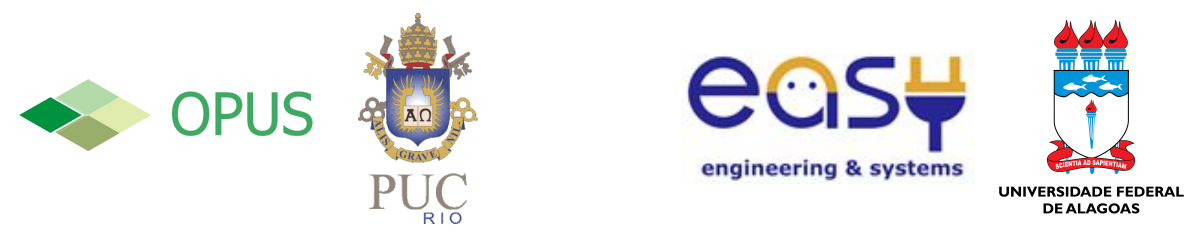

\section{EXPERIMENT ACTIVITIES}

\begin{tabular}{|c|c|}
\hline Activity & Description \\
\hline $\begin{array}{c}1 \\
\text { (time to } \\
\text { conclude } \\
=5 \mathrm{~min} \text { ) }\end{array}$ & $\begin{array}{l}\text { Welcome to the VazaZika application! Before starting to use it, you have to } \\
\text { create a new user. } \\
\text { Step by step } \\
\text { 1. Register in the application with your mobile device } \\
\text { 2. Now, please edit your user profile } \\
\text { 3. Fill out the profile data fields to conclude }\end{array}$ \\
\hline $\begin{array}{c}2 \\
\text { (time to } \\
\text { conclude } \\
=40 \text { min) }\end{array}$ & $\begin{array}{l}\text { Now you are an VazaZika user! It is time for creating teams and challenging a } \\
\text { rival team. } \\
\text { Step by step } \\
\text { - If you are in Environment A, do: } \\
\text { 1. Team up with your colleagues and choose a team leader } \\
\text { 2. If you are the team leader, create a new team called "Team A" via } \\
\text { VazaZika; otherwise, please wait! } \\
\text { 3. Join "Team A" created by the team leader, even if you are the leader } \\
\text { Wait for the calling of the Environment B instructor to continue } \\
\text { 4. If you are the team leader, do: } \\
\quad \text { o Pick challenge "Team Up!" } \\
\quad \text { O Please notify your team colleagues about the challenge goal } \\
\text { 5. Find as many mosquito breeding sites as you can in the environment you } \\
\text { are in, and provide reports of these sites using the application } \\
\text { - If you are in Environment B, do: } \\
\text { 1. Team up with your colleagues and choose a team leader } \\
\text { 2. If you are the team leader, create a new team called "Team B" via } \\
\text { VazaZika; otherwise, please wait! } \\
\text { 3. Join "Team B" created by the team leader, even if you are the leader } \\
\text { Wait for the calling of the Environment A instructor to continue } \\
\text { 4. If you are the team leader, please accept the invitation of "Time A" to } \\
\text { join the challenge "Team Up!" } \\
\text { 5. Find as many mosquito breeding sites as you can in the environment you } \\
\text { are in, and provide reports of these sites using the application }\end{array}$ \\
\hline $\begin{array}{l}3 \\
\text { (time to } \\
\text { conclude }\end{array}$ & $\begin{array}{l}\text { Congratulations! You have learned how to report mosquito breeding sites. Now } \\
\text { it is time to go validating the mosquito breeding sites that your colleagues have } \\
\text { reported! }\end{array}$ \\
\hline
\end{tabular}




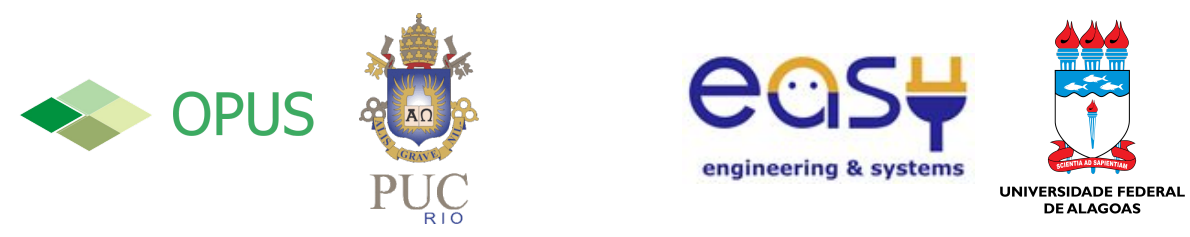

$=20 \mathrm{~min}$ )

Step by step

1. Via application, choose a mosquito breeding site reported by someone in the environment you are in

2. Try to find the reported location

3. Please confirm that you have found the site via application

4. Please comment something about this site in the application

5. Share the reported site if you have a Facebook or Twitter account 
G

Appendix G: Activity Experiment Form

This appendix presents the activity experiment form used in the study reported in Chapter 4. 


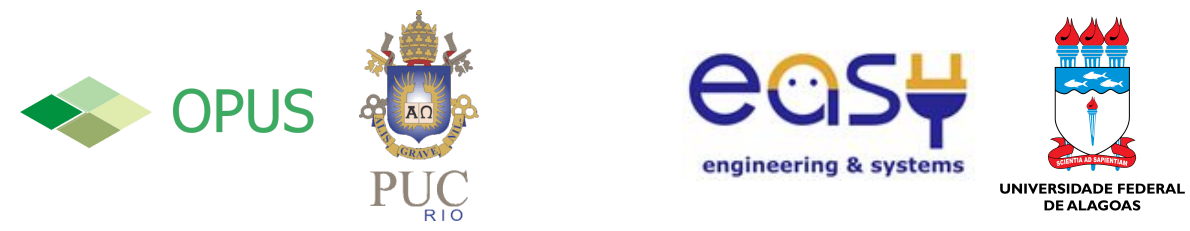

\section{ACTIVITY _ FORM}

1. What is your full name?

\begin{tabular}{|}
\begin{tabular}{|c|c|c|c|c|}
\hline 2. I found easy to complete this activity. \\
\hline Strongly agree & Partially agree & $\begin{array}{c}\text { I neither agree nor } \\
\text { disagree }\end{array}$ & Partially disagree & $\begin{array}{c}\text { Strongly } \\
\text { disagree }\end{array}$ \\
\hline$\square$ & $\square$ & $\square$ & $\square$ & $\square$ \\
\hline
\end{tabular}
\end{tabular}

Please justify your answer, even if you did not complete the activity:

\begin{tabular}{|c|c|c|c|c|}
\hline \multicolumn{5}{|c|}{ 3. I found fun to complete this activity. } \\
\hline Strongly agree & Partially agree & $\begin{array}{c}\text { I neither agree nor } \\
\text { disagree }\end{array}$ & Partially disagree & $\begin{array}{l}\text { Strongly } \\
\text { disagree }\end{array}$ \\
\hline$\square$ & $\square$ & $\square$ & $\square$ & $\square$ \\
\hline \multicolumn{5}{|c|}{ 4. I felt motivated to perform this activity again. } \\
\hline Strongly agree & Partially agree & $\begin{array}{c}\text { I neither agree nor } \\
\text { disagree }\end{array}$ & Partially disagree & $\begin{array}{l}\text { Strongly } \\
\text { disagree }\end{array}$ \\
\hline$\square$ & $\square$ & $\square$ & $\square$ & $\square$ \\
\hline
\end{tabular}

5. List at least 3 positive aspects of the application screens used during this activity.

6. List at least 3 negative aspects of the application screens used during this activity.

7. List the application features (functions, icons, text, etc.) used during this activity. 


\section{H}

\section{Appendix H: Follow-up Form}

This appendix presents the follow-up form used in the study reported in Chapter 4. 


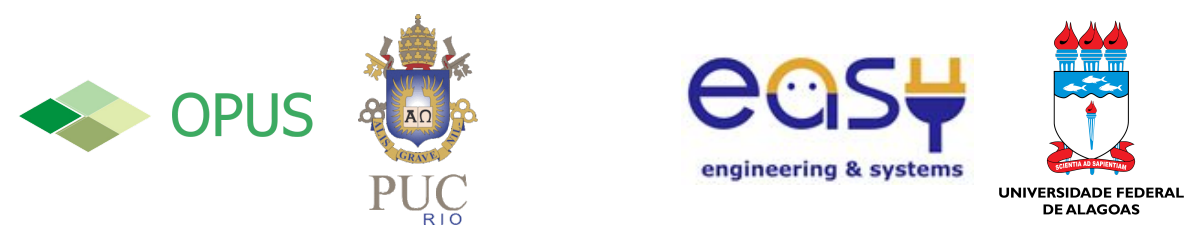

\section{FOLLOW-UP FORM}

1. What is your full name?

2. List 3 positive aspects of the experiment. Please justify each aspect. 1:

2

3. List 3 negative points of the experiment. Please suggest improvements.

1 :

4. Would you use the VazaZika application again? ( ) Yes ( ) No

5. Would you recommend the VazaZika application to your friends? ( ) Yes ( ) No

6. Which application features you have used during the activities?

( ) Avatar: abstraction of the VazaZika user profile

( ) Badge: rewards for one or more activities performed via VazaZika

( ) Challenge: group of activities with constrained time to complete

( ) Comment: comment about a mosquito breeding site reported by a user

( ) Level: user level in VazaZika when compared to other users

( ) Notification: alert on performed tasks, earned rewards, and so on

( ) Point: rewards for an activity performed via VazaZika

( ) Ranking: list of users sorted by level, number of reports, and validated reports

( ) Social Activity: list of activities recently performed by VazaZika users

( ) Social Sharing: sharing of reports via Facebook and Twitter

( ) Team: group of VazaZika users

( ) Vote: confirmation that a mosquito breeding site was correctly reported by a user 